Pontifícia Universidade C Católica

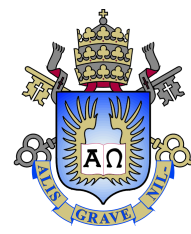

Débora Yohane Cunha Azevedo Martins

\title{
Modelagem Composicional em Escala de Reservatório do Fluxo de Gás Condensado: Efeitos da Permeabilidade Relativa
}

Dissertação de Mestrado

Dissertação apresentada como requisito parcial para obtenção do grau de Mestre pelo Programa de Pós-Graduação em Engenharia Mecânicada PUC-Rio.

Orientador : Prof. Márcio da Silveira Carvalho Coorientador: Dra. Paula Kozlowski Pitombeira Reis 
Pontifícia Universidade Catálica $_{\text {a }}$

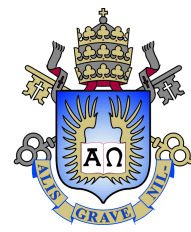

Débora Yohane Cunha Azevedo Martins

\author{
Modelagem Composicional em Escala de \\ Reservatório do Fluxo de Gás Condensado: \\ Efeitos da Permeabilidade Relativa
}

\begin{abstract}
Dissertação apresentada como requisito parcial para obtenção do grau de Mestre pelo Programa de Pós-Graduação em Engenharia Mecânica da PUC-Rio. Aprovada pela Comissão Examinadora:
\end{abstract}

Prof. Márcio da Silveira Carvalho

Orientador

Departamento de Engenharia Mecânica - PUC-Rio

Dra. Paula Kozlowski Pitombeira Reis

Coorientador

Departamento de Engenharia Mecânica - PUC-Rio

Profa. Angela Ourivio Nieckele

Departamento de Engenharia Mecânica - PUC-Rio

Dr. Marcos Vitor Barbosa Machado

Petrobras

Rio de Janeiro, 10 de Novembro de 2021 
Todos os direitos reservados. A reprodução, total ou parcial do trabalho, é proibida sem a autorização da universidade, do autor e do orientador.

\section{Débora Yohane Cunha Azevedo Martins}

Graduada em Engenharia de Petróleo e Gás pela Universidade Católica de Petrópolis em 2017. Atualmente trabalha como Engenheira Mecânica na área de projetos de completação e produção de petróleo e gás, enquanto cursa mestrado em Engenharia Mecânica na PUC-Rio.

Ficha Catalográfica

Martins, Débora Yohane Cunha Azevedo

Modelagem Composicional em Escala de Reservatório do Fluxo de Gás Condensado: Efeitos da Permeabilidade Relativa / Débora Yohane Cunha Azevedo Martins; orientador: Márcio da Silveira Carvalho; coorientador: Paula Kozlowski Pitombeira Reis. - 2021.

111 f: il. color. ; $30 \mathrm{~cm}$

Dissertação (mestrado) - Pontifícia Universidade Católica do Rio de Janeiro, Departamento de Engenharia Mecânica, 2021.

Inclui bibliografia

1. Engenharia Mecânica - Teses. 2. Gás retrógrado. 3. Reservatório de gás condensado. 4. Permeabilidade relativa. 5. Modelagem Composicional. I. Carvalho, Márcio da Silveira. II. Reis, Paula Kozlowski Pitombeira. III. Pontifícia Universidade Católica do Rio de Janeiro. Departamento de Engenharia Mecânica. IV. Título. 
Para os meus pais, para minha avó, e principalmente, para o meu marido David, por seu suporte e incentivo. 


\section{Agradecimentos}

Agradeço ao Professor Dr. Márcio Carvalho pela ajuda na escolha do tema, suporte e paciência durante todas as reuniões que antecederam a concepção desse trabalho.

Agradeço a Dra. Paula Reis pela grande orientação, paciência e colaboração técnica durante todas as reuniões e além dessas para que esse trabalho fosse concluído.

Agradeço ao meu marido, David, também pela paciência, parceria e noites em claro comigo para que eu não desistisse.

Agradeço, imensamente, ao Prof. Ivan Fabio Mota de Menezes, que por tantas vezes me orientou e ajudou durante todo esse caminho do mestrado.

Agradeço à Profa. Angela Ourivio Nieckele durante o curso e por todo apoio até aqui.

Agradeço também aos meus pais e minha avó que sempre acreditaram em mim.

"O presente trabalho foi realizado com apoio da Coordenação de Aperfeiçoamento de Pessoal de Nível Superior - Brasil (CAPES) - Código de Financiamento 001". 


\section{Resumo}

Martins, Débora Yohane Cunha Azevedo; Carvalho, Márcio da Silveira; Reis, Paula Kozlowski Pitombeira. Modelagem Composicional em Escala de Reservatório do Fluxo de Gás Condensado: Efeitos da Permeabilidade Relativa. Rio de Janeiro, 2021. 111p. Dissertação de Mestrado - Departamento de Engenharia Mecânica, Pontifícia Universidade Católica do Rio de Janeiro.

Em reservatórios de gás retrógrado com pressões inferiores à pressão de orvalho, a produtividade dos poços pode ser comprometida devido ao aparecimento e acúmulo da fase líquida nas suas imediações. Este fenômeno é conhecido como bloqueio por condensação retrógrada e está associado à uma série de desafios para compreendê-lo. Um deles é a determinação da permeabilidade relativa das fases líquida e gasosa, que comumente advém de curvas de permeabilidade obtidas a partir da extrapolação de poucos dados experimentais. Dessa forma, elas tendem a não representar fielmente efeitos importantes para o escoamento, comprometendo a precisão da modelagem do fluxo no meio poroso. A fim de investigar o efeito das curvas de permeabilidade relativa sobre a formação de bancos de condensado, foi desenvolvido um modelo composicional em escala de reservatório para o estudo do escoamento de gás e condensado. Com o modelo, o uso de curvas de permeabilidade relativa obtidas através de simulação do escoamento de gás retrógrado na escala de poros e de correlações propostas na literatura foi avaliado. Considera-se: sistema isotérmico, escoamento bifásico e incorporação dos efeitos de forças capilares por meio do modelo de permeabilidade relativa. Equações de balanço molar e consistência de volume formam um sistema não linear resolvido pelo método de Newton que fornece pressão e número de mols de cada componente, em todos os volumes de controle do modelo, a cada passo de tempo. Para o equilíbrio de fases, a equação de Peng \& Robinson foi implementada com uma rotina de flash a pressão e temperaturas constantes. O modelo foi validado contra a solução analítica para sistema monofásico e por fim, o simulador obteve a evolução temporal das curvas de pressão e saturação em função da distância do poço, a fim de comparar o efeito dos diferentes modelos de curvas de permeabilidade relativa na predição do bloqueio por condensado. Os resultados foram obtidos variando-se a permeabilidade absoluta do meio e a vazão de gás imposta no poço, e o impacto desses parâmetros no acúmulo de condensado foi avaliado.

\section{Palavras-chave}

Gás retrógrado; Reservatório de gás condensado; Permeabilidade relativa; Modelagem Composicional. 


\section{Abstract}

Martins, Débora Yohane Cunha Azevedo; Carvalho, Márcio da Silveira (Advisor); Reis, Paula Kozlowski Pitombeira (Co-Advisor). Compositional Modeling of a Reservoir Scale for GasCondensate Flow: Effects of Relative Permeability. Rio de Janeiro, 2021. 111p. Dissertação de Mestrado - Departamento de Engenharia Mecânica, Pontifícia Universidade Católica do Rio de Janeiro.

In gas-condensate reservoirs with pressures below the dew pressure, the productivity of wells can be compromised due to the accumulation of liquid in their surroundings. This phenomenon is known as condensate blockage and there are many challenges to understanding the formation of condensate banks. One of them is the determination of the relative permeability of the liquid and gas phases, which commonly comes from permeability curves obtained from the extrapolation of few experimental data. Thus, they tend not to reliably represent important effects for the flow, compromising the precision of the flow modeling in the porous medium. In order to investigate the effect of relative permeability curves on the formation of condensate banks, a reservoir-scale compositional model was developed for the study of flow of gas and condensate. With the model, the use of relative permeability curves obtained by simulating the gas-condensate flow at the pore-scale and with correlations proposed in the literature was evaluated. It is considered: isothermal system, two-phase flow and incorporation of capillary force effects through the relative permeability model. Molar balance and volume consistency equations form a nonlinear system solved by Newton's method that provides pressure and number of moles of each component, in all control volumes of the model, at each time step. For the phase equilibrium, calculations of the Peng \& Robinson equation was implemented in a constant pressure and temperature flash routine. The model was validated against the analytical solution for single-phase flow and, finally, the simulator obtained the temporal evolution of the pressure and saturation as a function of the distance from the well, in order to compare the effect of different models of relative permeability curves in the prediction of condensate blockage. The results were obtained by varying the absolute permeability of the medium and the gas flow imposed in the well, and the impact of these parameters on the accumulation of condensate was evaluated.

\section{Keywords}

Retrograde gas; Gas-condensate reservoir; Relative permeability; Compositional modelin. 


\section{Sumário}

1 Introdução $\quad 17$

1.1 Contexto 21

$\begin{array}{lll}1.2 & \text { Motivação } & 23\end{array}$

1.3 Problema 23

1.4 Objetivo 25

$\begin{array}{ll}1.5 & \text { Organização dos Capítulos } \\ \end{array}$

2 Revisão Bibliográfica $\quad 27$

2.1 Gás Retrógrado $\quad 27$

2.2 Escala do Modelo de Escoamento 28

2.3 Modelo de Permeabilidade Relativa 30

2.4 Modelo Composicional e Método de Solução 33

3 Modelo Composicional $\quad 35$

3.1 Descrição do Meio Poroso $\quad 35$

3.2 Equações Governantes 36

3.2.1 Equação do Balanço Molar 36

3.2.2 Equação da Consistência de Volume 37

$\begin{array}{lll}3.3 & \text { Equações Termodinâmicas } & 39\end{array}$

$\begin{array}{lll}3.3 .1 & \text { Equação de Estado } & 39\end{array}$

3.3.2 Equilíbrio de Fases 40

$\begin{array}{lll}\text { 3.3.3 Teste de Estabilidade } & 42\end{array}$

3.3.4 Desaparecimento de Fase 43

3.4 Cálculo da Viscosidade 43

3.5 Cálculo da Tensão Interfacial 43

3.6 Condições Iniciais e de Contorno 43

3.7 Curvas de Permeabilidade Relativa 45

4 Solução Numérica $\quad 49$

4.1 Descrição da Malha $\quad 49$

4.2 Discretização das Equações $\quad 51$

4.2.1 Equações de Conservação $\quad 51$

4.2.2 Equações de Volume $\quad 53$

4.3 Método de Solução $\quad 53$

4.4 Cálculo do Jacobiano 54

5 Resultados $\quad 57$

5.1 Validação do Modelo com caso Monofásico 57

5.2 Curvas de Permeabilidade 59

5.3 Análise do bloqueio da produção de gás devido à formação de banco de condensado $\quad 60$

5.3.1 Resultados obtidos com $k=169 \mathrm{mD}$ e $v=100 \mathrm{~m} / \mathrm{d}$

5.3.2 Resultados obtidos com $k=169 m D$ e $v=200 \mathrm{~m} / d$

5.3.3 Resultados obtidos com $k=5 m D$ e $v=100 m / d$ 
5.3.4 Resultados obtidos com $k=5 m D$ e $v=200 m / d$

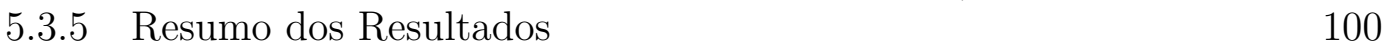

6 Conclusão 101

$\begin{array}{lll}\text { 6.1 Sugestões para trabalhos futuros } & 102\end{array}$

$\begin{array}{ll}\text { Referências bibliográficas } & 104\end{array}$

A Equações Numéricas do Jacobiano 109 


\section{Lista de figuras}

Figura 1.1 Diagramas de Fase para os seguintes fluidos: a) black oil b) óleo de baixo encolhimento c) óleo volátil d) gás úmido e) gás retrógrado f) gás retrógrado próximo ao ponto crítico g) gás seco h) óleo próximo ao ponto crítico (Adaptado de [53])

Figura 1.2 Resumo das aplicações de modelos de simulação de reservatórios no diagrama de fases pressão-temperatura [54]

Figura 1.3 Diagrama de fases de uma mistura de hidrocarbonetos com 3 condições explicitadas (Adaptado de [5])

Figura 1.4 Foto do campo de Arun [10] acompanhado do seu respectivo Envelope de Fases (Adaptado de [11])

Figura 2.1 Três regiões do comportamento de fluxo em um gás condensado. Adaptado de [14].

Figura 2.2 Representações de meio poroso em diversas escalas (a) Escala microscópica: subseção de um modelo de rede de poros gerado através de uma imagem micro-CT de uma amostra de arenito [52] (b) Escala macroscópica: abordagem do contínuo com volumes finitos.

Figura 2.3 Volume médio de tamanho suficiente de modo que represente o todo. (Adaptado de [19])

Figura 3.1 Fluxograma de relação entre teste de estabilidade e rotina de flash

Figura 3.2 Permeabilidade relativa com modelo de correlações empíricas com IFT $=1 \times 10^{-3} \mathrm{~N} / \mathrm{m}, \sigma^{*}=2,2 \times 10^{-3} \mathrm{~N} / \mathrm{m}$ e $n=$ 10

Figura 3.3 Curvas de permeabilidade relativa por velocidade de escoamento do gás calculadas pelo modelo em escala de poros em $[28]$

Figura 4.1 Exemplificação da malha cilíndrica para representação do meio poroso em escala de reservatório, onde o ponto central representa o poço e a borda é o final da rocha reservatório.

Figura 4.2 Exemplificação dos pontos da malha em coordenadas cilíndricas a fim de representar a divisão dos volumes de controle (pontilhado vermelho) e seus pontos centrais (pontilhado azul).

Figura 4.3 Representação esquemática da malha

Figura 4.4 Fluxograma da simulação

Figura 5.1 Comparação da Pressão ao Redor do Poço calculada com a solução analítica para gás real e com a solução numérica do modelo desenvolvido neste trabalho (para tempos de simulação de 25 e 50 dias) 
Figura 5.2 Comparação da Pressão ao Redor do Poço calculada com a solução analítica para gás real e com a solução numérica do modelo desenvolvido neste trabalho (para tempos de simulação de 75 e 100 dias)

Figura 5.3 Comparação de curva de permeabilidade com modelo em escala de poros com modelo ajustado para as velocidades de 7,5 $\mathrm{m} / \mathrm{d}$ e $15 \mathrm{~m} / \mathrm{d}$

Figura 5.4 Comparação de curva de permeabilidade com modelo em escala de poros com modelo ajustado para as velocidades de 30 $\mathrm{m} / \mathrm{d}$ e $45 \mathrm{~m} / \mathrm{d}$

Figura 5.5 Comparação de curva de permeabilidade com modelo em escala de poros com modelo ajustado para as velocidades de 60 $\mathrm{m} / \mathrm{d}$ e $90 \mathrm{~m} / \mathrm{d}$

Figura 5.6 Comparação de curva de permeabilidade com modelo em escala de poros com modelo ajustado para a velocidade de 150 $\mathrm{m} / \mathrm{d}$

Figura 5.7 Gráfico do Envelope de Fases da mistura apresentada na Tabela 5.1. [17]

Figura 5.8 Liquid Dropout da mistura utilizada por este trabalho para expansão com composição constante (CCE) e para depleção com volume constante (CVD).

Figura 5.9 Extensão do banco de condensado em função do tempo para $k=169 \mathrm{mD}$ e $v=100 \mathrm{~m} / d$.

Figura 5.10 para $k=169 \mathrm{mD}$ e $v=100 \mathrm{~m} / d$.

Figura 5.11 Saturação de líquido em função do tempo para $k=$ $169 \mathrm{mD}$ e $v=100 \mathrm{~m} / \mathrm{d}$.

Figura 5.12 Fração molar de $C_{16+}$ no condensado em função do tempo e do raio calculadas com ambos os modelos para $k=169 \mathrm{mD}$ e $v=100 \mathrm{~m} / d$.

(5.12(a) $\phi$ delo IFT

(5.12(B) $\phi$ delo de Rede

Figura 5.13 Permeabilidade relativa do líquido em função do tempo para $k=169 \mathrm{mD}$ e $v=100 \mathrm{~m} / d$.

Figura 5.14 Permeabilidade relativa do gás em função do tempo para $k=169 \mathrm{mD}$ e $v=100 \mathrm{~m} / \mathrm{d}$.

Figura 5.15 Produção acumulada de gás em condições standard em função do tempo para $k=169 m D$ e $v=100 m / d$.

Figura 5.16 Produção acumulada de gás em condições standard vindo de gás em condições de reservatório em função do tempo para $k=169 m D$ e $v=100 m / d$.

Figura 5.17 Permeabilidade relativa de gás em função do raio e do tempo para $k=169 \mathrm{mD}$ e $v=100 \mathrm{~m} / d$.

Figura 5.18 Produção acumulada de gás em condições standard vindo de condensado em condições de reservatório em função do tempo para $k=169 \mathrm{mD}$ e $v=100 \mathrm{~m} / \mathrm{d}$.

Figura 5.19 Permeabilidade relativa de líquido em função do raio e do tempo para $k=169 \mathrm{mD}$ e $v=100 \mathrm{~m} / \mathrm{d}$. 
Figura 5.20 Produção acumulada de condensado em condições standard em função do tempo para $k=169 \mathrm{mD}$ e $v=100 \mathrm{~m} / \mathrm{d}$.

Figura 5.21 Produção acumulada de condensado em condições standard vindo de gás em condições de reservatório em função do tempo para $k=169 \mathrm{mD}$ e $v=100 \mathrm{~m} / \mathrm{d}$.

Figura 5.22 Produção acumulada de condensado em condições standard vindo de condensado em condições de reservatório em função do tempo para $k=169 \mathrm{mD}$ e $v=100 \mathrm{~m} / d$.

Figura 5.23 Extensão do banco de condensado em função do tempo para $k=169 \mathrm{mD}$ e $v=200 \mathrm{~m} / \mathrm{d}$.

Figura 5.24 Saturação de líquido em função do tempo para $k=$ $169 \mathrm{mD}$ e $v=200 \mathrm{~m} / \mathrm{d}$.

Figura 5.25 Fração molar de $C_{16+}$ no condensado em função do tempo e do raio calculadas com ambos os modelos para $k=169 \mathrm{mD}$ e velocidades $v=100 \mathrm{~m} / d$ e $v=200 \mathrm{~m} / d$.

(5.25(aI $\phi$ delo IFT

(5.25(M) $\phi$ delo de Rede

Figura 5.26 IFT calculado com Modelo IFT em função do raio e do tempo para $k=169 \mathrm{mD}$ e velocidades $v=100 \mathrm{~m} / d$ e $v=200 \mathrm{~m} / \mathrm{d} .77$

Figura 5.27 Permeabilidade relativa do líquido em função do tempo para $k=169 m D$ e $v=200 m / d$.

Figura 5.28 Permeabilidade relativa do gás em função do tempo para $k=169 m D$ e $v=200 m / d$.

Figura 5.29 Produção acumulada de gás em condições standard em função do tempo para $k=169 m D$ e $v=200 \mathrm{~m} / d$.

Figura 5.30 Produção acumulada de gás em condições standard vindo de gás em condições de reservatório em função do tempo para $k=169 m D$ e $v=200 m / d$.

Figura 5.31 Permeabilidade relativa de gás em função do raio e do tempo para $k=169 \mathrm{mD}$ e $v=200 \mathrm{~m} / d$.

Figura 5.32 Saturação de líquido com Modelo IFT em função do raio e do tempo para $k=169 \mathrm{mD}$ e velocidades $v=100 \mathrm{~m} / \mathrm{d}$ e $v=$ $200 \mathrm{~m} / \mathrm{d}$.

Figura 5.33 Saturação de líquido com Modelo de Rede em função do raio e do tempo para $k=169 \mathrm{mD}$ e velocidades $v=100 \mathrm{~m} / \mathrm{d}$ e $v=200 \mathrm{~m} / d$.

Figura 5.34 Produção acumulada de gás em condições standard vindo de condensado em condições de reservatório em função do tempo para $k=169 \mathrm{mD}$ e $v=200 \mathrm{~m} / d$.

Figura 5.35 Produção acumulada de condensado em condições standard em função do tempo para $k=169 \mathrm{mD}$ e $v=200 \mathrm{~m} / \mathrm{d}$.

Figura 5.36 Produção acumulada de condensado em condições standard vindo de gás em condições de reservatório em função do tempo para $k=169 \mathrm{mD}$ e $v=200 \mathrm{~m} / d$.

Figura 5.37 Produção acumulada de condensado em condições standard vindo de condensado em condições de reservatório em função do tempo para $k=169 \mathrm{mD}$ e $v=200 \mathrm{~m} / \mathrm{d}$. 
Figura 5.38 Extensão do banco de condensado em função do tempo para $k=5 m D$ e $v=100 \mathrm{~m} / d$.

Figura 5.39 Saturação de líquido em função do tempo para $k=5 \mathrm{mD}$ e $v=100 \mathrm{~m} / d$.

Figura 5.40 Curvas de permeabilidade relativa de líquido com os dois modelos para $v=100 \mathrm{~m} / \mathrm{d}$.

Figura 5.41 Permeabilidade relativa do líquido em função do tempo para $k=5 m D$ e $v=100 m / d$.

Figura 5.42 Permeabilidade do gás em função do tempo para $k=$ $5 \mathrm{mD}$ e $v=100 \mathrm{~m} / \mathrm{d}$.

Figura 5.43 Produção acumulada de gás em condições standard em função do tempo para $k=5 \mathrm{mD}$ e $v=100 \mathrm{~m} / \mathrm{d}$.

Figura 5.44 Produção acumulada de gás em condições standard vindo de gás em condições de reservatório em função do tempo para $k=5 m D$ e $v=100 m / d$.

Figura 5.45 Produção acumulada de gás em condições standard vindo de condensado em condições de reservatório em função do tempo para $k=5 m D$ e $v=100 m / d$.

Figura 5.46 Produção acumulada de condensado em condições standard vindo de condensado em condições de reservatório em função do tempo para $k=5 \mathrm{mD}$ e $v=100 \mathrm{~m} / \mathrm{d}$.

Figura 5.47 Produção acumulada de condensado em condições standard vindo de gás em condições de reservatório em função do tempo para $k=5 \mathrm{mD}$ e $v=100 \mathrm{~m} / d$.

Figura 5.48 Produção acumulada de condensado em condições standard vindo de condensado em condições de reservatório em função do tempo para $k=5 \mathrm{mD}$ e $v=100 \mathrm{~m} / d$.

Figura 5.49 Produção acumulada de condensado em função do tempo para $k=5 m D$ e $v=200 \mathrm{~m} / d$.

Figura 5.50 Saturação de líquido em função do tempo para $k=5 \mathrm{mD}$ e $v=200 \mathrm{~m} / d$.

Figura 5.51 Permeabilidade relativa de líquido em função do tempo para $k=5 m D$ e $v=200 m / d$.

Figura 5.52 Curvas de permeabilidade relativa de líquido com os dois modelos para $v=200 \mathrm{~m} / \mathrm{d}$.

Figura 5.53 Permeabilidade relativa de gás em função do tempo para $k=5 m D$ e $v=200 m / d$.

Figura 5.54 Produção acumulada de gás em condições standard em função do tempo para $k=5 \mathrm{mD}$ e $v=200 \mathrm{~m} / \mathrm{d}$.

Figura 5.55 Produção acumulada de gás em condições standard vindo de gás em condições de reservatório em função do tempo para $k=5 m D$ e $v=200 m / d$.

Figura 5.56 Produção acumulada de gás em condições standard vindo de condensado em condições de reservatório em função do tempo para $k=5 m D$ e $v=200 m / d$.

Figura 5.57 Produção acumulada de condensado em condições standard em função do tempo para $k=169 m D$ e $v=100 m / d$. 
Figura 5.58 Produção acumulada de condensado em condições standard vindo de gás em condições de reservatório em função do tempo para $k=5 m D$ e $v=200 m / d$.

Figura 5.59 Produção acumulada de condensado em condições standard vindo de condensado em condições de reservatório em função do tempo para $k=5 m D$ e $v=200 m / d$. 


\section{Lista de tabelas}

Tabela 5.1 Composição do Fluido. [17] 62

Tabela 5.2 Pressão crítica $\left(P_{c}\right)$, Temperatura crítica $\left(T_{c}\right)$, Parachor

$(\mathcal{P})$ e Massa Molar para cada componente do fluido [17] 63

Tabela 5.3 Volume crítico $\left(V_{c}\right)$, Fator de compressibilidade crítico

$\left(Z_{c}\right)$, Fator acêntrico $(\omega)$ e Fator de Correção de Volume $(\nu)$ para cada componente do fluido [17]

Tabela 5.4 Composição do Fluido nas Proximidades do Poço ao Final da Simulação

Tabela 5.5 Produção Acumulada de Gás ao Final das Simulações 100

Tabela 5.6 Produção Acumulada de Condensado ao Final das Simulações 
George E. P. Box, . 


\section{Introdução}

A modelagem matemática do escoamento de fluidos em reservatórios de petróleo é uma ciência que tem como principais objetivos prever o comportamento de produção e encontrar melhores métodos de recuperação, tanto no desenvolvimento de novas jazidas, quanto no estudo de campos maduros. Ela começou a ser desenvolvida no final do século XIX e baseia-se em estruturar um sistema de equações que represente o escoamento de fluidos em uma rocha porosa [1].

O modelo de escoamento depende do comportamento dos fluidos nas condições de reservatório. A Figura 1.1 apresenta uma ilustração de diagramas de fases típicos para fluidos de oito tipos de reservatórios de petróleo. Essa classificação leva em conta a temperatura do reservatório, a temperatura crítica, a temperatura cricondentérmica e a forma que as linhas de mesma fração de líquido estão dispostas (chamadas linhas de qualidade [15]). A seguir, encontra-se uma breve descrição de cada um desses comportamentos:

(a) Black Oil - nestes reservatórios, tem-se, inicialmente, hidrocarboneto líquido, pois a sua temperatura é inferior a temperatura crítica. Seu diagrama de fases típico se encontra ilustrado na Figura 1.1 (a). Uma característica marcante desse tipo de fluido é a presença de linhas de qualidade equidistantes [15].

(b) Óleo de Baixo Encolhimento - a diferença deste tipo de reservatório para os de black oil é que as linhas de qualidade estão concentradas nas proximidades da curva de ponto de orvalho [15]. Seu diagrama de fases típico se encontra ilustrado na Figura 1.1 (b).

(c) Óleo de Alto Encolhimento ou Volátil - a diferença deste tipo de reservatório para os de black oil é que as linhas de qualidade estão concentradas nas proximidades da curva de pressão de bolha e mais espaçadas a baixas pressões [15]. Seu diagrama de fases típico se encontra ilustrado na Figura 1.1 (c). 

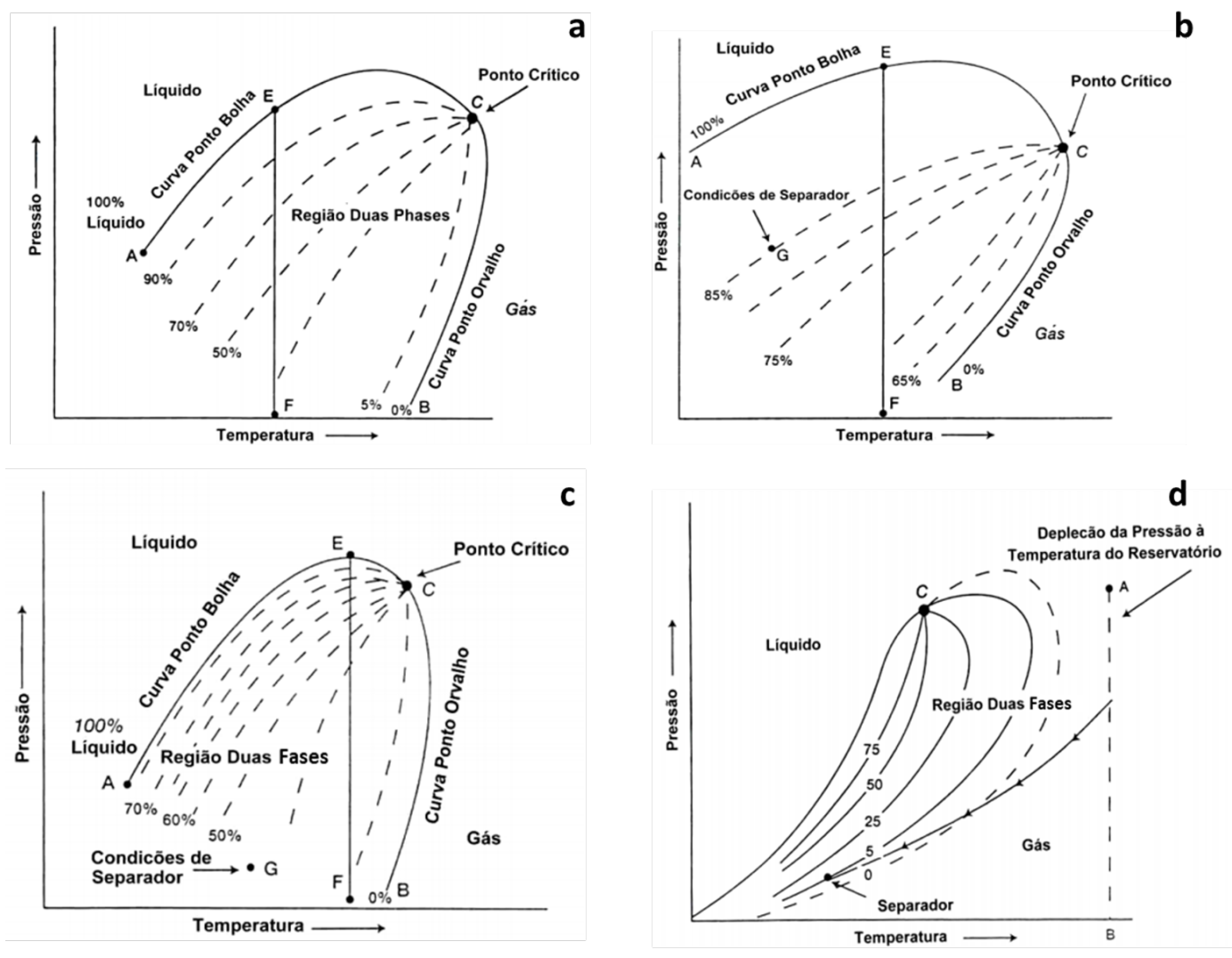

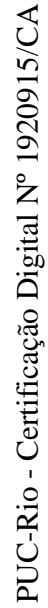
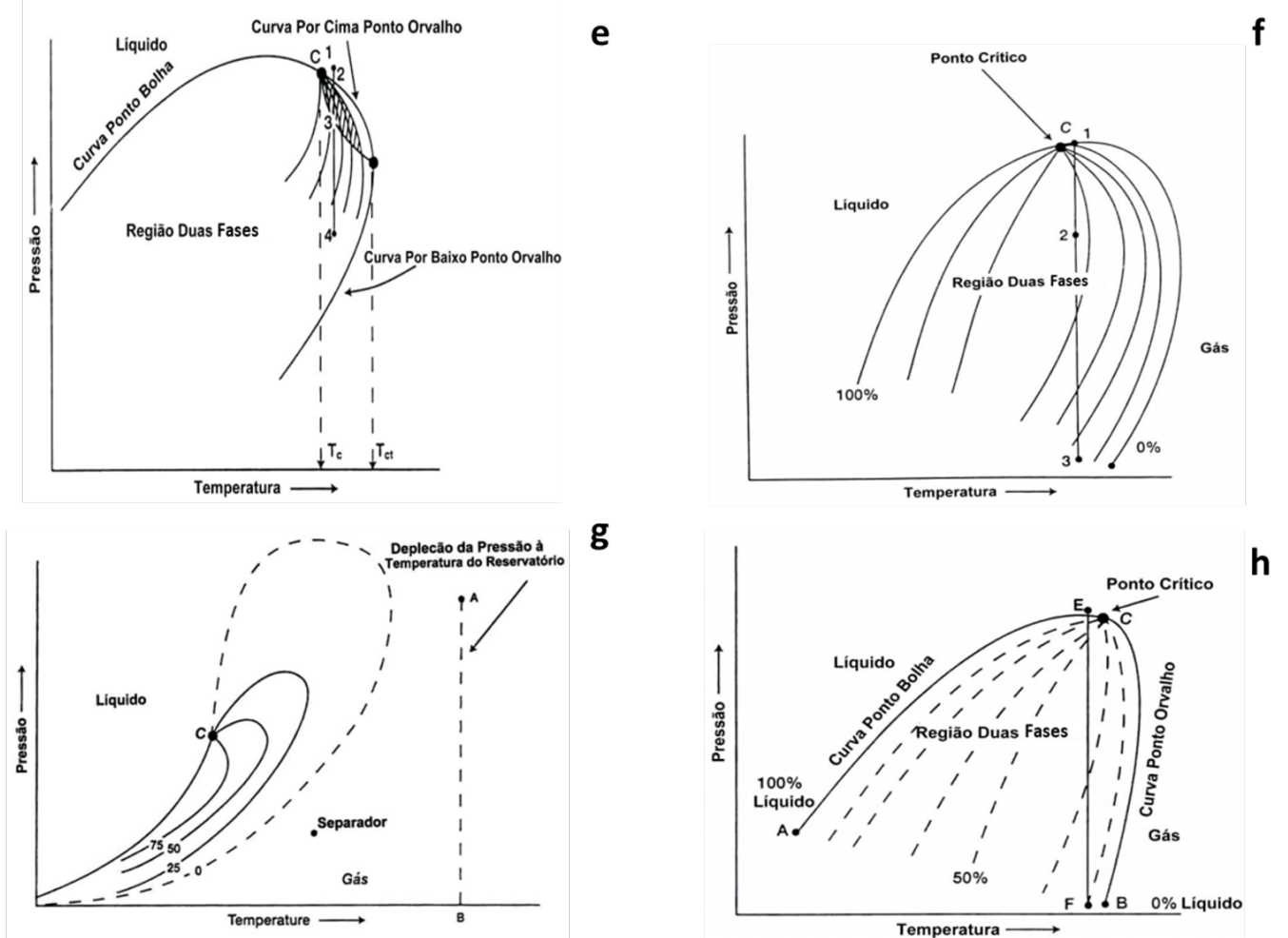

Figura 1.1: Diagramas de Fase para os seguintes fluidos: a) black oil b) óleo de baixo encolhimento c) óleo volátil d) gás úmido e) gás retrógrado f) gás retrógrado próximo ao ponto crítico g) gás seco h) óleo próximo ao ponto crítico (Adaptado de [53]) 
(d) Gás Úmido - nestes reservatórios, nunca haverá duas fases no reservatório, pois sua temperatura é superior à temperatura crincondentérmica. Seu diagrama de fases típico se encontra ilustrado na Figura 1.1 (d). Entretanto, esse tipo de gás entra na região de duas fases em condições do separador em superfície [15].

(e) Gás Retrógrado - nestes reservatórios, tem-se inicialmente, gás, pois sua temperatura é superior a temperatura crítica. Seu diagrama de fases típico se encontra ilustrado na Figura 1.1 (e). Neles, um processo isotérmico de redução de pressão leva a formação de condensado. Esse tipo de reservatório é o foco deste trabalho e será melhor descrito a seguir.

(f) Gás Retrógrado Próximo ao Ponto Crítico - a diferença deste tipo de reservatório para os de gás retrógrado é que, como as linhas de qualidade convergem para o ponto crítico, uma pequena redução de pressão abaixo da pressão de bolha leva a formação de uma grande quantidade de condensado [15]. Seu diagrama de fases típico se encontra ilustrado na Figura 1.1 (f).

(g) Gás Seco - a diferença deste tipo de reservatório para os de gás úmido é a quantidade de condensado produzida em superfície, que, nesse caso, deve ser zero ou muito baixa [15]. Seu diagrama de fases típico se encontra ilustrado na Figura 1.1 (g).

(h) Óleo Próximo ao Ponto Crítico - a diferença deste tipo de reservatório para os de black oil é que como as linhas de qualidade convergem para o ponto crítico, uma pequena redução de pressão abaixo da pressão de bolha leva a formação de uma grande quantidade de gás [15]. Seu diagrama de fases típico se encontra ilustrado na Figura 1.1 (h).

Como existem diversos tipos de reservatórios e de dados disponíveis, foram desenvolvidos vários modelos ao longo do tempo para atender necessidades específicas. Esses modelos se dividem entre analíticos e numéricos. Entre os modelos analíticos, pode-se citar:

- Análise de curvas de declínio: Baseia-se no ajuste de equações empíricas a dados históricos, sem levar em consideração as propriedades físicas do reservatório. Como é um modelo simplificado, é bastante usado em estudos preliminares, como, por exemplo, em testes de longa duração em poços exploratórios [12].

- Equação de balanço de materiais: Baseia-se no ajuste de uma reta com variáveis dependentes e independentes determinadas de acordo com 
o mecanismo de produção do reservatório analisado (influxo de água, capa de gás, ...) [16].

Já entre os modelos numéricos, pode-se citar:

- Modelos térmicos: Acrescentam a equação de conservação da energia à análise de curvas de declínio e são capazes de descrever o comportamento da produção de óleos pesados por métodos térmicos [4].

- Modelos black-oil: Eles são adequados para modelar reservatórios de óleo ou de gás em que não haja alteração significativa nas composições das fases. Consideram as variações nas propriedades físicas em áreas diferentes do reservatório, além de considerar três fases (óleo, água e gás) e a possibilidade de gás dissolvido no óleo [3].

- Modelos pseudo-composicionais: Diferem-se do black-oil, pois permitem modelar o óleo dissolvido na fase gás. Eles tem um melhor desempenho na modelagem de reservatórios de óleo leve e gás condensado retrógrado [3].

- Modelos composicionais: Surgiram para representar reservatórios em que as fases óleo e gás sofrem significativa variação composicional. Ele tem esse nome por considerar, além das fases óleo, água e gás, suas composições. Neles, as propriedades dos fluidos são determinadas através de equações dependentes da pressão, temperatura, saturação e composição [3].

A Figura 1.2 mostra a aplicabilidade de alguns desses modelos de acordo com as faixas de classificação do fluido no diagrama de fases pressãotemperatura.

O presente trabalho estuda reservatórios de gás condensado retrógrado, por isso, nele se utiliza modelo composicional como modelagem matemática, de acordo com a Figura 1.2. [2].

A Figura 1.3(a) ilustra a região de condensação retrógrada no diagrama de fases. No ponto (1), vê-se a condição com uma pressão acima da pressão de orvalho, contendo apenas gás. Tipicamente, esse ponto representa a condição inicial de um reservatório de gás retrógrado. Durante a produção, a pressão se torna inferior à do ponto de orvalho, no ponto (2), a partir do qual há a formação de líquido. Quando isso ocorre, devido à baixa mobilidade da fase líquida em relação à gasosa, há um acúmulo de condensado no meio poroso. Por esse motivo, a depender do liquid dropout (que é a variação da porcentagem de líquido em volume com a variação da pressão), das propriedades das fases e da morfologia do meio poroso, pode ocorrer a obstrução e a restrição dos 


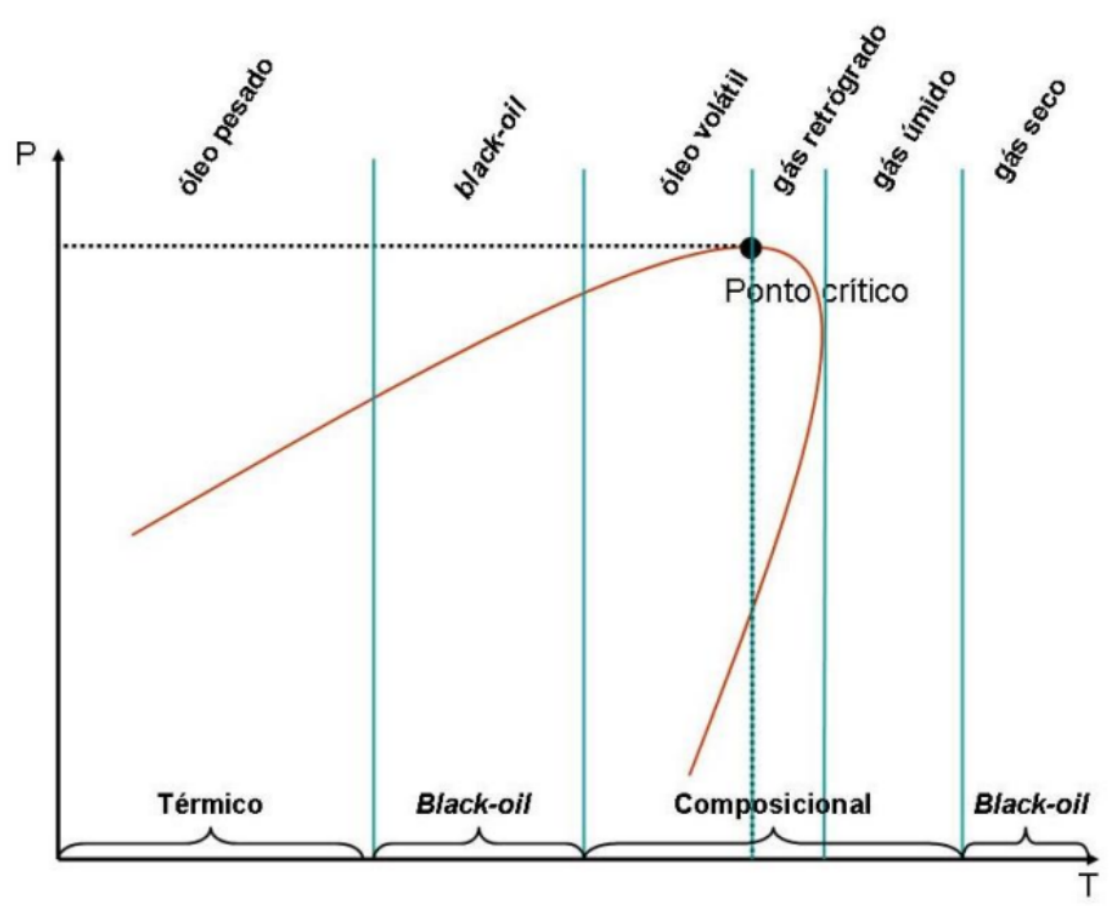

Figura 1.2: Resumo das aplicações de modelos de simulação de reservatórios no diagrama de fases pressão-temperatura [54]

poros para o escoamento do gás, o que, consequentemente, leva à perda de produtividade.

Caso a pressão seja reduzida ainda mais, atinge-se o ponto (3), a partir do qual se inicia um processo de revaporização. Entretanto, esse fenômeno pode não ocorrer no reservatório, por causa do acúmulo de componentes pesados no meio poroso, o que pode levar a uma mudança na composição do fluido no reservatório. Por isso, além da perda de produtividade, esses reservatórios de gás retrógrado sofrem também com a dificuldade de recuperação dos componentes pesados no fluido produzido.

Dada essa breve discussão sobre os conceitos básicos, este capítulo tem o objetivo de apresentar uma visão geral da dissertação, estabelecendo o contexto, mostrando a motivação, evidenciando os problemas e esclarecendo os objetivos desta pesquisa. Ele também destaca as contribuições da pesquisa para o meio científico e finaliza apresentando a estrutura da dissertação.

\section{1}

\section{Contexto}

Na indústria petrolífera, a modelagem de reservatórios é uma ferramenta muito útil para o desenvolvimento de um campo ao longo de sua vida produtiva. Os primeiros simuladores composicionais para prever e estudar melhores 


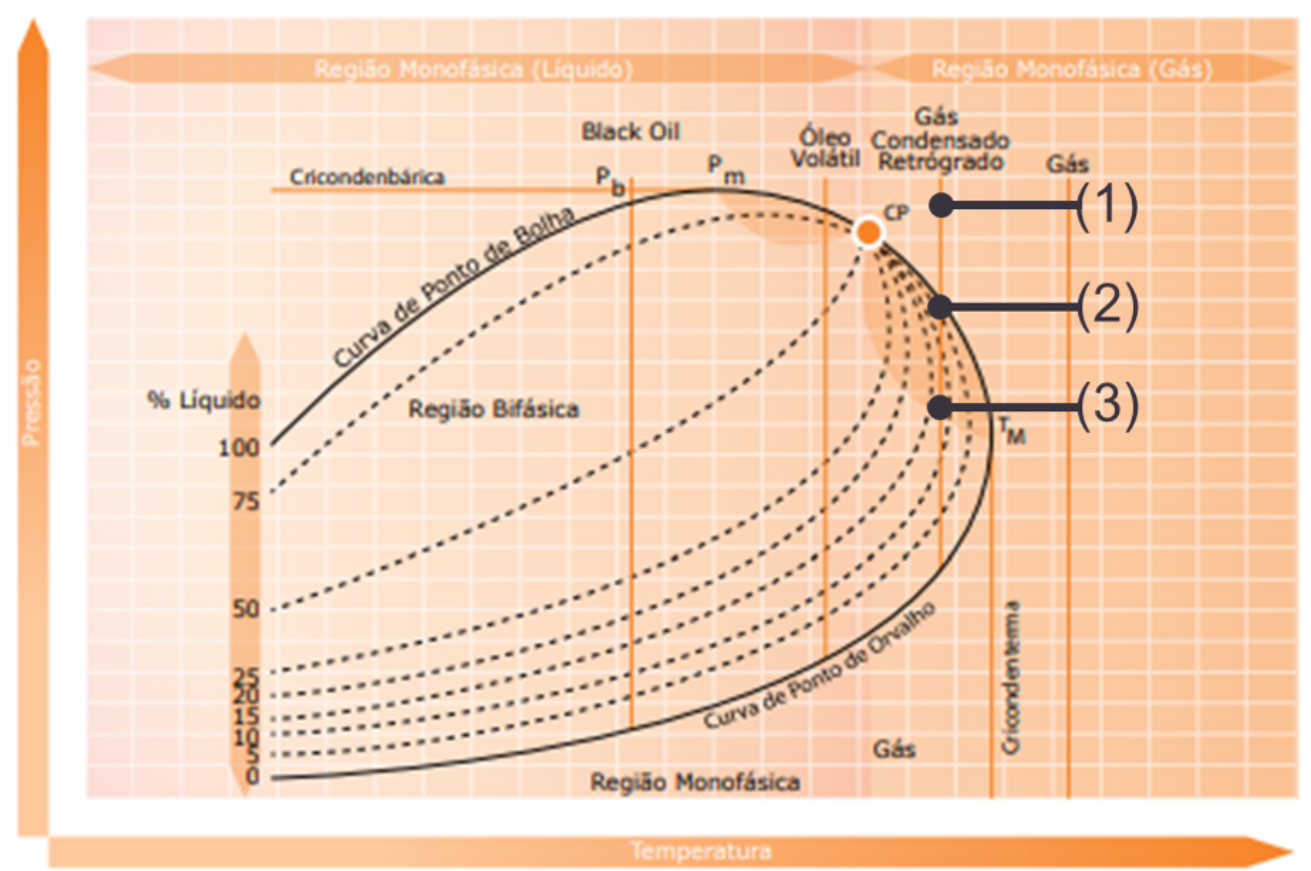

Figura 1.3: Diagrama de fases de uma mistura de hidrocarbonetos com 3 condições explicitadas (Adaptado de [5])

métodos de recuperação datam dos anos 60. Kniazeff e Naville (1965) [6] , Roebuck, Ford e Henderson $(1968,1969)$ [7] e Nolen (1973) [8] foram pioneiros e seus modelos usavam muitas simplificações. Somente em 1979, começa-se a aprimorar esses modelos, por exemplo, fazendo uso da equação de estado para obter as propriedades dos fluidos de maneira mais eficiente e mais realista [9]. A partir daí, uma quantidade significativa de esforços tem sido dedicada a desenvolver e melhorar técnicas de modelagem analítica e/ou numérica para simular o fluxo multifásico em meios porosos. Consequentemente, muitos métodos e modelos computacionais foram propostos e desenvolvidos com diferentes refinamentos e otimizações para que a simulação se tornasse mais precisa e mais eficiente computacionalmente. Este trabalho está inserido no contexto histórico da modelagem de reservatórios a fim de contribuir para a concepção de modelos mais representativos da realidade.

Atualmente, a maior parte dos métodos utilizados emprega correlações empíricas para descrever fenômenos de transporte decorridos do escoamento multifásico na escala de poros. A falta de precisão na descrição dos fenômenos físicos, principalmente na curva de permeabilidade relativa, compromete a qualidade das previsões dos resultados da análise de reservatório. 


\section{2 \\ Motivação}

A maior precisão na previsão da produção a partir de diferentes tipos de reservatórios engloba, indiretamente, um tópico bastante discutido hoje em dia que é o desenvolvimento sustentável. A geração de energia com baixa emissão de gás carbônico $\left(\mathrm{CO}_{2}\right)$ é fundamental para a sociedade e para a indústria. Assim, o gás passa a receber uma atenção diferenciada por causa da sua queima mais limpa se comparado ao óleo combustível.

Além da questão ambiental, o gás também se mostra mais barato se for comparado com outros produtos pesados de hidrocarbonetos. Por isso, é importante que se viabilize a produção otimizada e rentável das reservas de gás. Tendo em mente essa preocupação, é importante saber que o gás condensado está presente nos reservatórios high pressure, high temperature (HPHT) e em reservatórios de shale gas, que apresentaram custos elevados de desenvolvimento. Nesses últimos, ainda há a baixa permeabilidade, o que pode levar a um início de produção com pressão abaixo do ponto de orvalho. Dessa forma, a maioria dos reservatórios de shale gas produz com bancos de condensado por toda a sua vida.

Apesar das vantagens ambientais citadas, a produção de campos de gás retrógrado é bastante desafiadora. Por exemplo, em Sumatra (Indonésia), o campo de Arun é produtor de gás natural leve e está em atividade desde 1978. Durante a vida produtiva desse campo, sua capacidade produtiva foi reduzida em até $50 \%$ por causa do acúmulo de líquido no meio poroso, afetando a maioria dos 118 poços perfurados [11]. Como se pode ver na Figura 1.4, a causa do acúmulo de condensado é a queda de pressão do reservatório ao longo dos anos, o que o levou a entrar nas faixas correspondentes ao gás condensado retrógrado.

Apesar disso, esse campo já apresenta 90\% de suas reservas de gás recuperadas, e se tem a expectativa de que chegue aos $94 \%$ de recuperação. Isso só foi possível, em parte, por conta do desenvolvimento de ferramentas de modelagem mais representativas para campos de gás retrógrado, que auxiliaram no desenvolvimento de novas tecnologias para recuperação de gás desse campo [11].

\section{3}

\section{Problema}

Mesmo que seja possível produzir com os bancos de condensado, a produção dos poços tende a diminuir com o acúmulo de líquido. Isso acontece porque, apesar de parecer de pouca relevância em relação ao tamanho do 

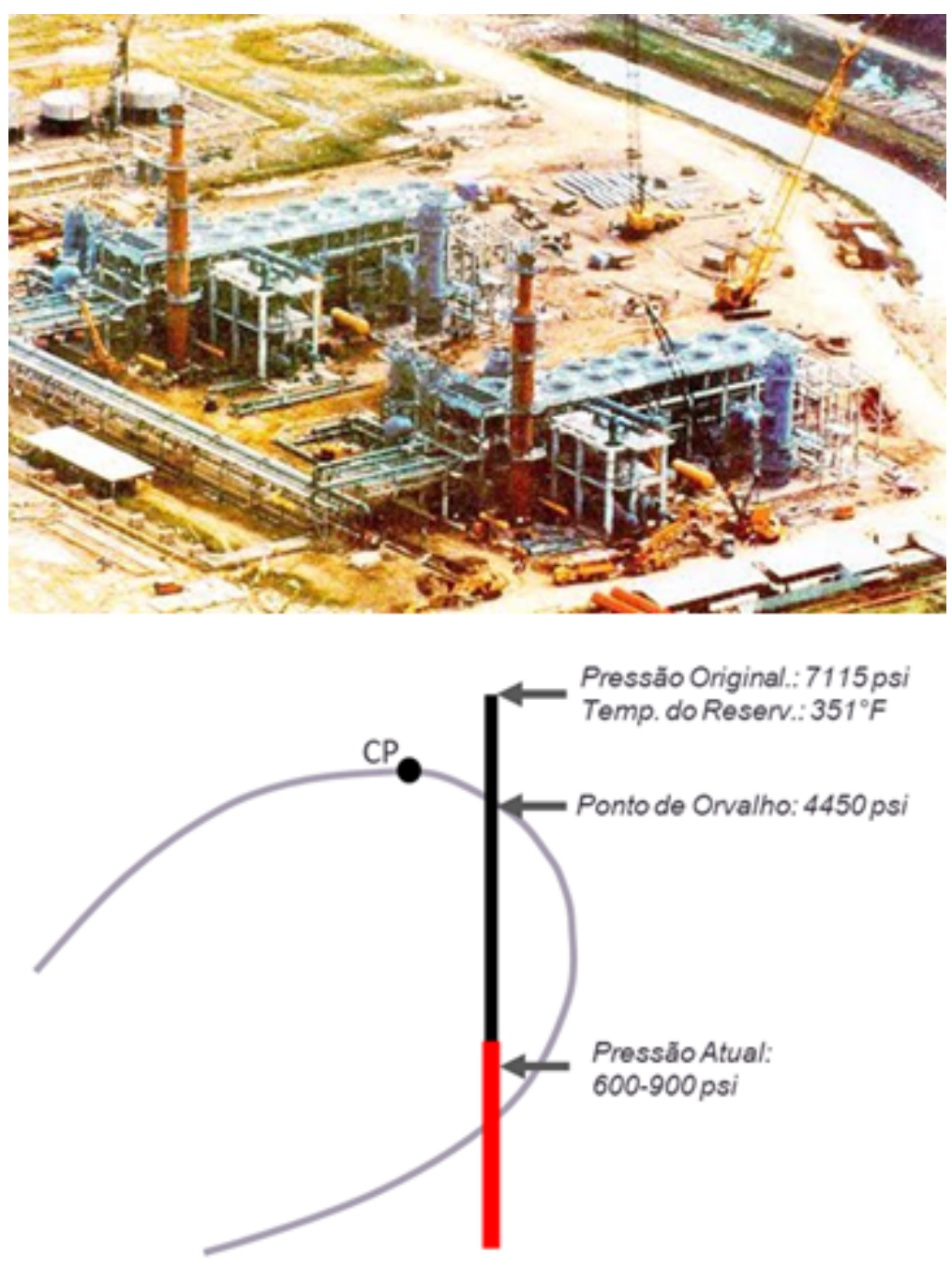

Figura 1.4: Foto do campo de Arun [10] acompanhado do seu respectivo Envelope de Fases (Adaptado de [11])

reservatório, o banco de condensado causa a interrupção de toda uma cadeia de poros que o gás poderia seguir até o poço.

Apesar do desenvolvimento ao longo dos anos da modelagem matemática de reservatórios, ainda existem muitos problemas a serem resolvidos a fim de se entender melhor a formação dos bancos de condensado em reservatórios de gás retrógrado. Entre eles, encontra-se a determinação da permeabilidade relativa das fases líquida e gasosa, que é utilizada como dado de entrada nos modelos de reservatório. Tipicamente, modelos de escala de reservatório utilizam curvas de permeabilidade relativa empíricas obtidas a partir de extrapolação de poucos dados experimentais. Elas comumente não consideram parâmetros importantes que governam o escoamento na escala de poros e, consequentemente, afetam a modelagem do fluxo no meio.

Erros na descrição de fenômenos na escala de poros causados pelo uso 
de curvas de permeabilidade relativas inapropriadas podem trazer grandes desvios nas previsões do comportamento do escoamento no reservatório. Com a modelagem mais representativa na escala de reservatórios, pode-se responder de forma mais correta qual seriam as condições ótimas de produção para que se minimize o acúmulo de líquido e bloqueio do fluxo de gás.

Dessa forma, a principal questão endereçada por este trabalho é: Qual é o efeito, na previsão do comportamento do escoamento de gás condensado, do uso de curvas de permeabilidade relativa que representam de forma mais precisa os mecanismos de transporte na escala de poros? Mais especificamente, este trabalho foca nas seguintes questões derivadas da questão principal:

- Como utilizar modelos de permeabilidade relativa baseados na simulação do escoamento na escala de poros em uma simulação na escala de reservatório?

- Qual o efeito da vazão de produção na formação dos bancos de condensado?

- Qual o efeito da permeabilidade absoluta na formação dos bancos de condensado?

\section{4}

\section{Objetivo}

O objetivo do presente trabalho é desenvolver um modelo computacional para o estudo do escoamento de gás retrógrado em torno de um poço utilizando curvas de permeabilidade relativa obtidas através de simulação do escoamento de gás retrógrado na escala de poros. Essas curvas representam de forma mais completa os diferentes fenômenos físicos observados durante o escoamento multifásico na escala de poros. Os resultados são comparados com os obtidos usando a modelagem de permeabilidade relativa proposta por Hartman \& Cullick [21], onde as curvas de permeabilidade relativa são definidas pela interpolação de dados experimentais e curvas para escoamento miscível, em função da tensão interfacial entre gás e condensado.

\section{5}

\section{Organização dos Capítulos}

O contexto, motivação, problema e objetivos foram tratados neste primeiro capítulo.

O segundo capítulo apresenta uma revisão bibliográfica dividida em duas partes. A primeira parte aborda modelos de reservatórios e seu uso em 
problemas de gás condensado. A segunda parte trata de algumas formulações para modelos composicionais contínuos.

O terceiro capítulo abrange a modelagem matemática do problema composicional na escala de reservatórios. Nele é feita a descrição das equações governantes utilizadas com as condições de contorno necessárias para a resolução do problema e as curvas de permeabilidade citadas anteriormente.

O quarto capítulo descreve a solução numérica da formulação apresentada no capítulo anterior. Descrevem-se nesse a discretização das equações de fluxo e o método de solução do problema.

No quinto capítulo são apresentados a validação da implementação e os resultados da simulação com diferentes modelos de permeabilidade relativa, velocidades de escoamento de gás no poço e permeabilidades absoluta.

Por último, o sexto capítulo apresenta as conclusões e propostas de trabalhos futuros. 


\section{2 \\ Revisão Bibliográfica}

Para permitir um melhor posicionamento sobre o problema descrito no capítulo anterior, este trabalho levantou na literatura como os seguintes quatro grandes temas são tratados: gás retrógrado, escala do modelo de escoamento, modelagem de permeabilidade relativa e modelagem composicional.

\section{1}

\section{Gás Retrógrado}

Como já citado, o foco deste trabalho é nos reservatórios de gás retrógrado e, por isso, são descritas a seguir algumas de suas características principais. Estes tipicamente contém componentes voláteis, como o metano, e uma porção menor de hidrocarbonetos pesados (<15 mol \%) [13]. Porém, mesmo estando em menor porcentagem, essas porções pesadas são as responsáveis pelo comportamento de gás retrógrado condensado. Esse fenômeno foi explicado no capítulo anterior, tomando como base a Figura 1.3. A mobilidade do condensado tende a ser muito menor do que a mobilidade do gás, ocasionando assim seu acúmulo e a obstrução dos poros no reservatório.

Essa obstrução por condensado é crítica, especialmente em dois casos: (1) se a queda de pressão do reservatório até o poço for percentualmente significativa em relação à queda de pressão total do reservatório até o separador na superfície e (2) se o reservatório apresenta baixa a média permeabilidade (<10-50md) [13]. Em ambos os casos, esses bancos de condensados são críticos, pois podem levar a uma queda significativa na produção de gás.

Whitson e Fevang [14] especificam as três regiões de fluxo em um reservatório de gás condensado, de modo que se pode ter um melhor entendimento da localização dos bancos de condensado citados anteriormente. Essa especificação é representada na Figura 2.1, na qual se veem três regiões delimitadas:

- Região 3 - essa região somente existe em reservatórios de gás retrógrado sub-saturado e nela a pressão é acima da pressão de orvalho, ou seja, nela somente há gás. A composição do fluido nessa região é constante e igual a do gás original do reservatório.

- Região 2 - ela é definida pelo início da formação de condensado, pois a pressão está abaixo do ponto de orvalho. Nessa região, somente gás está 
fluindo, porque a saturação da fase líquida é baixa e sua mobilidade é zero ou quase zero. Essa região é maior no início da vida produtiva do poço, mas vai reduzindo conforme a Região 1 vai crescendo.

- Região 1 - se localiza nas proximidades do poço e nela, há gás e óleo fluindo simultaneamente, porém em velocidades diferentes. A saturação da fase líquida tende a ser alta, levando a baixos valores da permeabilidade efetiva da fase gasosa e, consequentemente, a baixas vazões de produção de gás. [14].

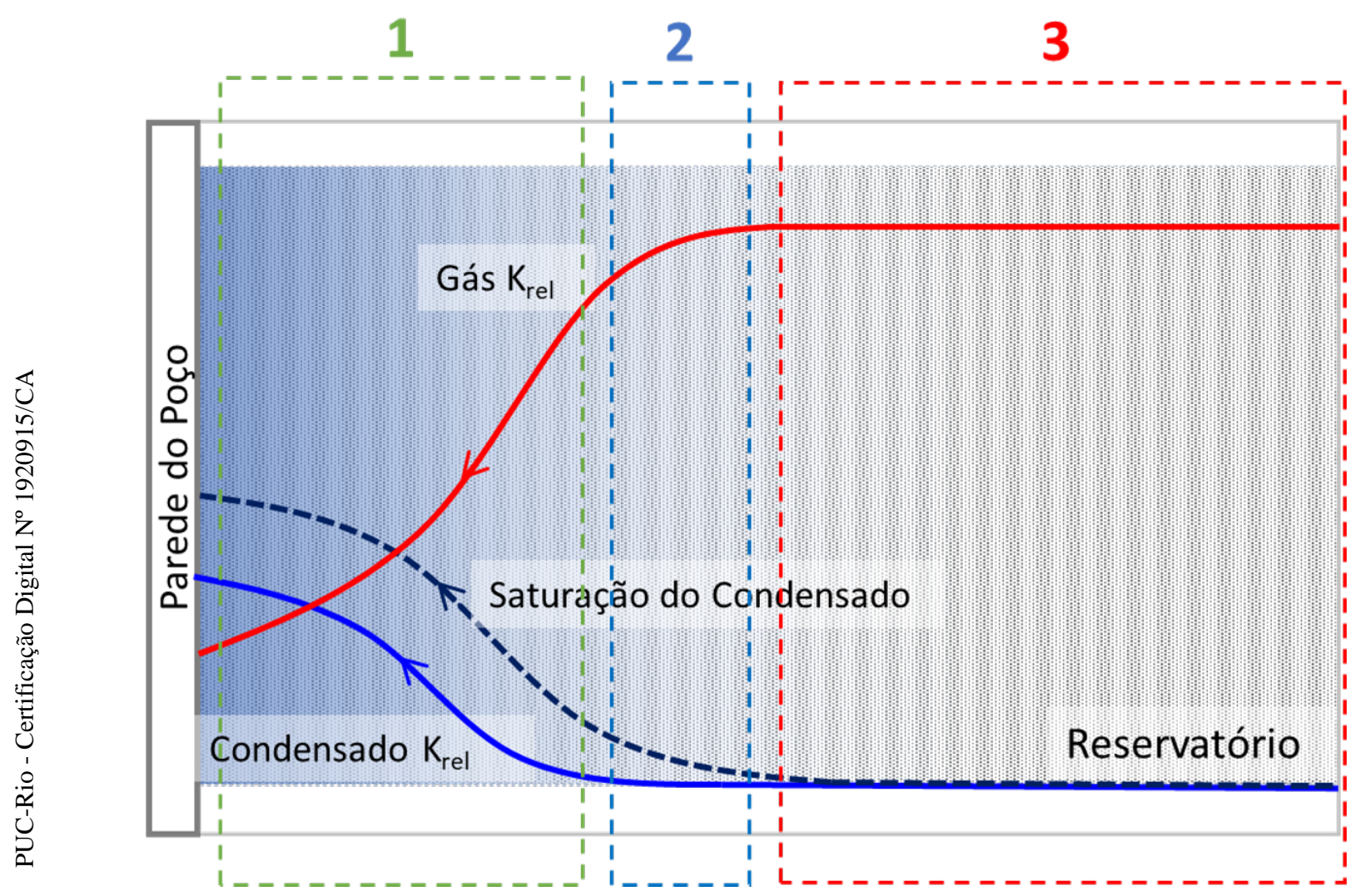

Figura 2.1: Três regiões do comportamento de fluxo em um gás condensado. Adaptado de [14].

\section{2}

\section{Escala do Modelo de Escoamento}

O fluxo em meios porosos pode ser estudado em diferentes escalas, a depender dos objetivos da análise. A primeira delas é a escala microscópica, ilustrada na Figura 2.2 (a), também chamada de escala de poros.

A grande resolução dessa escala permite definir detalhadamente a geometria do meio poroso e o comportamento do escoamento derivado das interações rocha-fluido e fluido-fluido. Entretanto, esse nível de detalhe gera grandes 
custos computacionais para que as simulações sejam executadas e, consequentemente, seu volume de domínio se restringe, comumente, a milímetros. Os métodos mais utilizados para esse nível de detalhamento estão descritos por Goldparvar et. al. [34]. Nele, comparam-se três tipos de técnicas utilizadas na escala microscópica. São elas:

- Modelagem de Tubos Capilares (Bundle of Capillary Tube Modeling - BCTM) - Este modelo representa o espaço poroso com tubos capilares de seção transversal de tamanho e forma variável. Apesar da simples abordagem, esta é bastante utilizada para simular o fluxo multifásico em meios porosos. Nos estudos mais recentes, os tubos capilares contém seção transversal irregular e foram extraídos diretamente de imagens de rochas a fim de simular as características do fluido juntamente com a função de fluxo. Porém, este modelo não captura toda a conectividade dos poros de uma amostra real e dificulta a representação de fenômenos-chave de deslocamento, como aprisionamento e mobilização de gânglios.

\section{- Modelagem de Rede de Poros (Pore Network Modeling - PNM)} - Neste modelo, o espaço poroso é recriado a partir de redes de estruturas geométricas simplificados representando poros e gargantas. Estas redes podem ser regulares ou construídas a partir de imagens em escala de poro do meio a ser representado. Ele foi inicialmente desenvolvido para simular o fluxo dominado por forças capilares dando, assim, origem à modelagem de rede de poros quase estática. Em estudos mais recentes, modelos dinâmicos foram desenvolvidos para incorporar o efeito de forças viscosos no escoamento em meios porosos (Løvoll et al., 2005 [35]).

- Modelagem direta em escala de poros ( Direct Pore Scale Modeling - DPSM) - Diferentemente do modelo anterior, nestes modelos o espaço poroso é representado com mais detalhes em alta resolução. As equações que descrevem o escoamento de fluidos são resolvidas em um domínio 3D complexo, que representa o espaço poroso. Atualmente, tem sido bastante utilizado na simulação de fluxo monofásico, devido à dificuldade de modelagem de interfaces entre diferentes fluidos e entre fluidos e rocha.

A escala utilizada por este trabalho é a macroscópica, que se encontra ilustrada na Figura 2.2 (b). Nela, o escoamento é descrito por equações diferenciais e o comportamento na escala de poros é representado indiretamente por propriedades e funções macroscópicas, como, porosidade, permeabilidade absoluta, curvas de pressão capilar e permeabilidade relativa. Essa abordagem 


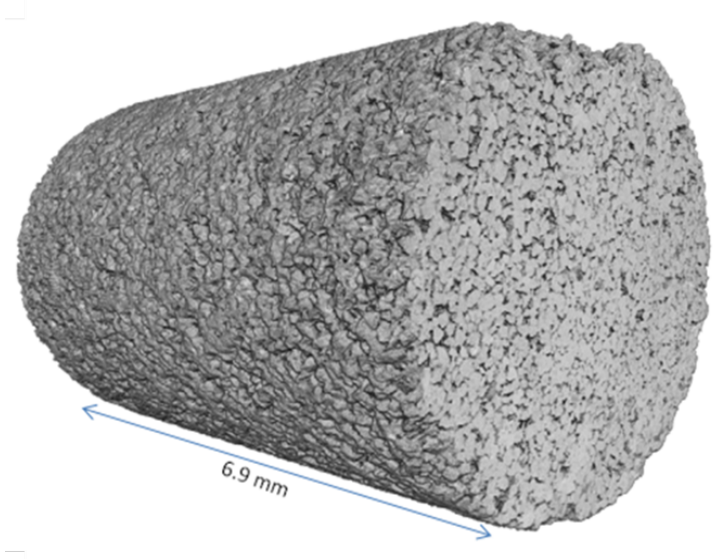

(a)

\begin{tabular}{|l|l|l|}
\hline$\phi_{1}$ & $\phi_{2}$ & $\phi_{3}$ \\
$K_{1}$ & $K_{2}$ & $K_{3}$ \\
\hline$\phi_{4}$ & $\phi_{5}$ & $\phi_{6}$ \\
$K_{4}$ & $K_{5}$ & $K_{6}$ \\
\hline$\phi_{7}$ & $\phi_{8}$ & $\phi_{9}$ \\
$K_{7}$ & $K_{8}$ & $K_{9}$ \\
\hline
\end{tabular}

(b)

Figura 2.2: Representações de meio poroso em diversas escalas (a) Escala microscópica: subseção de um modelo de rede de poros gerado através de uma imagem micro-CT de uma amostra de arenito [52] (b) Escala macroscópica: abordagem do contínuo com volumes finitos.

pressupõe a existência de um volume elementar representativo (REV), que representa o menor volume para o qual as médias das propriedades (porosidade, permeabilidade, etc.) sejam representativas do todo [18]. Essa ideia do REV é ilustrada pela Figura 2.3.

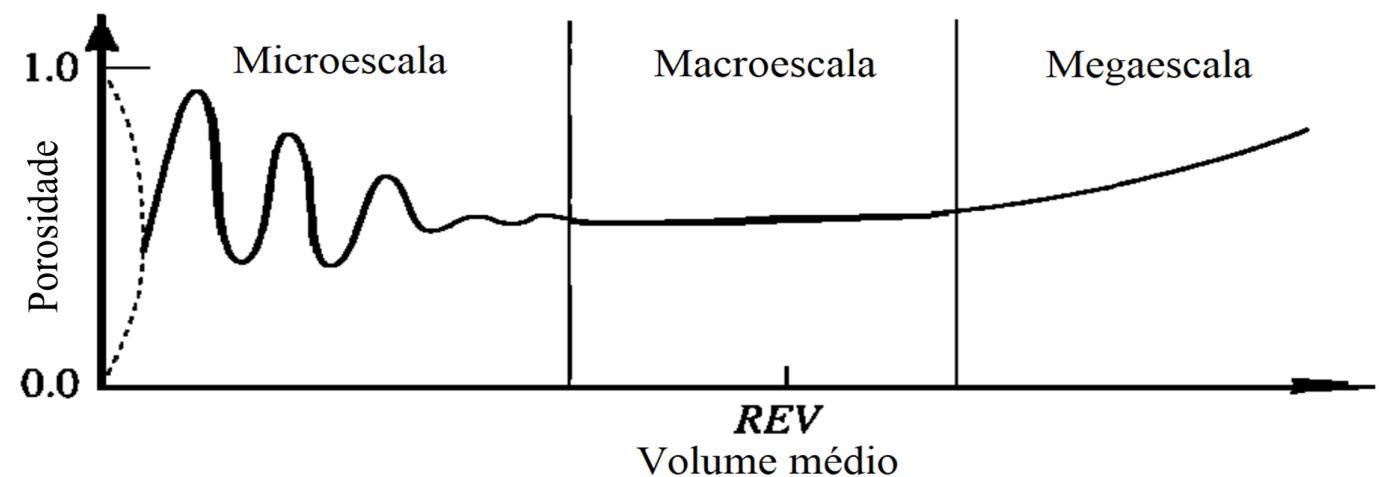

Figura 2.3: Volume médio de tamanho suficiente de modo que represente o todo. (Adaptado de [19])

\section{3}

\section{Modelo de Permeabilidade Relativa}

Entende-se permeabilidade como a propriedade que caracteriza a facilidade com que um meio poroso é percolado por uma ou mais fases, definida a 
partir das experiências realizadas por Henry Darcy em 1856 [20]. A permeabilidade absoluta é uma característica intrínseca ao meio poroso, sem depender das interações rocha-fluido. No caso de escoamento multifásico, é importante levar em conta as interações rocha-fluido e entre fluidos. Logo, neste caso é importante definir o conceito de permeabilidade efetiva, que depende da distribuição das fases no espaço poroso e das condições de escoamento. A permeabilidade relativa é definida como a razão entre as permeabilidades efetiva e absoluta.

Comumente, definem-se as curvas de permeabilidade relativa em função da saturação dos fluidos no meio poroso. Entretanto, é importante ressaltar que as curvas de permeabilidade relativa para o gás condensado dependem também da velocidade do fluxo e da tensão interfacial. Em Henderson et. al. (1997) [36], foram conduzidos experimentos a fim de determinar o efeito da vazão e da tensão interfacial nas curvas de permeabilidade relativa. Foi observado que o efeito da velocidade de fluxo e da tensão interfacial é importante, principalmente, para o fluxo próximo ao poço em reservatórios de condensado de gás, onde as forças viscosas aumentam significativamente. Durante a repetição de testes com vazões crescentes, a permeabilidade relativa de ambas as fases aumentaram com o aumento da velocidade. Já para o aumento da tensão interfacial entre as fases, foi constatado que houve maior redução da permeabilidade relativa na fase gás se comparado com a fase condensada.

Existem diversos métodos para se determinar a permeabilidade relativa, mas os principais são os experimentais, as correlações empíricas e a modelagem em escala de poros. Os métodos experimentais são realizados em laboratório através de medições utilizando testemunhos de rocha-reservatório. As correlações empíricas buscam desenvolver equações que generalizem o comportamento das curvas observadas experimentalmente em função de parâmetros como saturação, velocidade e IFT [20].

Nos métodos experimentais, Henderson et. al. (1997) [36] realizaram uma série de experimentos com gás condensado por meio da aplicação de alta pressão em amostras de arenitos a fim de mensurar, como já citado anteriormente, os efeitos de vazão e tensão interfacial nas imediações de um poço isolado. Em 2009 [24], Thomas et al. utilizam um testemunho e fazem medições diretas relativas ao escoamento de fluidos através dele. Com a abordagem de injeção de fluido bifásico, os autores conseguem um conjunto de dados bastante completo para uso em simulação de reservatórios de gás condensado.

Já nos métodos de correlações empíricas para permeabilidade relativa, um trabalho pioneiro foi desenvolvido por Coats (1980) [37], a fim de modelar 
a mobilidade das fases corretamente. Nele, foi proposto um modelo de permeabilidade relativa em que eram interpoladas curvas de escoamentos miscíveis e imiscíveis utilizando uma função da tensão interfacial como parâmetro de interpolação.

Segundo um procedimento similar ao de Coats, Hartman e Cullick (1994) [21] utilizam, como dado de entrada em seu modelo de simulação de escoamento de gás retrógrado, curvas de permeabilidade relativa parametrizadas pela tensão interfacial (IFT) acopladas a um modelo de IFT dependente da pressão. Essas correlações propostas por Hartman e Cullick [21] são descritas com mais detalhes no Capítulo 3 deste trabalho.

Por outro lado, Blom \& Hagoort (1998) [38] analisaram o fluxo de condensado na região próxima a um poço isolado e calibraram quatro correlações advindas de conjuntos de dados experimentais. Nesse estudo, os autores concluíram que o método mais adequado para a representação do escoamento de gás e condensado foi o proposto por Whitson \& Fevang (1996) [14], capaz de reproduzir os aspectos mais importantes da dependência entre a permeabilidade relativa e o número de capilaridade, que representa a razão entre as forças viscosas e forças capilares.

Já em Pope et al. (2000) [39], os autores desenvolveram um novo modelo de interpolação baseado em um parâmetro chamado pelos autores de trapping number, em vez da tensão interfacial. Isso possibilitou aos autores modelarem as permeabilidades relativas de gás e condensado, que foram comparadas com os dados experimentais, obtendo bons resultados e indicando que o modelo de permeabilidade relativa interpolado com o trapping number é mais geral que o modelo interpolado somente com a tensão interfacial.

Ainda sobre os modelos de correlação empírica, Whitson et al. (2003) [13] desenvolvem um modelo empírico consistente para o cálculo da permeabilidade relativa de gás e condensado. Os autores usam as equações composicionais de fluxo e consideram a razão entre permeabilidade relativa de gás e condensado como uma variável puramente termodinâmica. Dessa forma, eles constroem um sistema de equações termodinâmicas independentes do sistema hidrodinâmico, de modo que todas as variáveis termodinâmicas dependem somente da pressão. Seu modelo empírico permite modelar, com consistência, diferentes tipos de rochas, regiões de reservatório e variações de saturação.

Alternativamente, os métodos de modelagem em escala de poros utilizam simulação em cima de uma topologia de poros para determinar curvas de permeabilidade relativa variando parâmetros como a velocidade de escoamento e saturação das fases. As topologias utilizadas podem ser sintéticas ou baseadas em imagens de amostras de rochas. Os modelos de rede são usados por Fang 
et al. (1996) [23] e Li \& Firoozabadi (2000) [22] para estudar os efeitos da gravidade, das forças viscosas, da tensão interfacial e da molhabilidade na saturação crítica de condensado e nas permeabilidades relativas de gás e condensado. Ainda na escala de poros, Reis e Carvalho [17], [27] e [28] utilizam modelos de rede de poros para calcular a permeabilidade relativa para diferentes velocidades de escoamento do gás e para diferentes saturações de gás e condensado. Essas curvas são apresentadas com mais detalhes no Capítulo 3 deste trabalho.

\section{4}

\section{Modelo Composicional e Método de Solução}

A simulação composicional permite modelar o escoamento dos componentes do fluido no reservatório em função do tempo e do espaço, além de calcular o equilíbrio de fases[4]. Esse tipo de modelo é muito importante para as análises de produção de gás retrógrado que, devido à formação de bancos de condensado, são extremamente dependentes da composição do fluido em cada fase. Em comparação com modelos do tiplo black-oil, os modelos composicionais exigem maior esforço computacional. Este trabalho estuda gás retrogrado e, portanto, utiliza um modelo composicional para simulação do reservatório, fazendo uso de uma equação de estado para calcular o equilíbrio de fases e o cálculo das propriedades do fluido.

Um ponto importante sobre o modelo composicional é qual o método de solução utilizado para resolver o sistema de equações diferencias nãolineares e dependentes do tempo que representam o escoamento de escoamentos multifásicos em meio poroso. Os pioneiros desse tipo de modelagem são Fussel \& Yanosik [40], pois foram os primeiros a propor a utilização de uma equação de estado para calcular o equilíbrio de fases em um simulador de reservatórios. Em seu trabalho, eles fazem uso da equação de estado de Redlich-Kwong e, como o sistema que as incorpora é não-linear, há a necessidade de um método de iteração para a solução. Para esse fim, eles fazem uso do método de NewtonRaphson, pois ele é um dos métodos que não resultam em divergência quando se aproxima de pontos críticos (ponto de bolha, ponto de orvalho e bifásico perto da região crítica). Com esse método, eles foram capazes de resolver simultaneamente as equações de equilíbrio de fases e as restrições de saturação em função da pressão e das composições de uma das fases. O artigo apresenta um método iterativo sequencial confiável para prever o equilíbrio de fases de recuperação de óleo miscível e, além disso, também calcula a pressão de saturação e o equilíbrio de fases na região bifásica.

Coats [37], assim como os autores anteriores, utilizou uma formulação 
implícita e composicional para equacionar o fluxo em reservatórios. Em seu trabalho, utilizou a equação de Redlich-Kwong modificada e o método de Newton-Raphson para resolver as equações de balanço molar em função da pressão, as saturações de ambas fases (gás e líquido) e as composições para uma das fases. Porém, tanto o modelo de Coats [37] quanto o de Fussel et al. [40] ainda exigem bastante esforço computacional por causa da dimensão da matriz Jacobiana associada ao Método de Newton.

Já em Collins et al. [41], é apresentado um método robusto e mais eficiente para modelagem composicional, se comparado com os modelos citados anteriormente, propostos por Coats[37] e Fussel et al.[40]. A característica principal dessa formulação é o desacoplamento entre solução das equações transporte e os cálculos de flash. Com a nova formulação de Collins et al. [41], equações de balanço molar e de consistência de volume são solucionadas com o método de Newton-Raphson, enquanto o cálculo de equilíbrio de fase é resolvido a cada iteração desse método. Dessa maneira, as equações de fluxo e de equilíbrio de fase convergem simultaneamente. Portanto, tem-se maior liberdade para escolha do método de solução para as equações de equilíbrio de fase. Este trabalho utiliza a mesma solução proposta por Collins et al. [41]. 


\section{3}

\section{Modelo Composicional}

Para analisar o escoamento de gás e condensado em reservatórios é proposto um modelo de escoamento em torno de um poço que faz uso da simulação composicional e considera duas fases (líquida e gasosa) de hidrocarbonetos. Essa modelagem tem como premissas as seguintes características:

- sistema isotérmico

- escoamento monofásico ou bifásico

- equilíbrio termodinâmico instantâneo

- meio poroso incompressível

- ausência de reações químicas rocha-fluido

- $n_{c}$ componentes presentes

- forças capilares consideradas no modelo de permeabilidade relativa

- ausência de efeitos gravitacionais

- ausência de fase aquosa

\section{1}

\section{Descrição do Meio Poroso}

Neste trabalho, o meio poroso em escala de reservatório é considerado axissimétrico e representado em coordenadas cilíndricas, com o domínio indo desde a parede do poço até o limite do reservatório. São consideradas as seguintes propriedades físicas e químicas do fluido:

- $P(r, t):$ Pressão;

- $N^{k}(r, t)$ : Número de moles do componente $k$;

- $x^{k}(r, t)$ : Fração molar do componente $k$ na fase líquida;

- $y^{k}(r, t)$ : Fração molar do componente $k$ na fase gasosa;

- $S_{j}(r, t)$ : Saturação da fase $j$, que é definida como sendo a fração do volume poroso ocupada pelo fluido $j$.

Além disso, são consideradas as seguintes propriedades do meio poroso: 
- $k$ : Permeabilidade absoluta;

- $\phi$ : Porosidade;

- $r_{\max }$ : Raio externo do reservatório;

- $r_{\text {well }}$ : Raio interno do poço.

\section{2}

\section{Equações Governantes}

\subsection{1}

\section{Equação do Balanço Molar}

A equação do balanço molar representa a conservação de cada um dos componentes no volume de controle em consideração, ou seja, a diferença entre os fluxos molares de entrada e saída de cada componente $k$ tem que ser igual a quantidade molar de cada componente $k$ acumulada no volume de controle. Para deduzir a equação utilizada neste trabalho, partiu-se da equação de conservação molar para fluxo bifásico unidimensional em coordenadas cartesianas, conforme proposto em Shi, 2009 [29]:

$\frac{\partial}{\partial t}\left[\phi\left(x^{k} \xi_{\text {liq }} S_{\text {liq }}+y^{k} \xi_{\text {gas }} S_{\text {gas }}\right)\right]+\frac{\partial}{\partial x}\left(x^{k} \xi_{\text {liq }} v_{\text {liq }}+y^{k} \xi_{\text {gas }} v_{\text {gas }}\right)=0, \quad k=1, \ldots, n_{c}$

onde $\xi_{l i q}$ e $\xi_{\text {gas }}$ são, respectivamente, a densidade molar da fase líquida e da fase gás, $v_{l i q}$ e $v_{\text {gas }}$ são, respectivamente, a velocidade local do fluxo na fase líquida e na fase gás, advinda da lei de Darcy, e $n_{c}$ é o número de componentes.

Considere também as expressões algébricas para as velocidades $\left(v_{j}\right)$, densidade molar do componente $k\left(G_{k}\right)$ e mobilidade do componente $k\left(m_{k}\right)$ como sendo:

$$
\begin{gathered}
v_{l i q}=-\frac{k k_{r l i q}}{\mu_{\text {liq }}} \frac{\partial P}{\partial x} \\
v_{\text {gas }}=-\frac{k k_{\text {rgas }}}{\mu_{\text {gas }}} \frac{\partial P}{\partial x} \\
G_{k}=x^{k} \xi_{\text {liq }} S_{\text {liq }}+y^{k} \xi_{\text {gas }} S_{\text {gas }} \\
m_{k}=x^{k} \xi_{l i q} S_{l i q} \frac{k k_{r l i q}}{\mu_{l i q}}+y^{k} \xi_{\text {gas }} S_{\text {gas }} \frac{k k_{\text {rgas }}}{\mu_{\text {gas }}}
\end{gathered}
$$

onde $k_{r l i q}$ e $k_{\text {rgas }}$ são, respectivamente, a permeabilidade relativa da fase líquida e da fase gás, $\mu_{\text {liq }}$ e $\mu_{\text {gas }}$ são, respectivamente, a viscosidade da fase líquida e da fase gás, $S_{l i q}$ e $S_{g a s}$ são, respectivamente, a saturação da fase líquida e da fase gás. 
Substituindo essas definições na Equação 3-1 e considerando a porosidade do meio $(\phi)$ como constante, tem-se:

$$
\phi \frac{\partial G_{k}}{\partial t}-\frac{\partial}{\partial x}\left(m_{k} \frac{\partial P}{\partial x}\right)=0
$$

Como este trabalho se propõe a estudar o fluxo em outro sistema de coordenadas, faz-se necessário transformar a Equação 3-6 para coordenadas cilíndricas:

$$
\phi \frac{\partial G_{k}}{\partial t}-\frac{1}{r} \frac{\partial}{\partial r}\left(r m_{k} \frac{\partial P}{\partial r}\right)=0
$$

Além disso, sabe-se que a densidade molar do componente, $G_{k}$, é definida por:

$$
G_{k}=\frac{N^{k}}{V_{\text {poroso }}}
$$

onde $V_{\text {poroso }}$ é o volume poroso, que é ocupado inteiramente pela mistura.

Substituindo a Equação (3-8) na Equação (3-7) e considerando que o volume não varia no tempo, tem-se:

$$
\frac{\phi}{V_{\text {poroso }}} \frac{\partial N^{k}}{\partial t}-\frac{1}{r} \frac{\partial}{\partial r}\left(r m_{k} \frac{\partial P}{\partial r}\right)=0
$$

onde $N_{i}$ é o número total de mols do componente.

Por fim, reorganizando a Equação 3-9, obtém-se a forma da equação de balanço molar que é utilizada neste trabalho:

$$
\frac{\partial N^{k}}{\partial t}-\frac{V_{\text {poroso }}}{\phi r} \frac{\partial}{\partial r}\left(r m_{k} \frac{\partial P}{\partial r}\right)=0
$$

\subsection{2}

\section{Equação da Consistência de Volume}

Como neste trabalho o escoamento é bifásico, com uma fase sendo condensado e a outra gás, a equação da consistência do volume considera o volume poroso total do sistema equivalente à soma entre o volume de gás e o de condensado em cada instante de tempo. Assim, para cada instante de tempo tem-se que:

$$
V_{\text {poroso }}=V_{l i q}+V_{\text {gas }}
$$

onde $V_{\text {poroso }}, V_{\text {liq }}$ e $V_{\text {gas }}$ são dados, respectivamente, por: 


$$
\begin{gathered}
V_{\text {poroso }}=V \phi \\
V_{l i q}=\frac{N_{l i q}}{\xi_{l i q}} \\
V_{\text {gas }}=\frac{N_{\text {gas }}}{\xi_{\text {gas }}}
\end{gathered}
$$

Por fim, substituindo as Equações (3-12), (3-13) e (3-14) na Equação (3-15), tem-se a forma da equação da consistência de volumes que é utilizada neste trabalho:

$$
V \phi=\frac{N_{l i q}}{\xi_{l i q}}+\frac{N_{\text {gas }}}{\xi_{\text {gas }}}
$$

onde $N_{\text {liq }}$ e $N_{\text {gas }}$ podem ser calculados da seguinte forma:

$$
\begin{gathered}
N_{\text {liq }}=\mathcal{L} \sum_{k=1}^{n_{c}} N^{k} \\
N_{\text {gas }}=(1-\mathcal{L}) \sum_{k=1}^{n_{c}} N^{k}
\end{gathered}
$$

onde $\mathcal{L}$ é a fração molar de líquido.

As densidades molares de cada fase $\xi_{l i q}$ e $\xi_{\text {gas }}$ são calculadas a partir da equação de estado com uma correção no volume para forçar a aderência entre os seus dados e os obtidos em laboratório [33]. Assim, elas podem ser obtidas por:

$$
\begin{aligned}
\xi_{\text {liq }} & =\frac{1}{\frac{Z_{l i q} R T}{P}-\sum_{k=1}^{n_{c}} x^{k} \nu^{k}} \\
\xi_{\text {gas }} & =\frac{1}{\frac{Z_{\text {gas }} R T}{P}-\sum_{k=1}^{n_{c}} y^{k} \nu^{k}}
\end{aligned}
$$

onde $\sum_{k=1}^{n_{c}} x^{k} \nu^{k}$ e $\sum_{k=1}^{n_{c}} y^{k} \nu^{k}$ correspondem às correções de volume das fases líquida e gasosa, $\nu_{k}$ é o fator de correção de volume para o componente $k, Z_{l i q}$ e $Z_{\text {gas }}$ são, respectivamente, as compressibilidades de líquido e de gás e $R$ é a constante universal dos gases.

Com as definições de (3-16) a (3-19) pode-se escrever a equação de consistência dos volumes calculada em (3-15) em função do número de mols de cada fase, pressão e temperatura, de modo que: 


$$
\begin{aligned}
V \phi & =N_{l i q}\left(\frac{Z_{l i q} R T}{P}-\sum_{k=1}^{n_{k}} v_{k} x_{k}\right)+N_{\text {gas }}\left(\frac{Z_{\text {gas }} R T}{P}-\sum_{k=1}^{n_{k}} v_{k} y_{k}\right) \\
& =N_{l i q}\left[\mathcal{L}\left(\frac{Z_{l i q} R T}{P}-\sum_{k=1}^{n_{k}} v_{k} x_{k}\right)+(1-\mathcal{L})\left(\frac{Z_{\text {gas }} R T}{P}-\sum_{k=1}^{n_{k}} v_{k} y_{k}\right)\right]
\end{aligned}
$$

\section{3}

\section{Equações Termodinâmicas}

\subsection{1}

\section{Equação de Estado}

Para a equação de estado, utiliza-se a formulação proposta por Peng \& Robinson [30] a fim de calcular as propriedades do fluido e o equilíbrio de fases, pois ela apresenta melhores resultados nas proximidades dos pontos críticos:

$$
P=\frac{R T}{\bar{V}-b}-\frac{a(T)}{\bar{V}(\bar{V}+b)+b(\bar{V}-b)}
$$

onde $\bar{V}$ é o volume molar.

A Equação (3-21) é derivada da Equação de Van der Waals, os parâmetros $a(T)$ e $b$, podem ser obtidos da seguinte forma:

$$
\begin{gathered}
a(T)=\sum_{k=1}^{n_{c}} \sum_{m=1}^{n_{c}} z^{k} z^{m} \sqrt{a_{k} a_{m}}\left(1-\lambda_{k m}\right) \\
b=\sum_{k=1}^{n_{c}} z^{k} b_{k}
\end{gathered}
$$

onde $z_{k}$ e $z_{m}$ são as frações molares de cada componente $k$ e $m$ da mistura, $\lambda$ é o coeficiente de interação binária entre os componentes $k$ e $m$, e $a_{k}$ e $b_{k}$ são parâmetros calculados da seguinte forma:

$$
\begin{gathered}
a_{k}=\frac{0,45724 R^{2} T_{c k}^{2}}{P_{c k}} \alpha_{k} \\
\alpha_{k}=\left(1+\left(0,37464+1,54226 \omega_{k}-0.26992 \omega_{k}^{2}\right)\left(1-T_{r k}^{0,5}\right)\right)^{2} \\
T_{r k}=\frac{T}{T_{c k}}
\end{gathered}
$$

onde $T_{c k}, P_{c k}$ e $\omega_{k}$ são, respectivamente, temperatura crítica, pressão crítica e fator acêntrico do componente $k$.

Por outro lado, tem-se a expressão algébrica da compressibilidade $Z$ apresentada na Equação 3-27: 


$$
Z=\frac{P V}{R T}
$$

A partir dessa disso, substituindo a Equação (3-27) na Equação (3-21), tem-se uma equação cúbica:

$$
Z^{3}-(1-B) Z^{2}+\left(A-2 B-3 B^{2}\right) Z-\left(A B-B^{2}-B^{3}\right)=0
$$

onde:

$$
\begin{gathered}
A=\frac{a P}{R^{2} T^{2}} \\
B=\frac{b P}{R T}
\end{gathered}
$$

Resolvendo a Equação 3-28, obtém-se 3 soluções, para as quais existem dois casos possíveis:

- três soluções reais, sendo que a maior é atribuída à fase gás, a menor à fase líquida e a intermediária descartada

- uma solução real que é aproveitada e duas complexas que são descartadas

Além das equações anteriores, faz-se necessário o cálculo dos coeficientes de fugacidade $\phi_{k}$ para cada componente $k$ :

$$
\ln \phi_{k}=\frac{b_{k}}{b}(Z-1)-\ln (Z-B)-\frac{A}{2 \sqrt{2} B}\left(\frac{2}{a} \sum_{m=1}^{n_{c}}\left(z_{m} a_{k m}\right)-\frac{b_{k}}{b}\right) \ln \frac{Z+(1+\sqrt{2}) B}{Z+(1-\sqrt{2}) B}
$$

onde:

$$
a_{k m}=\sqrt{a_{k} a_{m}}\left(1-\lambda_{k m}\right)
$$

\subsection{2}

\section{Equilíbrio de Fases}

A rotina de flash é um método matemático para determinar a fração molar de cada componente em cada uma das fases do sistema dada uma certa pressão e temperatura. No caso deste trabalho, utiliza-se a rotina de flash implementada em [4], a qual calcula as frações molares de cada componente $k$ na fase líquida $x^{k}$ e na fase gás $y^{k}$, bem como a fração molar de líquido $\mathcal{L}$.

Para a formulação do cálculo de flash no equilíbrio termodinâmico entre fases, é adotado a consideração de que as fugacidades de cada componente sejam iguais em cada fase, portanto:

$$
f_{\text {gas }}^{k}\left(T, P, y^{k}\right)=f_{l i q}^{k}\left(T, P, x^{k}\right)
$$


A partir da equação (3-33) e das definições do coeficiente de fugacidade sendo: $\phi_{\text {liq }}^{k}=\frac{f_{g a s}^{k}}{y^{k} P}$ e $\phi_{g a s}^{k}=\frac{f_{g a s}^{k}}{x^{k} P}$, as constantes de equilíbrio de fase podem ser escrita como:

$$
K^{k}=\frac{y^{k}}{x^{k}}=\frac{\phi_{l i q}^{k}}{\phi_{\text {gas }}^{k}}
$$

Nosso problema calcula, assumindo $P$ e $T$ constantes, qual fração molar de líquido $(\mathcal{L})$ do número de mols totais $(N)$ de composição $z$ pertence à fase líquida e qual sua composição $x_{k}$, assim como o contrário, $1-\mathcal{L}$, define a fase gasosa e sua composição $y_{k}$. Sendo assim, é possível escrever $N=N_{l i q}+N_{\text {gas }}$, como sendo:

$$
z^{k}=\frac{x^{k} \sum_{k=1}^{n_{c}} N_{l i q}^{k}+y^{k} \sum_{k=1}^{n_{c}} N_{g a s}^{k}}{\sum_{k=1}^{n_{c}} N^{k}}=\mathcal{L} x^{k}+(1-\mathcal{L}) y^{k}
$$

Visto que para cada componente $k$ pode-se definir uma constante de equilíbrio dada como $K^{k}=\frac{y^{k}}{x^{k}}$, pode-se reescrever (3-35) como:

$$
\begin{aligned}
x^{k} & =\frac{z^{k}}{\mathcal{L}+(1-\mathcal{L}) K^{k}} \\
y^{k} & =\frac{K^{k} z^{k}}{\mathcal{L}+(1-\mathcal{L}) K^{k}}
\end{aligned}
$$

Respeitando as restrições de $\sum^{k}\left(x^{k}\right)=1$ e $\sum^{k}\left(y^{k}\right)=1$, tem-se que $\sum^{k}\left(x^{k}\right)-\sum^{k}\left(y^{k}\right)=0$, e com isso, tem-se em (3-38) a equação de Rachford-Rice. Essa equação tem um papel importante nos cálculos de flash, por determinar a fração molar de líquido e, com isso, as constantes de equilíbrio, $x^{k}$ e $y^{k}$, como podemos ver nas seguintes equações (3-38) e (3-33):

$$
\sum_{k=1}^{n_{c}} \frac{z^{k}\left(1-K^{k}\right)}{\mathcal{L}+(1-\mathcal{L}) K^{k}}=0
$$

Neste trabalho, conforme apresentado em [4], utiliza-se o seguinte método de iterações sucessivas para resolver o cálculo da separação de fases:

1. Estimativa inicial de $K^{k}$ através da fórmula de Wilson, $\ln \left(K^{k}\right)=$ $5,37\left(1+\omega_{k}\right)\left(1-T_{c} k / T\right)+\ln \left(P_{r} k\right)[48]$.

2. Solução da Equação 3-38 pelo Método de Newton-Raphson e atualização de $\mathcal{L}, x^{k}$ e $y^{k}$.

3. Conclusão da execução se o resultado convergiu como $\max _{k=1}^{n_{c}}\left|\frac{f_{g a s}^{k}\left(T, P, y^{k}\right)}{f_{l i q}^{k}\left(T, P, x^{k}\right)}-1\right| \leq \epsilon$ caso contrário, atualização de $K^{k}$ com as Equações 3-31 e 3-34. 


\subsection{3}

\section{Teste de Estabilidade}

Os cálculos de flash não conseguem prever o número de fases de antemão quando se tem os valores de temperatura, pressão e composição. Isso é um problema, pois, dessa forma, o flash é calculado independentemente do sistema ser monofásico ou bifásico. Por isso, a fim de evitar cálculos de flash desnecessários e, portanto, economizar tempo de simulação, Michelsen (1982) [45] propôs um critério para decidir se o sistema monofásico é termodinamicamente estável.

O teste se baseia em que, para um sistema monofásico, uma nova fase é criada somente se há redução da energia de Gibbs do sistema. Pode-se definir para a mistura monofásica, a seguinte equação da energia de Gibbs:

$$
G_{0}=\sum_{k=1}^{n_{c}} N^{k} \mu_{0}^{k}
$$

onde, $\mu_{0}^{k}$ é o potencial químico do componente $k$ da mistura. Utilizando a expansão de série de Taylor proposta por Michelsen e considerando que a nova fase contém um número infinitesimal de mols $(\epsilon)$, a energia de Gibbs em comparação com o sistema antigo, que agora contém duas fases, deve respeitar:

$$
\Delta G=\epsilon \sum_{k=1}^{n_{c}} y^{k}\left(\mu^{k}(y)-\mu_{0}^{k}\right) \leq 0
$$

para qualquer composição $y$ da nova fase.

Caso o sistema já seja bifásico, o teste de estabilidade não é utilizado e o algoritmo evolui diretamente para o cálculo de flash. A relação entre o teste de estabilidade e a rotina de flash é apresentada na Figura 3.1.

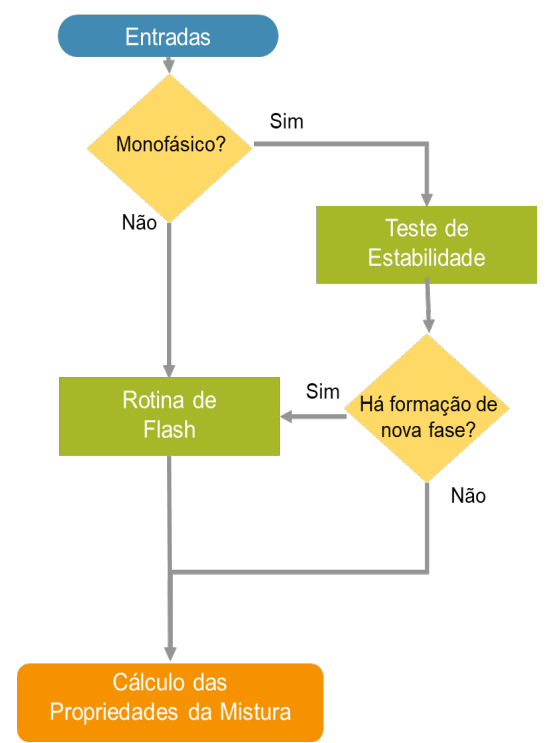

Figura 3.1: Fluxograma de relação entre teste de estabilidade e rotina de flash 


\subsection{4}

\section{Desaparecimento de Fase}

Após um cálculo de flash se a fração molar na fase líquida, $\mathcal{L}$ apresenta valores $\mathcal{L}>1$ ou $\mathcal{L}<0$, há o desaparecimento de uma fase. Nesse caso, $\mathcal{L}$ tem seu valor corrigido para 0 ou 1 .

\section{4}

\section{Cálculo da Viscosidade}

A fim de descrever o comportamento da viscosidade de líquido $\left(\mu_{l i q}\right)$ e de gás $\left(\mu_{\text {gas }}\right)$ em função de temperatura, pressão e composição, a correlação de Lohrenz-Bray-Clark (LBC) [46] foi utilizada.

\section{5}

\section{Cálculo da Tensão Interfacial}

Para calcular a tensão interfacial (IFT) entre gás e condensado para o fluido estudado neste trabalho, usa-se a correlação de Weinaug \& Katz [42]:

$$
I F T=\left[\sum_{k=1}^{n_{c}}\left(\mathcal{P}^{k} x^{k} \frac{\rho_{\text {liq }}}{M_{\text {liq }}}-\mathcal{P}^{k} y^{k} \frac{\rho_{\text {gas }}}{M_{\text {gas }}}\right)\right]^{4}
$$

onde $\mathcal{P}^{k}$ é o valor de parachor do componente $j, M_{l i q}$ e $M_{g a s}$ são as massas molares de condensado e de gás, $\rho_{l i q}$ e $\rho_{\text {gas }}$ são as massas específicas de condensado e de gás.

\section{6}

\section{Condições Iniciais e de Contorno}

Para que o problema de escoamento fique bem determinado, é necessário especificar as condições iniciais e de contorno. Começando pelas condições iniciais, como este trabalho estuda reservatórios de gás retrógrado, a condição inicial de pressão considerada é que a pressão no reservatório é uniforme e acima da pressão de orvalho do fluido. Para estimar a pressão de orvalho em um primeiro momento, faz-se uso da seguinte correlação proposta por Nemeth e Kennedy em 1967 [26]:

$$
\begin{array}{r}
\ln p_{\text {orv }}(\text { psia })=A_{1}\left[z^{C_{2}}+z^{C_{2}}+z^{H_{2} S}+z^{C_{6}}+2\left(z^{C_{3}}+z^{C_{4}}\right)+z^{C_{5}}+0.4 z^{C_{1}}+0.2 z^{N_{2}}\right]+ \\
+A_{2} d_{C_{7+}}+A_{3} \frac{z^{C_{1}}}{\left[z^{C_{7+}}+0.002\right]}+A_{4} T+x^{C_{7+}}\left(A_{5}+A_{6} x^{C_{7+}}+A_{7}\left(x^{C_{7+}}\right)^{2}\right)+ \\
\left.+y^{C_{7+}}\left(A_{8}+A_{9} y^{C_{7+}}+A_{10}\left(y^{C_{7+}}\right)^{2}\right)\right)+A_{11}, \quad \text { (3-42) }
\end{array}
$$


onde $z^{k}$ é a fração molar do componente $k, d$ a densidade em relação à água, $M$ a massa molecular e $T$ a temperatura $\left({ }^{\circ} \mathrm{R}\right)$,

$$
\begin{gathered}
x_{C_{7+}}=z_{C_{7+}} M_{C_{7+}}, \\
y_{C_{7+}}=\frac{M_{C_{7+}}}{d_{C_{7+}}+10^{-4}}
\end{gathered}
$$

e:

$$
\begin{aligned}
& A_{1}=-2,0623054 \\
& A_{2}=6,6259728 \\
& A_{3}=4,4670559 \times 10^{3} \\
& A_{4}=1,0448346 \times 10^{4} \\
& A_{5}=0,032673714 \\
& A_{6}=3,6453277 \times 10^{3} \\
& A_{7}=7,4299951 \times 10^{5} \\
& A_{8}=-0,11381195 \\
& A_{9}=6,2476497 \times 10^{4} \\
& A_{10}=1,0716866 \times 10^{6} \\
& A_{11}=10,746622
\end{aligned}
$$

Antes de tratar, especificamente, das condições de contorno, vale salientar que, neste trabalho, o escoamento no interior do poço não será resolvido, apesar de acoplado ao escoamento no reservatório. Ele tem uma física própria [25], que excede o escopo do presente trabalho. Dessa forma, as condições de contorno consideradas são localizadas geometricamente no poço e no limite do reservatório. O modelo desenvolvido permite executar a simulação com dois tipos de condições diferentes:

- Condições de Neumann - são especificadas a vazão no poço e/ou a vazão no limite do reservatório. Essas condições foram utilizadas para a maioria das simulações deste trabalho;

- Condições Mistas - são especificadas a vazão no poço e a pressão no limite do reservatório. Essas condições foram utilizadas para validar o modelo em comparação com a solução analítica para um reservatório infinito, conforme é apresentado no Capítulo 5. 


\section{7}

\section{Curvas de Permeabilidade Relativa}

Conforme citado no Capítulo 2, com a intenção de comparar os efeitos de diferentes modelos de permeabilidade relativa na modelagem da condensação retrógrada, este trabalho faz uso de curvas de permeabilidade advindas de correlações empíricas e de modelagem em escala de poros. O modelo de correlações empíricas utilizado aqui foi elaborado por Hartman \& Cullick [21] e é utilizado em Shi (2009) [29] para estudar o escoamento de gás retrógrado em meios porosos. A fim de calcular a permeabilidade relativa, o modelo interpola entre curvas de permeabilidade relativa miscíveis e imiscíveis utilizando uma função da tensão interfacial. Utilizando esse modelo, as permeabilidades relativas de condensado $\left(k_{r l i q}\right)$ e de gás $\left(k_{r g a s}\right)$, a uma determinada saturação, são dadas por:

$$
\begin{gathered}
k_{r l i q}=f(\sigma) k_{r c i}+(1-f(\sigma)) k_{r c m} \\
k_{r g a s}=f(\sigma) k_{r g i}+(1-f(\sigma)) k_{r g m} \\
f(\sigma)=\left(\frac{\sigma}{\sigma^{*}}\right)^{\frac{1}{n}}
\end{gathered}
$$

onde $\sigma$ é a tensão interfacial (IFT), $\sigma^{*}$ é uma tensão interfacial de referência, $k_{r c m}$ e $k_{r g m}$ são as permeabilidades relativas de condensado e de gás em condições miscíveis, $k_{r c i}$ e $k_{r g i}$ são as permeabilidade relativas de condensado e de gás em condições imiscíveis, ou seja, com tensões interfaciais maiores ou iguais a $\sigma^{*}$, e $n$ é um expoente ajustável.

Baseado em dados experimentais, [21] elaboraram a seguinte correlação para a saturação residual de condensado com relação ao gás como uma função da tensão interfacial:

$$
S_{\text {crg }}(\sigma)=\left[1+0,67 \log \left(\frac{\sigma}{\sigma^{*}}\right)\right] S_{\text {crgi }},
$$

onde $S_{c r g i}$ é a saturação residual de condensado com relação ao gás em condições imiscíveis.

Prosseguindo, a correção para a saturação crítica de gás é dada por:

$$
S_{g c}(\sigma)=\frac{\sigma}{\sigma^{*}} S_{g c}\left(\sigma^{*}\right)
$$

As permeabilidades relativas em condições miscíveis são normalizadas com relação às correlações de saturação dependente da tensão interfacial da seguinte forma: 


$$
\begin{gathered}
k_{r c m}=\frac{S_{l i q}-S_{c r g}(\sigma)}{1-S_{c r g}(\sigma)} \\
k_{r g m}=\frac{S_{g a s}}{1-S_{g c}(\sigma)}
\end{gathered}
$$

Por outro lado, as permeabilidades relativas em condições imiscíveis são dadas por:

$$
\begin{gathered}
k_{r c i}=\left[\frac{S_{l i q}-S_{c r g}(\sigma)}{1-S_{c r g}(\sigma)}\right]^{2} \\
k_{r g i}=\left[\frac{S_{g a s}}{1-S_{g c}(\sigma)}\right]^{2}
\end{gathered}
$$

Como ilustração, na Figura 3.2 é apresentado graficamente esse modelo de permeabilidade relativa com correlação empírica para as seguintes condições apresentadas em [21]: tensão interfacial (IFT) de $1 \times 10^{-3} \mathrm{~N} / \mathrm{m}, \sigma^{*}=2,2 \times 10^{-3}$ $\mathrm{N} / \mathrm{m}, n=10$ e $S_{\text {crgi }}=0$.

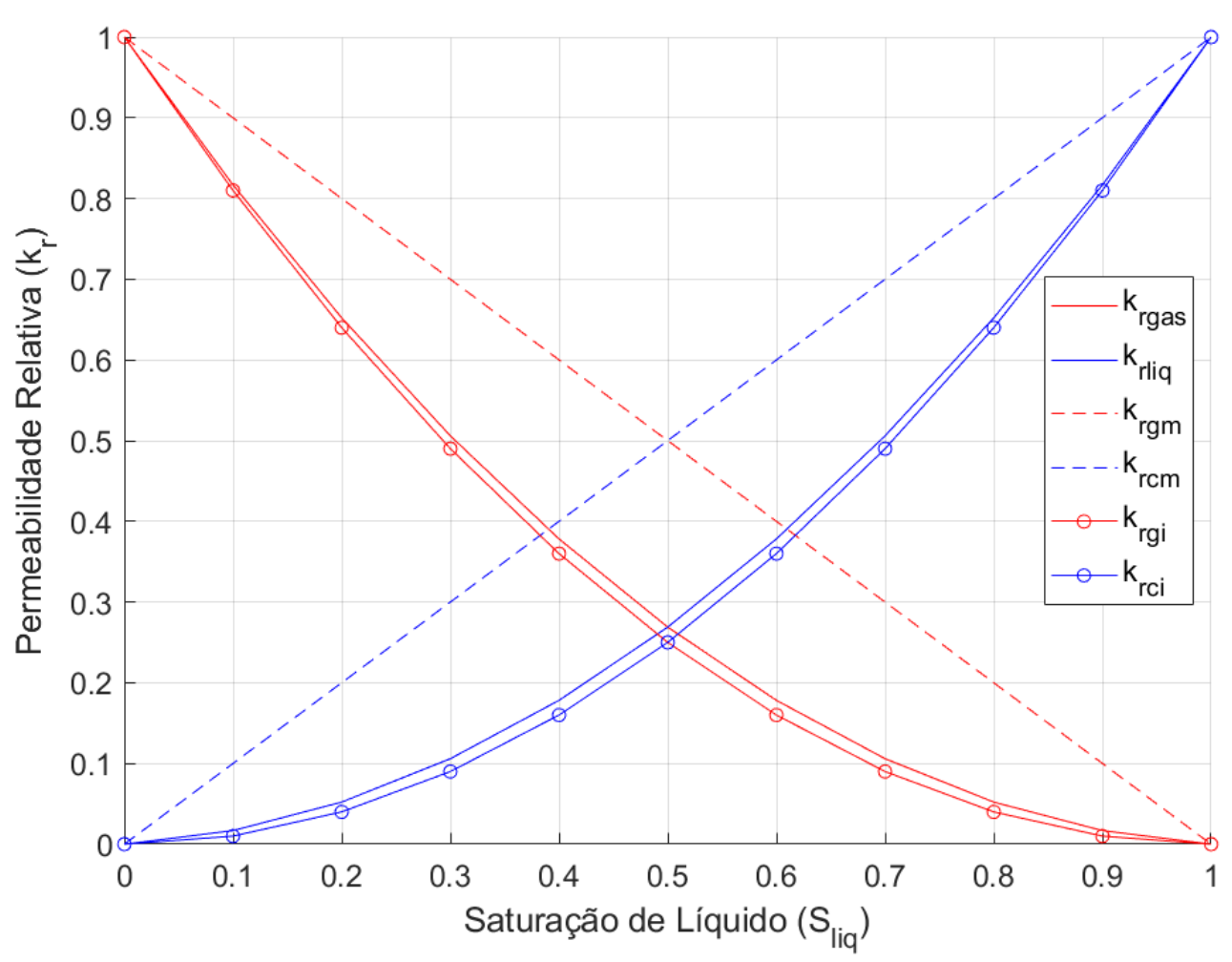

Figura 3.2: Permeabilidade relativa com modelo de correlações empíricas com $\mathrm{IFT}=1 \times 10^{-3} \mathrm{~N} / \mathrm{m}, \sigma^{*}=2,2 \times 10^{-3} \mathrm{~N} / \mathrm{m}$ e $n=10$

A maioria dos modelos de correlação empírica incorporam erros advindos 
de restrições experimentais, visto que eles tendem a não reproduzir fielmente as condições extremas de pressão e temperatura, nem usar composições complexas que ocorrem em reservatórios de gás retrógrado. Essas considerações levam a incertezas significativas nos resultados, e os modelos resultantes nem sempre capturam com precisão as características de fluxo de um reservatório de gás condensado. [27]

A fim de solucionar esse problema, Reis e Carvalho [27] propuseram um modelo de rede de poros 3D composicional para representar o deslocamento de gás e condensado em reservatórios de gás retrógrado desconsiderando a presença de água. A rede proposta possui capilares constritos circulares e, de acordo com a molhabilidade do meio, a saturação e as forças viscosas e capilares, esses capilares apesentam diferentes modos de condensação e padrões de escoamento. A pressão e número de mols são resolvidos através de equações acopladas de balanço molar e consistência dos volumes. De forma similar ao trabalho de Collins [41], é resolvido um cálculo de flash para cada nó, considerando pressão e temperatura constante, e com base na equação de estado de Peng \& Robinson, de forma que as saturações e composições da fase sejam atualizados. Como resultado do trabalho, foram geradas curvas de permeabilidade para gás e condensado para sete velocidades de fluxo de gás $(7,5 \mathrm{~m} / d, 15 \mathrm{~m} / d, 30 \mathrm{~m} / \mathrm{d}, 45 \mathrm{~m} / \mathrm{d}, 60 \mathrm{~m} / \mathrm{d}, 90 \mathrm{~m} / \mathrm{d}$ e $150 \mathrm{~m} / \mathrm{d})$ para uma composição de fluido típica de um reservatório de gás condensado.

Essas curvas estão apresentadas na Figura 3.3. A partir delas, foi ajustado um modelo quadrático na saturação e linear na velocidade de gás para representar essas curvas. Dessa forma, a estrutura algébrica dessas curvas, é dada por:

$$
\begin{aligned}
& k_{r l i q}=a_{1}^{l}+a_{2}^{l} v_{\text {gas }}+a_{3}^{l} S_{l i q}+a_{4}^{l} v_{\text {gas }} S_{l i q}+a_{5}^{l} S_{\text {liq }}^{2}, \\
& k_{\text {rgas }}=a_{1}^{g}+a_{2}^{g} v_{\text {gas }}+a_{3}^{g} S_{\text {liq }}+a_{4}^{g} v_{\text {gas }} S_{\text {liq }}+a_{5}^{g} S_{\text {liq }}^{2},
\end{aligned}
$$

onde $a_{i}^{l}$ e $a_{i}^{g}$ são coeficientes do ajuste realizado.

Além desse equacionamento, o modelo de ajuste teve que ser limitado para continuar representando a física a que se propõe. Como não faz sentido, na maioria das vezes, que a permeabilidade relativa seja maior que a observada no caso miscível, pode-se reformular o equacionamento apresentado nas Equações 3-54 e 3-55 da seguinte forma: 


$$
\begin{aligned}
k_{\text {rliq }} & =\min \left(a_{1}^{l}+a_{2}^{l} v_{\text {gas }}+a_{3}^{l} S_{\text {liq }}+a_{4}^{l} v_{\text {gas }} S_{\text {liq }}+a_{5}^{l} S_{\text {liq }}^{2}, S_{\text {liq }}\right) \\
k_{\text {rgas }} & =\min \left(a_{1}^{g}+a_{2}^{g} v_{\text {gas }}+a_{3}^{g} S_{\text {liq }}+a_{4}^{g} v_{\text {gas }} S_{\text {liq }}+a_{5}^{g} S_{\text {liq }}^{2}, S_{\text {gas }}\right)
\end{aligned}
$$

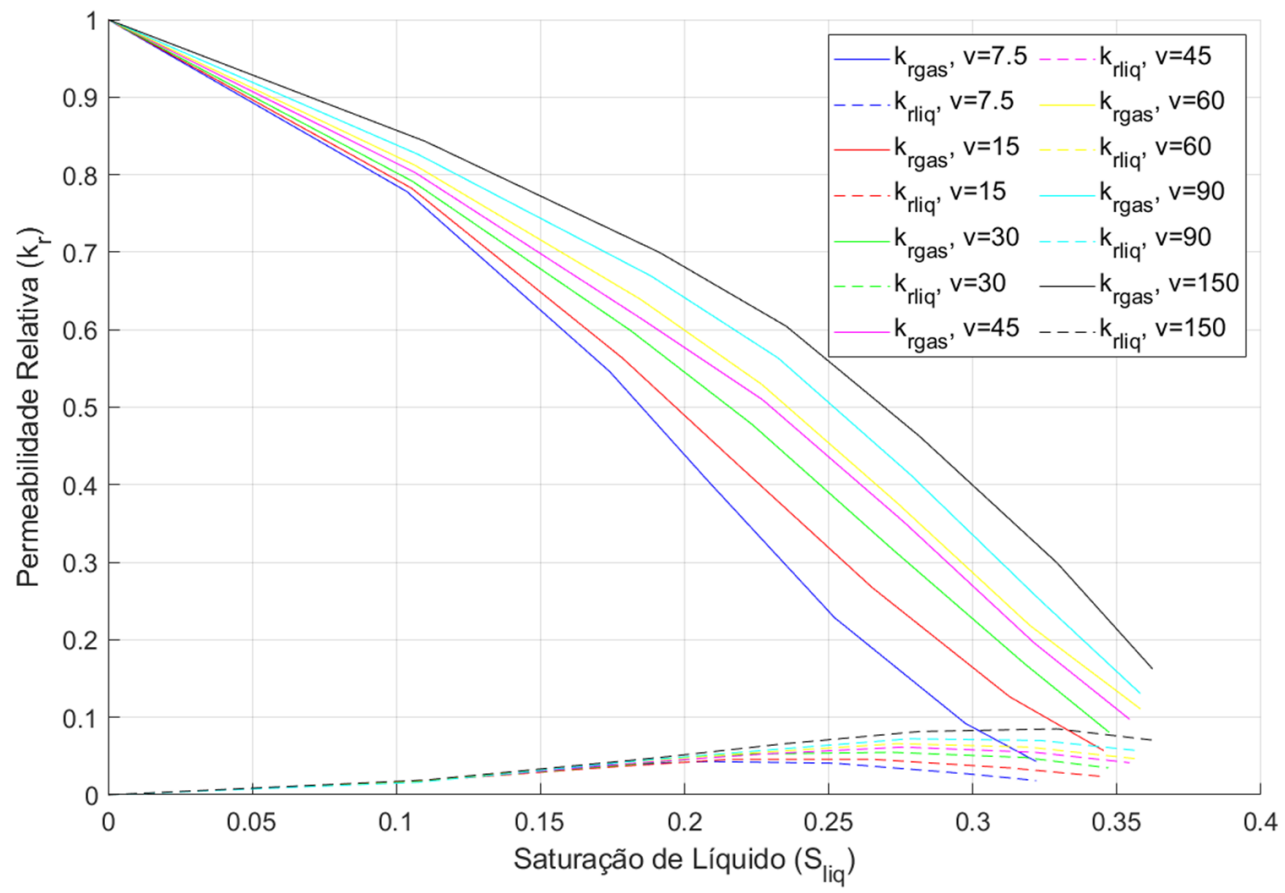

Figura 3.3: Curvas de permeabilidade relativa por velocidade de escoamento do gás calculadas pelo modelo em escala de poros em [28] 


\section{4}

\section{Solução Numérica}

Neste capítulo serão apresentados os métodos utilizados na solução numérica do sistema de equações diferenciais apresentado no capítulo anterior. De modo sucinto, o método de diferenças finitas é utilizado na discretização das equações diferenciais. A cada passo de tempo, um sistema algébrico não linear é obtido. O sistema é resolvido pelo método de Newton-Raphson. Caso o método esteja divergindo, a atualização é feita utilizando um fator de subrelaxação para reduzir as variações e facilitar a convergência [32]. As seções seguintes apresentam em maiores detalhes esses cálculos.

\section{1}

\section{Descrição da Malha}

Para representar o reservatório axissimétrico em coordenadas cilíndricas com uma dimensão, utiliza-se uma malha não uniforme com volumes de controle em forma de coroas cilíndricas, de forma a ter uma concentração maior desses volumes de controle nas proximidades do poço, como ilustrado na Figura 4.1, pois o gradiente de pressão é mais alto nesta região.

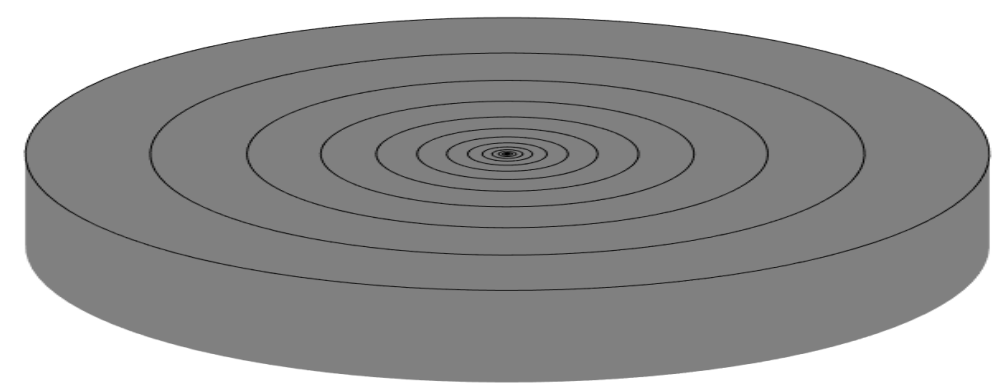

Figura 4.1: Exemplificação da malha cilíndrica para representação do meio poroso em escala de reservatório, onde o ponto central representa o poço e a borda é o final da rocha reservatório.

Neste trabalho, cada volume de controle $i$ da malha, representado, em vista de topo, como as coroas circulares vermelhas na Figura 4.2, tem as seguintes propriedades geométricas: 
- $V_{i}$ : Volume da coroa cilíndrica delimitada pelas linhas vermelhas na 4.2;

- $r_{i}$ : Raio do ponto central representado pelas linhas azuis na 4.2.

- $r_{f c, i}, r_{f c, i+1}$ : Raios das faces interna e externa do volume de controle.

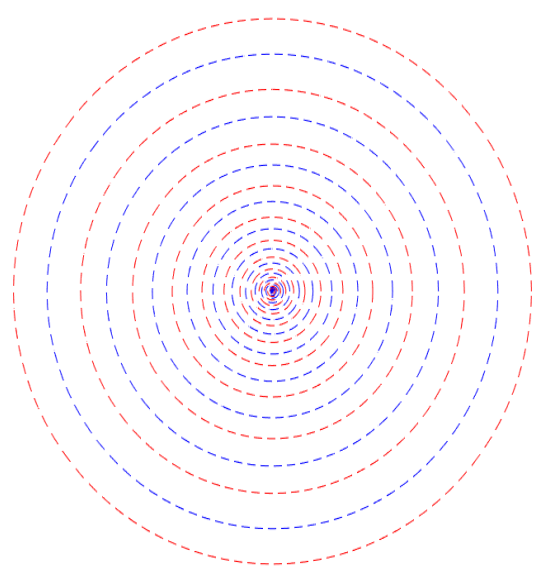

Figura 4.2: Exemplificação dos pontos da malha em coordenadas cilíndricas a fim de representar a divisão dos volumes de controle (pontilhado vermelho) e seus pontos centrais (pontilhado azul).

Dadas essas propriedades e considerando $N_{\text {cells }}$ como a quantidade total de volumes de controle, $d r_{\min }$ e $d r_{\max }$ como as maiores e menores larguras das coroas cilíndricas, $r_{w}$ como o raio do poço e $n$ como o valor do expoente da lei de potência, pode-se especificar as equações utilizadas para descrever a malha cilíndrica apresentada:

$$
\begin{gathered}
r_{f c, i}=r_{w}+\sum_{m=0}^{i-1}\left(C m^{n}+D\right) \\
r_{i}=\frac{r_{f c, i}+r_{f c, i+1}}{2}
\end{gathered}
$$

onde:

$$
\begin{gathered}
C=\frac{d r_{\max }-d r_{\min }}{N^{n}-1} \\
D=d r_{\min }-C
\end{gathered}
$$




\section{2}

\section{Discretização das Equações}

Nesta seção, é feita a discretização das equações de balanço molar e de consistência de volumes. Para isso, considere a representação simplificada de uma malha em coordenadas cilíndricas apresentada na Figura 4.3. A partir daqui, os índices $(f c, i)$ e $(f c, i+1)$ são usados para representar as propriedades na face $i$ e $i+1$ respectivamente.

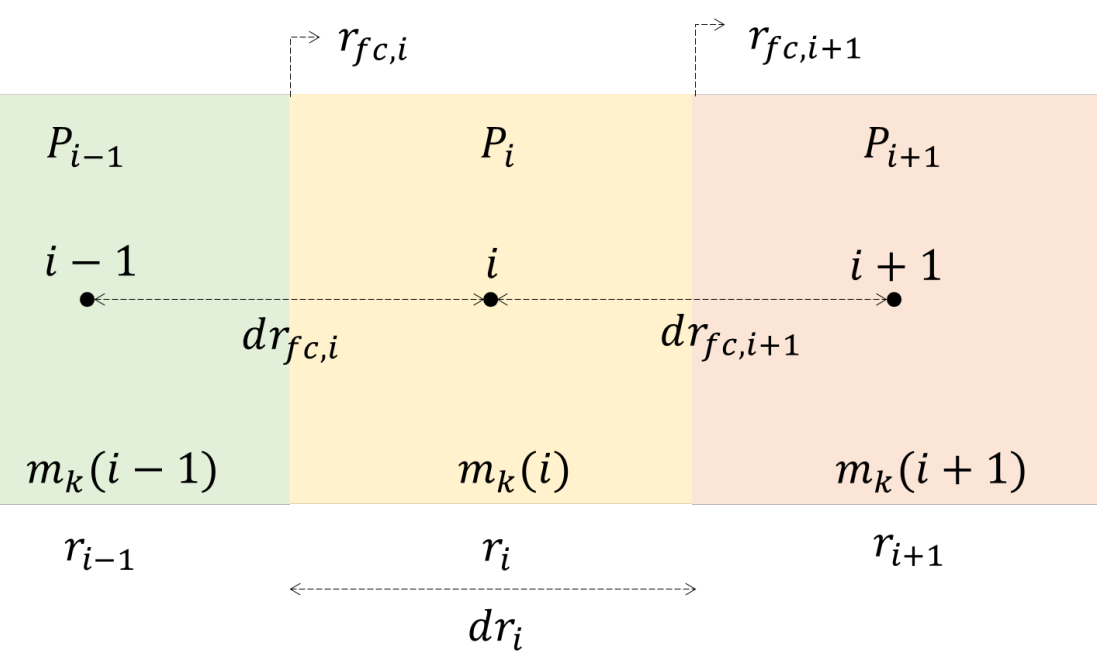

Figura 4.3: Representação esquemática da malha

\subsection{1}

\section{Equações de Conservação}

Partindo da Equação 3-10 e considerando uma formulação implícita com diferenças finitas para a pressão e número de mols, tem-se que:

$\frac{N_{i}^{k, t}-N_{i}^{k, t-1}}{d t}-\frac{V_{\text {poroso }, i}}{\phi} \frac{1}{r_{i} d r_{i}}\left[r_{f c, i+1}\left(m_{k}^{\tau}\right)_{f c, i+1}\left(\frac{P_{i+1}^{t}-P_{i}^{t}}{d r_{f c, i+1}}\right)-r_{f c, i}\left(m_{k}^{\tau}\right)_{f c, i}\left(\frac{P_{i}^{t}-P_{i-1}^{t}}{d r_{f c, i}}\right)\right]=0$

onde $\tau$ é a iteração anterior do método de Newton-Raphson.

Agora, é preciso reescrever algumas dessas grandezas em função de parâmetros mais elementares. Começando com $V_{i}$, o volume do volume de controle, vê-se pela Figura 4.1 que ele é igual ao volume da coroa cilíndrica delimitada por $r_{f c, i}$ e $r_{f c, i+1}$. Assim, tem-se que:

$$
V_{\text {poroso }, i}=\phi \pi h\left(r_{f c, i+1}^{2}-r_{f c, i}^{2}\right)
$$

sendo o raio $r_{i}$ e a espessura do volume de controle $d r_{i}$ iguais a: 


$$
\begin{aligned}
r_{i} & =\frac{r_{f c, i}+r_{f c, i+1}}{2} \\
d r_{i} & =r_{f c, i+1}-r_{f c, i}
\end{aligned}
$$

Substituindo as Equações 4-6 a 4-8 na Equação 4-5, é possível chegar a seguinte equação:

$\frac{N_{i}^{k, t}-N_{i}^{k, t-1}}{d t}-\frac{2 \pi h}{\phi}\left[r_{f c, i+1}\left(m_{k}^{\tau}\right)_{f c, i+1}\left(\frac{P_{i+1}^{t}-P_{i}^{t}}{d r_{f c, i+1}}\right)-r_{f c, i}\left(m_{k}^{\tau}\right)_{f c, i}\left(\frac{P_{i}^{t}-P_{i-1}^{t}}{d r_{f c, i}}\right)\right]=0$

A Equação 4-9 pode ser representada simplificadamente da seguinte forma:

$$
N_{i}^{k, t}-N_{i}^{k, t-1}-\Delta t\left[\left(T_{f}^{\tau}\right)_{f c, i+1}-\left(T_{f}^{\tau}\right)_{f c, i}\right]=0
$$

onde $\left(T_{f}^{\tau}\right)_{f c, i}$ e $\left(T_{f}^{\tau}\right)_{f c, i+1}$ são as vazões molares pelas faces $i$ e $i+1$ do volume de controle no tempo $t$, respectivamente.

Para calcular essas vazões molares através das faces, primeiramente, devese avaliar os termos de mobilidade nas faces. Por questões de continuidade do escoamento, a melhor forma de representar a mobilidade nas interfaces é através da média harmônica das mobilidades nos volumes adjacentes [32]. Assim, tem-se que:

$$
\begin{aligned}
\left(m_{k}^{\tau}\right)_{f c, i} & =\frac{2 m_{k}^{\tau}(i) m_{k}^{\tau}(i-1)}{m_{k}^{\tau}(i)+m_{k}^{\tau}(i-1)} \\
\left(m_{k}^{\tau}\right)_{f c, i+1} & =\frac{2 m_{k}^{\tau}(i) m_{k}^{\tau}(i+1)}{m_{k}^{\tau}(i)+m_{k}^{\tau}(i+1)}
\end{aligned}
$$

sendo $m_{k}$ a mobilidade do componente $k$.

Como já citado, este trabalho utiliza condições de contorno de Neumann (vazão de gás $Q_{\text {well }}$ especificada no poço e reservatório isolado $Q_{\text {res }}=0$ ) e mistas (vazão de gás $Q_{\text {well }}$ especificada no poço e pressão $P_{\text {res }}$ especificada no reservatório). Assim, é necessário adaptar as Equações 4-10 e 4-11 para o primeiro e para o último volume de controle. Por não haver um volume de controle a oeste do primeiro volume de controle, a Equação 4-11 se reduz a:

$$
\left(m_{k}^{\tau}\right)_{f c, 1}=m_{k}^{\tau}(1)
$$

Além disso, aplicando a Lei de Darcy na face oeste do primeiro volume de controle, tem-se que o diferencial de pressão na face oeste é dado por:

$$
\left(\frac{\partial P^{t}}{\partial r}\right)_{f c, 1}=\frac{Q_{\text {well }}}{k\left[2 \pi r_{1} h\right]} \frac{\mu_{\text {gas }}}{k_{\text {rgas }}}
$$


Por outro lado, por não haver um volume de controle a leste do último volume de controle, a Equação 4-11 se reduz a:

$$
\left(m_{k}^{\tau}\right)_{f c, N_{\text {cells }}+1}=m_{k}^{\tau}\left(N_{\text {cells }}\right)
$$

Agora, resta analisar as modificações para os dois tipos de condição contorno no limite do reservatório. Quando a pressão no reservatório $P_{\text {res }}$ é especificada, o diferencial de pressão na face leste é dado por:

$$
\left(\frac{\partial P^{t}}{\partial r}\right)_{f c, N_{\text {cells }}+1}=\frac{P_{r e s}-P_{N_{c e l l s}}^{t}}{d r_{N_{\text {cells }}}}
$$

Por fim, quando o reservatório é isolado, o diferencial de pressão na face leste se reduz a:

$$
\left(\frac{\partial P^{t}}{\partial r}\right)_{f c, N_{\text {cells }}+1}=0
$$

No modelo deste trabalho, as equações de conservação para cada componente, cada volume de controle e cada instante de tempo são representadas pelo resíduo $R_{N}^{t}$, dado por:

$$
R_{N}^{t}=\left(\begin{array}{c}
N_{1}^{1, t}-N_{1}^{1, t-1}-\Delta t\left[\left(T_{f}^{\tau}\right)_{f c, 2}-\left(T_{f}^{\tau}\right)_{f c, 1}\right] \\
\vdots \\
N_{N_{\text {cells }}}^{n_{c}, t}-N_{N_{\text {cells }}}^{n_{c}, t-1}-\Delta t\left[\left(T_{f}^{\tau}\right)_{f c, N_{\text {cells }}+1}-\left(T_{f}^{\tau}\right)_{f c, N_{\text {cells }}}\right]
\end{array}\right)
$$

\subsection{2}

\section{Equações de Volume}

No modelo deste trabalho, as equações de consistência de volume para da volume de controle são representadas pelo resíduo $R_{V}^{t}$, obtido a partir da Equação 3-15 e dado por:

$$
R_{V}^{t}=\left(\begin{array}{c}
V_{1} \phi-\frac{N_{l i q, 1}^{t}}{\xi_{\text {liq }, 1}^{\tau}}-\frac{N_{g a s, 1}^{t}}{\xi_{g a s, 1}^{\tau}} \\
\vdots \\
V_{N_{\text {cells }} \phi} \phi-\frac{N_{\text {liq }, N_{\text {cells }}}^{t}}{\xi_{\text {liq }, N_{\text {cells }}}^{\tau}}-\frac{N_{\text {gas }, N_{\text {cells }}}^{t}}{\xi_{\text {gas }, N_{\text {cells }}}^{\tau}}
\end{array}\right)
$$

\section{3}

\section{Método de Solução}

Esta seção especifica com detalhes o procedimento utilizado na simulação. Na Figura 4.4, é apresentado o fluxograma descritivo da simulação.

A partir das entradas, calcula-se a rotina de flash para determinar as características iniciais da mistura, como as frações molares de cada componente em cada fase, e calcula-se a viscosidade de cada fase do fluido através do método 
LBC. Determinado como está o equilíbrio de fases, a simulação entra no loop principal, em que calcula as variáveis para cada passo de tempo até que o tempo de simulação exceda o tempo máximo especificado.

O cálculo das variáveis dentro do loop de tempo é feito através do método de Newton-Raphson. Nele, calcula-se o resíduo $R=\left[R_{N} ; R_{V}\right]$ conforme as Equações 4-18 e 4-19 e o Jacobiano conforme especificado na seção seguinte. De posse do Jacobiano e do resíduo, é possível calcular o passo do método de Newton-Raphson como $\Delta u=-J^{-1} R$. Entretanto, a atualização das variáveis depende de como está a convergência do método. Caso o método esteja divergindo, a atualização é feita utilizando um fator de sub-relaxação para desacelerar as variações e facilitar a convergência [32].

Em seguida, como o modelo de permeabilidade relativa em escala de poros é dependente da velocidade de gás, é preciso atualizar a velocidade do gás caso seja ele que está sendo simulado. Caso contrário, é preciso atualizar a tensão interfacial, porque o modelo de correlações empíricas é dependente da IFT.

Atualizadas as variáveis, caso o número de iterações seja menor que o máximo de iterações itmax, segue-se para uma execução da rotina de teste de estabilidade e flash, seguida da comparação do resíduo encontrado com a tolerância.

Por outro lado, caso o número de iterações exceda o máximo de iterações itmax, reduz-se o passo de tempo para garantir a convergência e se restauram as variáveis para seu estado anterior, reiniciando o loop do método de NewtonRaphson.

Por fim, após a convergência do método de Newton-Raphson, é necessário avaliar o balanço de massa. Caso haja erro no balanço de massa, o algoritmo reduz o passo de tempo e segue como já citado. Caso contrário, atualiza-se o tempo de simulação e verifica-se se o número de iterações utilizado para convergir é menor que itdobra. No caso positivo, para acelerar a simulação, dobra-se o passo de tempo, antes de fazer a verificação de término da simulação no loop principal.

\section{4}

\section{Cálculo do Jacobiano}

Por se tratar de solução de sistema não-linear utilizando o método de Newton-Raphson, é necessário calcular a matriz Jacobiana, que é a matriz das derivadas parciais das funções do sistema em relação às variáveis $J_{i j}=\frac{\partial f_{i}}{\partial x_{j}}$ e, para calculá-lo de maneira mais eficiente, este trabalho encontra analiticamente as derivadas com relação às variáveis $P_{i}$ e $N_{i}$. 
As derivadas analíticas com relação a pressão $\left(P_{i}\right)$ são apresentadas no Apêndice A. Pode-se adotar procedimento semelhante para o cálculo das derivadas em relação ao número de mols de cada componente $\left(N_{i}^{k}\right)$, sendo, por isso, suprimido deste trabalho.

Por outro lado, as derivadas e $x_{i}^{k}, y_{i}^{k}$ e $\mathcal{L}_{i}$ com relação às variáveis $\left(P_{i}\right.$ e $\left.N_{i}^{k}\right)$, foram obtidos conforme procedimento apresentado em Wong \& Aziz [47]. As demais derivadas parciais são calculadas utilizando as expressões apresentadas em [4] e [43], [44]. 


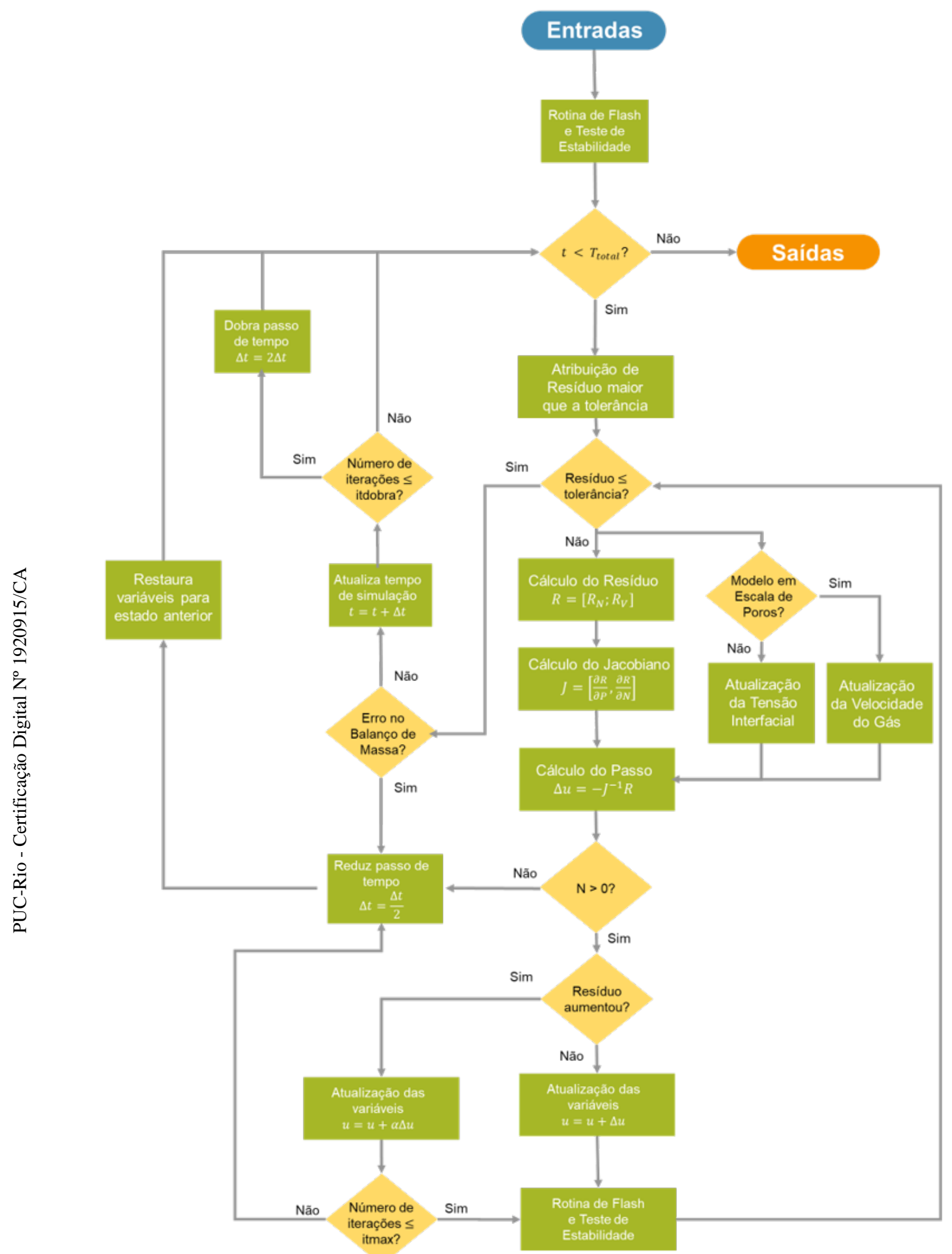

Figura 4.4: Fluxograma da simulação 


\section{Resultados}

\section{1}

\section{Validação do Modelo com caso Monofásico}

Para validar a implementação do modelo, compara-se a solução numérica obtida com pressão acima da pressão de orvalho, o que leva ao escoamento monofásico de gás, com a solução exata analítica para o caso de escoamento monofásico 1-D de gás real em reservatório radial com vazão constante e reservatório isolado. Para esse caso, a solução analítica é dada por:

$m(P)=m\left(P_{\text {ini }}\right)-\frac{1}{2 \pi k h} \frac{2 Q_{0} P_{0} T}{T_{0}}\left[\frac{2 k t}{\phi\left(\mu c_{g}\right)_{\text {ini }} r_{\max }^{2}}+\frac{1}{2}\left(\frac{r_{i}}{r_{\max }}\right)^{2}+\ln \left(\frac{r_{\text {max }}}{r_{i}}\right)-\frac{3}{4}\right]$

onde $P_{0}$ e $T_{0}$, são respectivamente, a pressão e a temperatura em condições standard $\left(101.325 \mathrm{~Pa}\right.$ e $\left.15^{\circ} \mathrm{C}\right), Q_{0}$ é a vazão de gás em condições standard, $\mu_{i n i}$ e $c_{g, i}$ são a viscosidade e a compressibilidade do gás nas condições iniciais do reservatório e $m(P)$ é a pseudopressão do gás real.

Para comparar com a solução analítica, a simulação foi executada com um reservatório com $r_{\max }=844 \mathrm{~m}$ e com os diversos parâmetros necessários calculados numericamente a partir dos dados obtidos com a equação de estado. Nas Figuras 5.1 e 5.2 são apresentados gráficos da pressão calculada de forma analítica e numérica ao longo do reservatório para quatro diferentes tempos de simulação. Em todas elas, é possível observar que a diferença entre as soluções não é significativa com relação ao valor da variável, não ultrapassando $0,21 \%$, o que indica que o modelo numérico desenvolvido está adequado. 

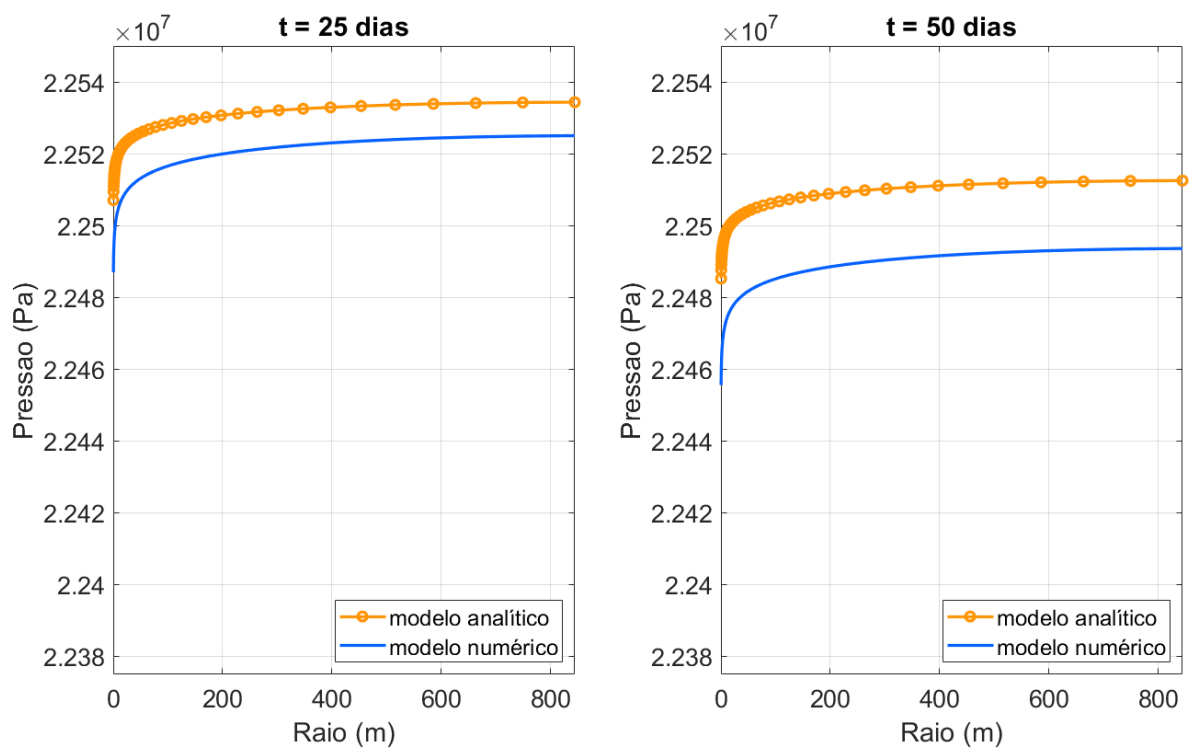

Figura 5.1: Comparação da Pressão ao Redor do Poço calculada com a solução analítica para gás real e com a solução numérica do modelo desenvolvido neste trabalho (para tempos de simulação de 25 e 50 dias)
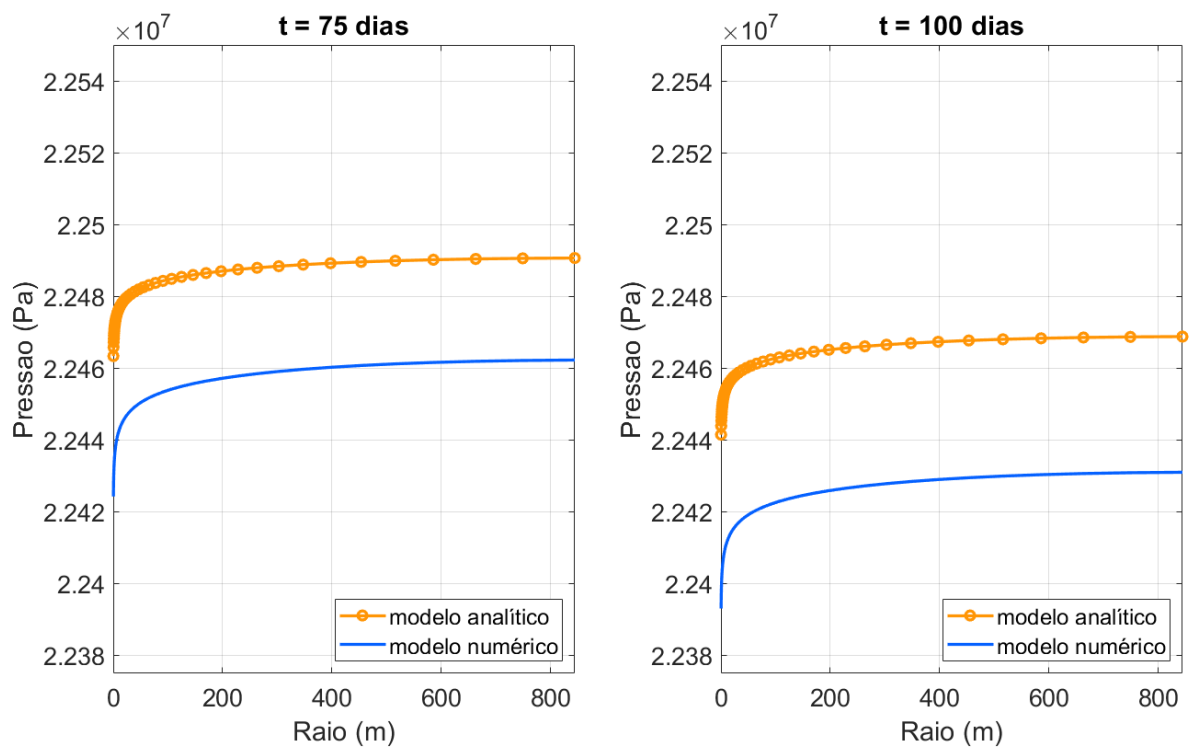

Figura 5.2: Comparação da Pressão ao Redor do Poço calculada com a solução analítica para gás real e com a solução numérica do modelo desenvolvido neste trabalho (para tempos de simulação de 75 e 100 dias) 


\section{2}

\section{Curvas de Permeabilidade}

Como já citado na seção 3.7 , as curvas de permeabilidade relativa calculadas através do modelo de rede para diferentes velocidades são utilizadas para o ajuste do modelo apresentado nas Equações (3-54) e (3-55). Nas Figuras 5.3 a 5.6, são apresentados gráficos das curvas de permeabilidade relativa originais e as calculadas pelo modelo de ajuste. De uma forma geral, é possível ver pelos gráficos que se tem um bom ajuste. $\mathrm{O}$ modelo ajustado tem os seguintes parâmetros $a_{1}^{l}=2,7163 \times 10^{-4}, a_{2}^{l}=-7,6266 \times 10^{-5}, a_{3}^{l}=0,3053$, $a_{4}^{l}=0,0012, a_{5}^{l}=-0,6207, a_{1}^{g}=0,9898, a_{2}^{g}=2,373 \times 10^{-4}, a_{3}^{g}=-1,91813$, $a_{4}^{g}=0,0052$ e $a_{5}^{g}=-2,8259$.
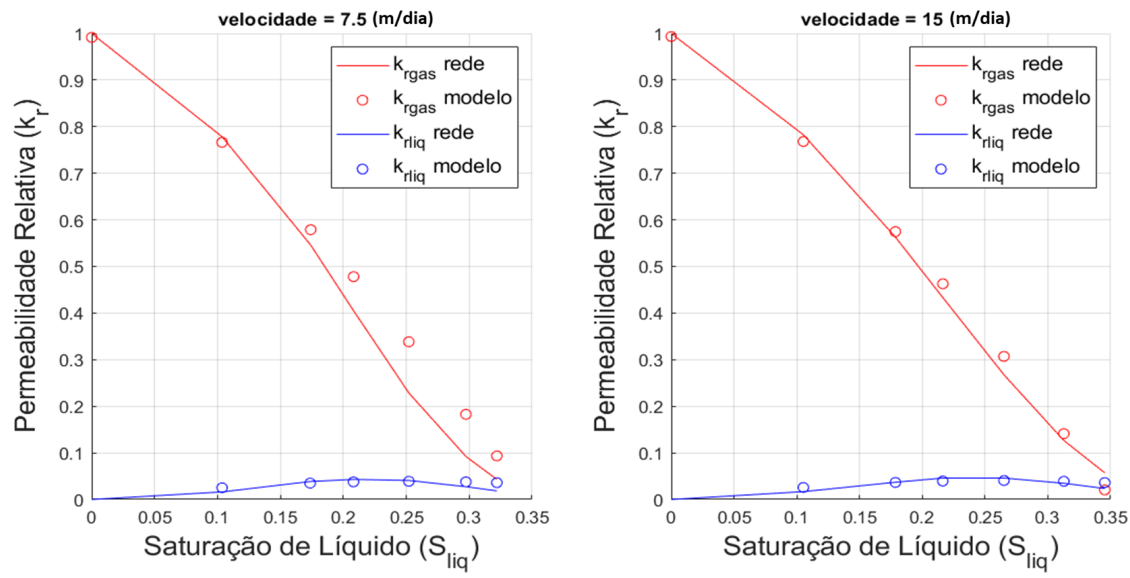

Figura 5.3: Comparação de curva de permeabilidade com modelo em escala de poros com modelo ajustado para as velocidades de $7,5 \mathrm{~m} / \mathrm{d}$ e $15 \mathrm{~m} / \mathrm{d}$
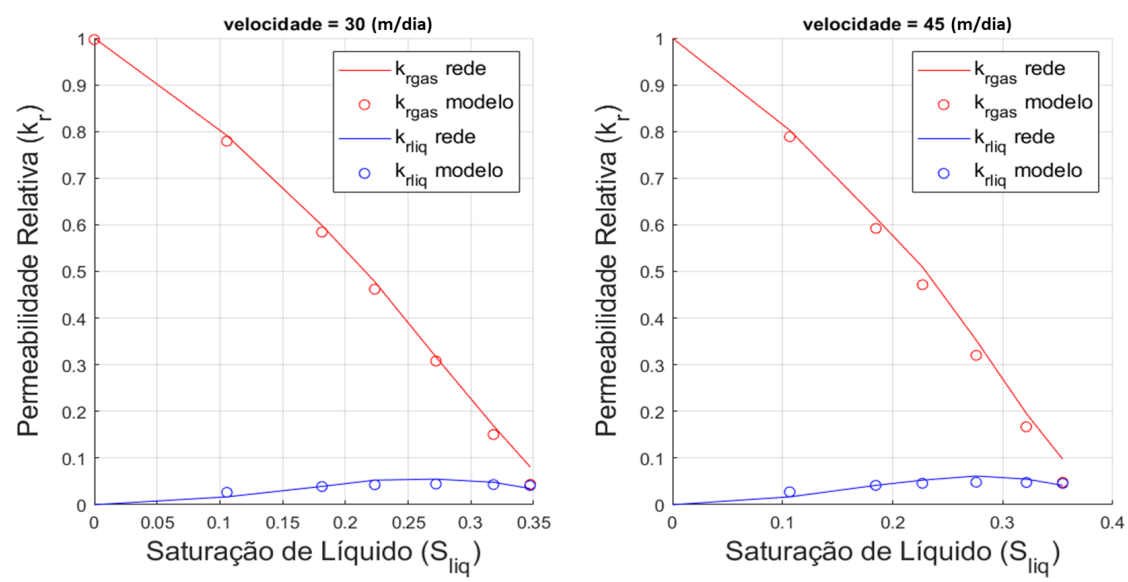

Figura 5.4: Comparação de curva de permeabilidade com modelo em escala de poros com modelo ajustado para as velocidades de $30 \mathrm{~m} / \mathrm{d}$ e $45 \mathrm{~m} / \mathrm{d}$ 

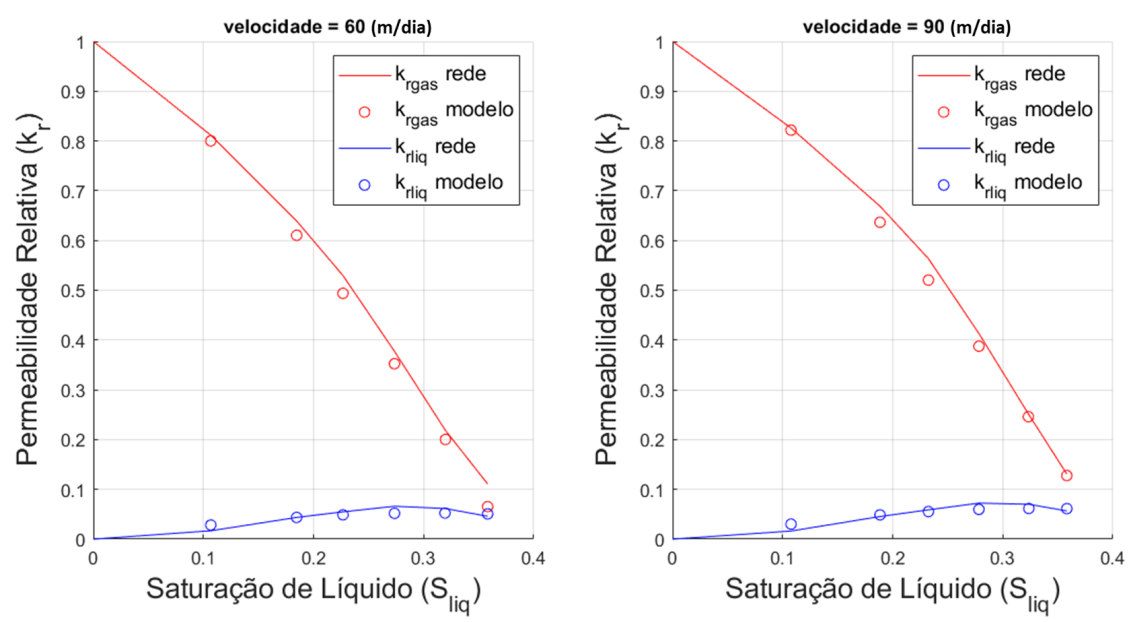

Figura 5.5: Comparação de curva de permeabilidade com modelo em escala de poros com modelo ajustado para as velocidades de $60 \mathrm{~m} / \mathrm{d}$ e $90 \mathrm{~m} / \mathrm{d}$

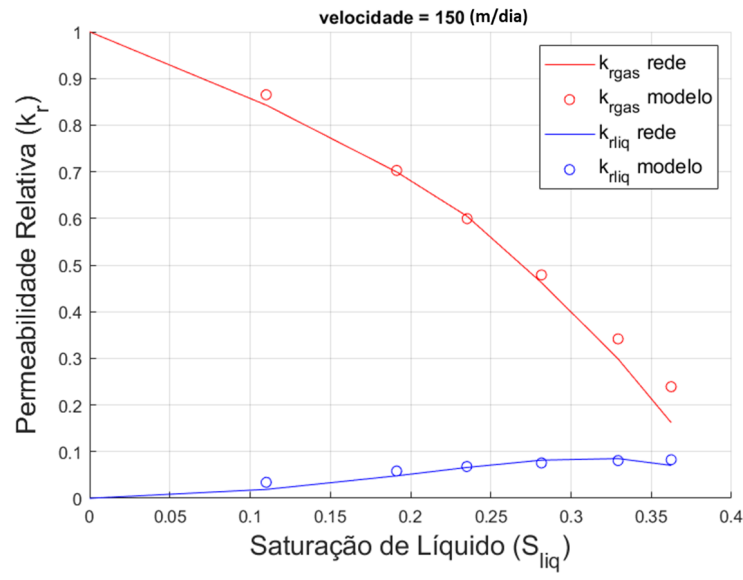

Figura 5.6: Comparação de curva de permeabilidade com modelo em escala de poros com modelo ajustado para a velocidade de $150 \mathrm{~m} / \mathrm{d}$

\section{3}

\section{Análise do bloqueio da produção de gás devido à formação de banco de condensado}

Nessa seção, o modelo proposto foi empregado na análise da perda de produtividade de um poço em decorrência da formação e acúmulo de condensado em seu entorno. Durante os testes realizados, os efeitos da permeabilidade absoluta do meio, vazão de produção de gás e modelo da permeabilidade relativa na severidade do bloqueio por condensado foram avaliados.

Para a avaliação da influência da permeabilidade da rocha reservatório sobre a formação e acúmulo de condensado, foram efetuados testes utilizando- 
se $k=5 m D$ e $k=169 m D$. A permeabilidade de $169 m D$ vem de [31] e foi a mesma utilizada para calcular as curvas de permeabilidade relativa do modelo em escala de poros. Já a permeabilidade de $5 \mathrm{mD}$ foi escolhida para testar a influência da permeabilidade absoluta no comportamento do escoamento. Essa análise se mostra relevante, dado que a permeabilidade do meio poroso é apontada na literatura como um parâmetro determinante na redução do fluxo de gás durante a produção abaixo do ponto de orvalho. Em [49] e [50], ambos autores comprovam a afirmação anterior através de diferentes métodos de predição da produção de gás condensado.

Já para a avaliação dos efeitos da vazão de produção de gás, foram testados valores diferentes de velocidade, $100 \mathrm{~m} / \mathrm{d}$ e $200 \mathrm{~m} / \mathrm{d}$ na entrada do poço, o que equivale, respectivamente, às vazões volumétricas de $67,15 \mathrm{~m}^{3} / \mathrm{d}$ e 134,30 m³ d em condições de reservatório. Ao se aumentar a vazão de produção em reservatórios de gás e condensado, efeitos contrastantes no fluxo de fases podem ser observados. Por um lado, é sabido que velocidades altas afetam positivamente o fluxo de gás e condensado [51]. Por outro, maiores vazões de escoamento implicam maiores gradientes de pressão ao redor do poço, o que leva a valores mais altos de tensão interfacial e a bancos de condensado mais extensos. Durante a análise conduzida nesse trabalho, portanto, será analisado se impacto combinado destes dois fatores produz resultados positivos ou negativos na produção.

Por fim, todos os testes conduzidos nessa seção serão repetidos adotandose dois modelos de permeabilidade relativa. O primeiro, proposto por Hartman \& Cullick [21], leva em consideração o efeito da tensão interfacial e saturação no escoamento acoplado de gás e condensado, enquanto o segundo, formulado a partir de resultados obtidos com o modelo de rede de poros [28], determina valores de permeabilidade relativa de gás e condensado levando em consideração a velocidade de escoamento de gás, saturação e, indiretamente, IFT.

Como parâmetros comuns a todas as simulações, tem-se que a rocha reservatório apresenta porosidade de $(\phi)$ 17,1\% [31], raio do reservatório de $177 \mathrm{~m}$, espessura do reservatório de $5 \mathrm{~m}$, o raio do poço produtor de $0,25 \mathrm{~m}$ e temperatura de $80{ }^{\circ} \mathrm{C}$.

Adicionalmente, o fluido empregado em todos os casos apresenta a composição e as propriedades mostradas nas Tabelas 5.1, 5.2 e 5.3. A composição apresentada na Tabela 5.1 foi escolhida por representar uma mistura típica de reservatórios de gás condensado, compostos por dióxido de carbono e hidrocarbonetos leves, intermediários e pesados. Essa mistura exibe comportamento de gás condensado retrógrado entre as temperaturas de $15^{\circ} \mathrm{C}$ e $207^{\circ} \mathrm{C}$, conforme pode ser visto no diagrama de fases apresentado na Figura 5.7, obtido através 
do software WINPROP [17].

Tabela 5.1: Composição do Fluido. [17]

\begin{tabular}{ll} 
Componente & Fração Molar \\
\hline$C O_{2}$ & 0,07 \\
$C 1$ & 0,65 \\
$C 2$ & 0,13 \\
$C 3$ & 0,07 \\
$C 6$ & 0,05 \\
$C 10$ & 0,025 \\
$C 16+$ & 0,005 \\
\hline
\end{tabular}

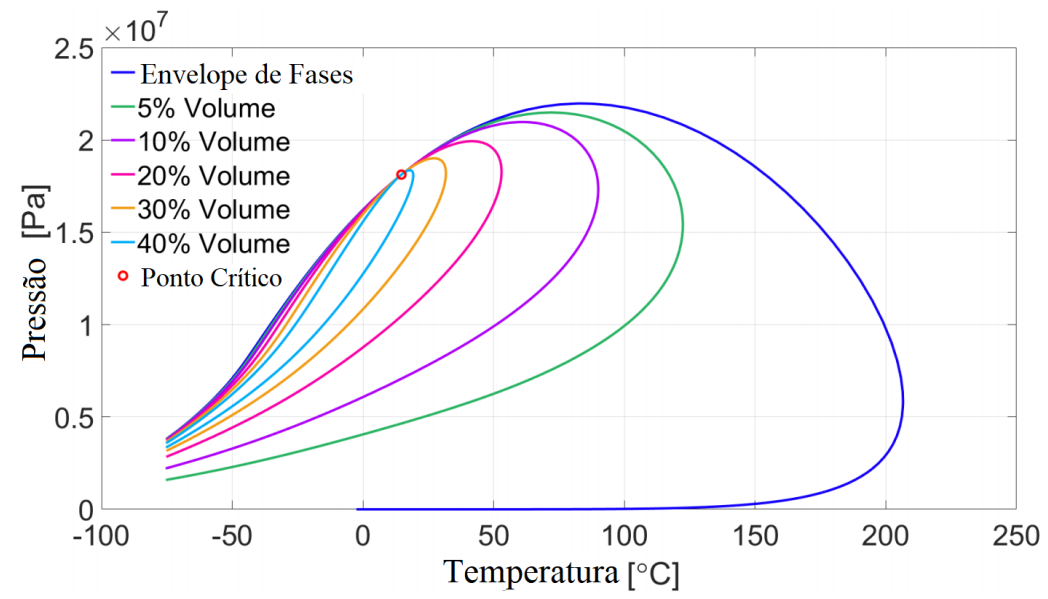

Figura 5.7: Gráfico do Envelope de Fases da mistura apresentada na Tabela 5.1. $[17]$

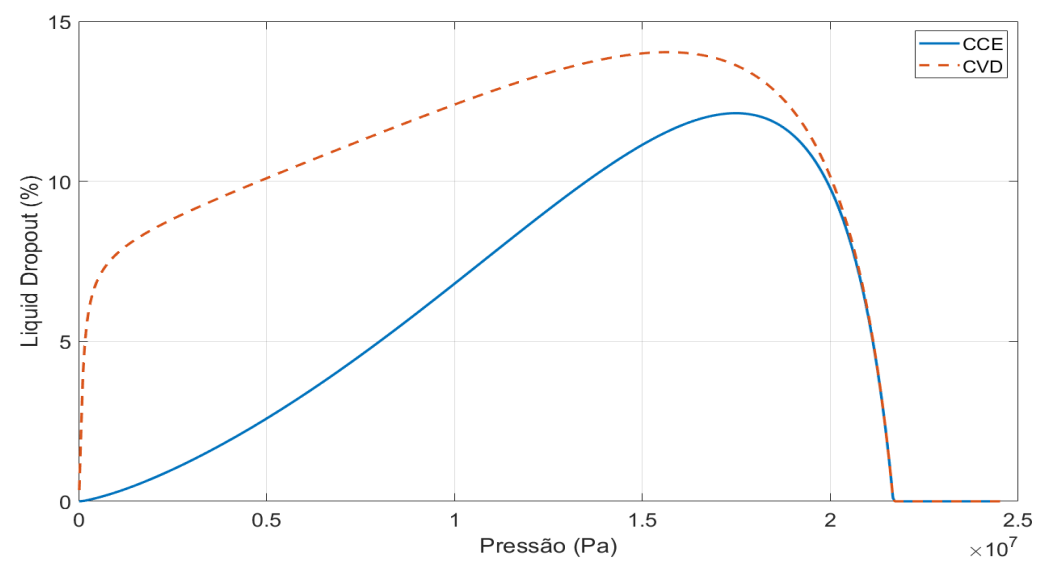

Figura 5.8: Liquid Dropout da mistura utilizada por este trabalho para expansão com composição constante $(\mathrm{CCE})$ e para depleção com volume constante (CVD). 
Além da composição, as propriedades de pressão crítica $\left(P_{c}\right)$, temperatura crítica $\left(T_{c}\right)$, volume crítico $\left(V_{c}\right)$, fator de compressibilidade crítico $\left(Z_{c}\right)$, o parâmetro parachor $(\mathcal{P})$, o fator acêntrico $(\omega)$ e o fator de correção do volume $(\nu)$ dos componentes utilizados no modelo são apresentados nas Tabelas 5.2 e 5.3. Também é apresentado o liquid dropout da mistura utilizada por este trabalho a $80^{\circ} \mathrm{C}$ tanto para expansão com composição constante (CCE) quanto para depleção com volume constante (CVD) na Figura 5.8 [20].

Tabela 5.2: Pressão crítica $\left(P_{c}\right)$, Temperatura crítica $\left(T_{c}\right)$, Parachor $(\mathcal{P})$ e Massa Molar para cada componente do fluido [17]

\begin{tabular}{ccccc} 
Componente & $T_{c}[\mathbf{K}]$ & $P_{c}[\mathbf{p s i}]$ & $\mathcal{P}$ & Massa Molar \\
\hline $\mathrm{CO} 2$ & 304,2 & 72,8 & 78,0 & 44,01 \\
$\mathrm{C} 1$ & 190,6 & 45,4 & 77,0 & 16,043 \\
$\mathrm{C} 2$ & 305,4 & 48,2 & 108,0 & 30,07 \\
$\mathrm{C} 3$ & 369,8 & 41,9 & 150,3 & 44,097 \\
$\mathrm{C} 6$ & 507,4 & 29,3 & 271,0 & 86,178 \\
$\mathrm{C} 10$ & 617,6 & 20,8 & 431,5 & 142,286 \\
$\mathrm{C} 16+$ & 717,0 & 14,0 & 679,6 & 226,448 \\
\hline
\end{tabular}

Tabela 5.3: Volume crítico $\left(V_{c}\right)$, Fator de compressibilidade crítico $\left(Z_{c}\right)$, Fator acêntrico $(\omega)$ e Fator de Correção de Volume $(\nu)$ para cada componente do fluido [17]

\begin{tabular}{ccccc} 
Componente & $V_{c}\left[\mathrm{~m}^{3}\right]$ & $Z_{c}[\mathbf{1} / \mathbf{p s i}]$ & $\omega$ & $\nu$ \\
\hline $\mathrm{CO}_{2}$ & 0,094 & 0,070 & 0,225 & $-0,0817$ \\
$\mathrm{C} 1$ & 0,099 & 0,650 & 0,008 & $-0,1595$ \\
$\mathrm{C} 2$ & 0,148 & 0,130 & 0,098 & $-0,1134$ \\
$\mathrm{C} 3$ & 0,203 & 0,070 & 0,152 & $-0,0863$ \\
$\mathrm{C} 6$ & 0,370 & 0,050 & 0,296 & $-0,0080$ \\
$\mathrm{C} 10$ & 0,603 & 0,025 & 0,490 & 0,0655 \\
$\mathrm{C} 16+$ & 0,956 & 0,005 & 0,742 & 0,956 \\
\hline
\end{tabular}

A pressão inicial empregada nos casos analisados é de 2,256 × $10^{7} \mathrm{~Pa}$. Sendo assim, essa pressão é maior do que a pressão de orvalho e, portanto, a saturação inicial de gás é igual a 1 . Como o problema simulado tem vazão imposta no poço e reservatório isolado, a pressão será constantemente reduzida 
e, por isso, o escoamento não atinge regime permanente. Dessa forma, foi escolhido um critério de parada para as simulações e elas são concluídas quando a pressão no poço atinge o valor de $1,5 \times 10^{7} \mathrm{~Pa}$.

Uma vez definidos todos os parâmetros empregados nos testes, são discutidos os critérios utilizados durante a avaliação da severidade do bloqueio de condensado em cada caso analisado. Primeiramente, foi analisada a extensão do banco de condensado formado ao redor do poço durante o período testado, bem como a celeridade com que este banco é formado. Adicionalmente, é feita a análise da saturação do líquido ao longo do tempo na extensão do reservatório marcada pela presença deste banco. Em conjunto com esta análise, avaliam-se os valores de permeabilidade relativa do líquido e do gás em torno do poço. Dessa maneira, é possível aferir o quanto o banco de líquido formado prejudica o escoamento das fases de gás e condensado.

Para avaliar as diferenças da produção obtida com os dois modelos, são apresentados os gráficos de produção acumulada, ao longo do tempo, de gás e de condensado originados a partir de gás e de condensado em condições de reservatório. Esta análise é de fundamental importância, dado que está diretamente ligado à perspectiva de receita com a produção do campo avaliado.

\subsection{1}

Resultados obtidos com $k=169 \mathrm{mD}$ e $v=100 \mathrm{~m} / \mathrm{d}$

Os primeiros resultados apresentados nesta análise foram obtidos com o valor de permeabilidade absoluta de $169 \mathrm{mD}$ e com a velocidade de 100 m/d. Conforme indicado na Figura 5.9, utilizando ambos os modelos de permeabilidade relativa, a formação de condensado se inicia em 30 dias e, em 2 dias, há a prolongação deste para toda a extensão do reservatório $(177 \mathrm{~m})$. Como o gráfico ilustra, a condensação retrógrada se iniciou ao mesmo tempo com os dois modelos, porque, enquanto monofásico, a queda de pressão é igual utilizando-se os dois modelos. Além disso, mesmo logo após o aparecimento da fase líquida, aos 31 dias, a diferença no campo de pressão previsto pelos modelos, mostrada na Figura 5.10, é muito pequena, o que leva à praticamente a mesma formação do condensado ao longo do reservatório com os dois modelos. 


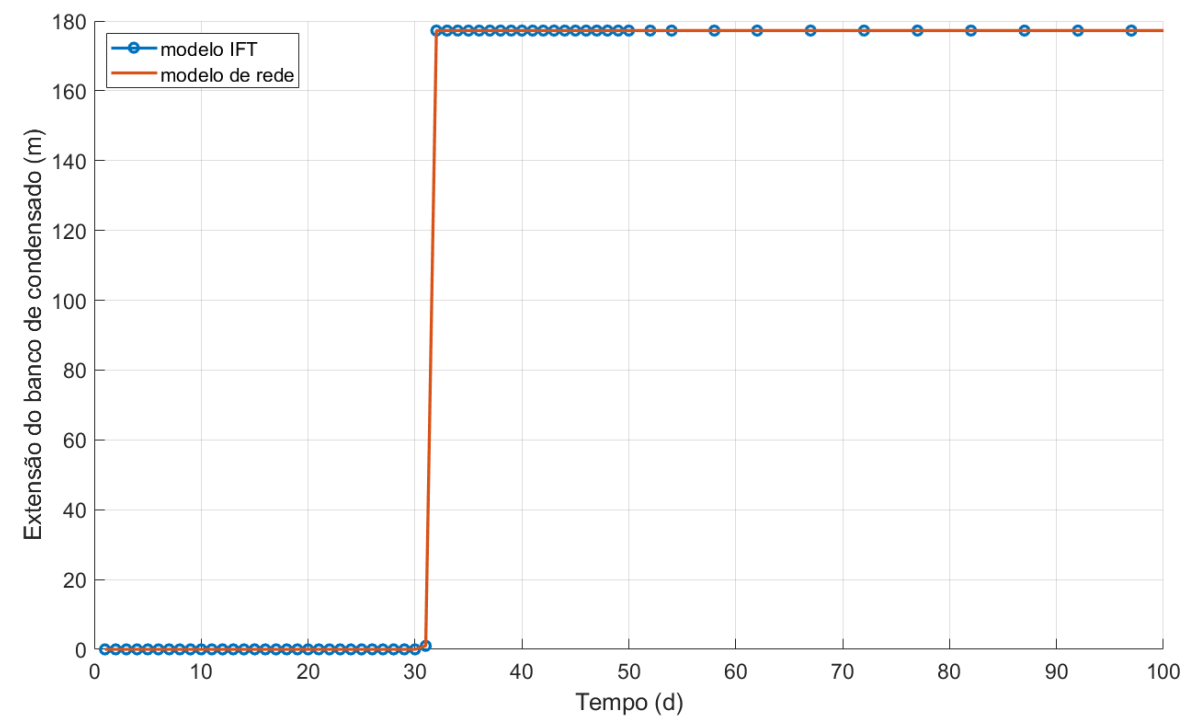

Figura 5.9: Extensão do banco de condensado em função do tempo para $k=$ $169 \mathrm{~m} D$ e $v=100 \mathrm{~m} / \mathrm{d}$.

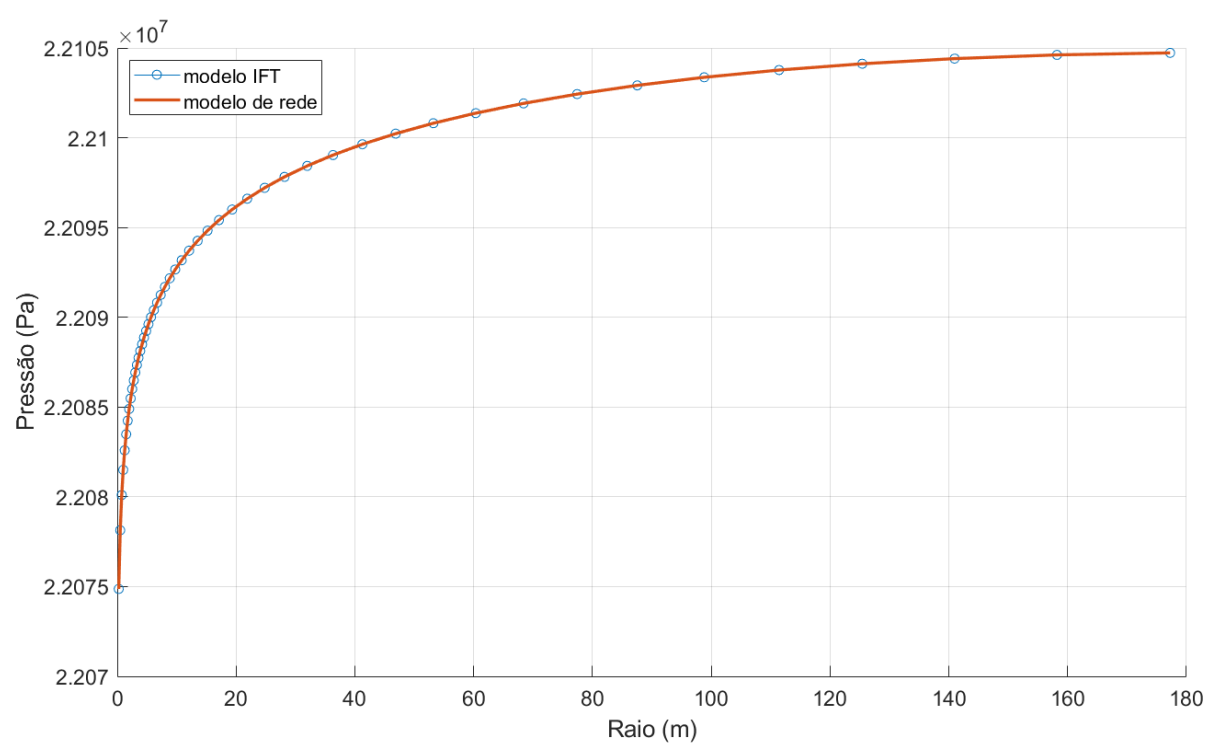

Figura 5.10: para $k=169 \mathrm{mD}$ e $v=100 \mathrm{~m} / d$.

Na Figura 5.11 é apresentado o resultado para a saturação de líquido no poço utilizando-se os dois modelos. Em ambos os casos, é possível observar que a saturação de líquido é crescente até atingir um ponto de máximo em 400 dias e começa a decrescer suavemente a partir dos 420 dias. Além disso, apesar das semelhanças, é possível ver também que a saturação de condensado no poço ao final da simulação é maior utilizando o modelo IFT $(0,1371)$ do que utilizando o modelo de rede $(0,1273)$. 
Esse comportamento de acúmulo de condensado com posterior redução em sua saturação pode ser causado por revaporização ou por varredura do condensado. Para entender o que realmente está acontecendo, é importante analisar a fração de componentes pesados no condensado ao longo do tempo e isso é apresentado na Figura 5.12 a) e b). Percebe-se que, utilizando ambos os modelos, o comportamento geral é semelhante: fração de componentes pesados no condensado é sempre crescente ao longo do tempo de simulação, mas, no começo a fração molar de componentes pesados no condensado aumenta com a redução do raio e essa tendência se inverte, indicando que pode estar acontecendo a revaporização. Entretanto, com o modelo de rede, essa mudança na tendência da fração molar de componentes pesados com o raio muda mais cedo, mostrando, que além da revaporização, há o efeito positivo da velocidade na varredura do condensado.

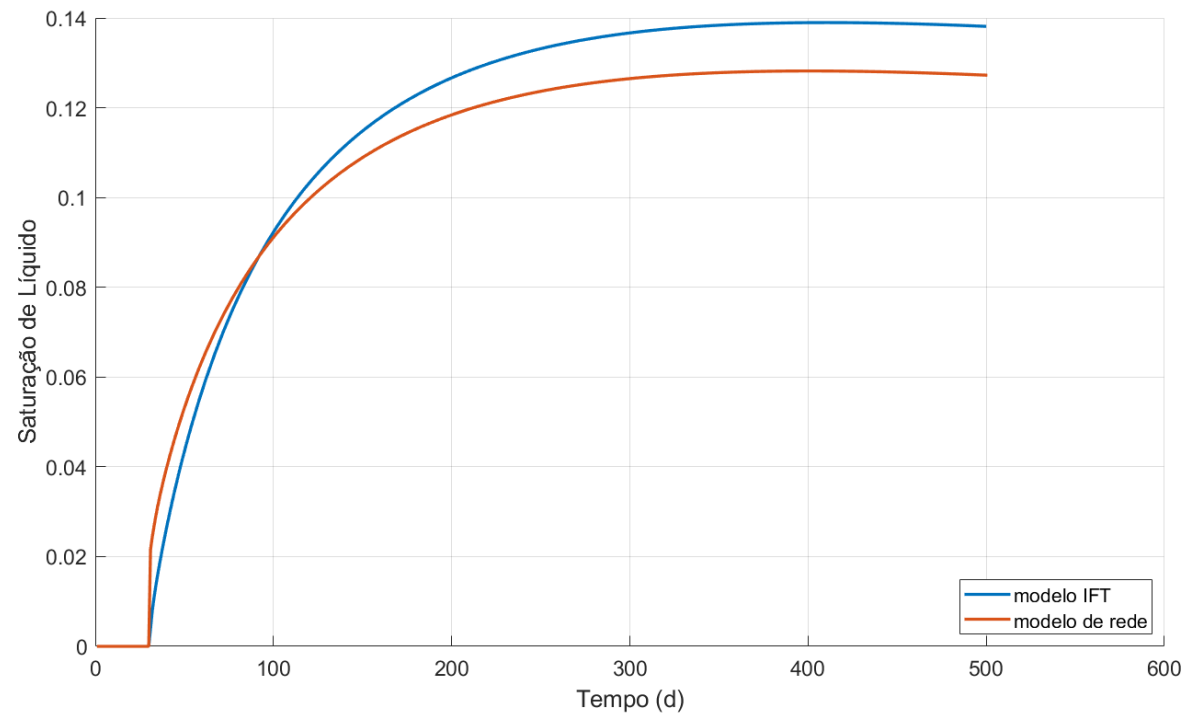

Figura 5.11: Saturação de líquido em função do tempo para $k=169 m D$ e $v$ $=100 \mathrm{~m} / \mathrm{d}$. 


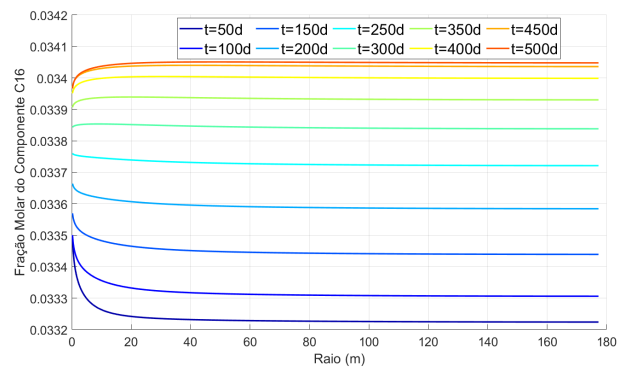

(5.12(a)) Modelo IFT

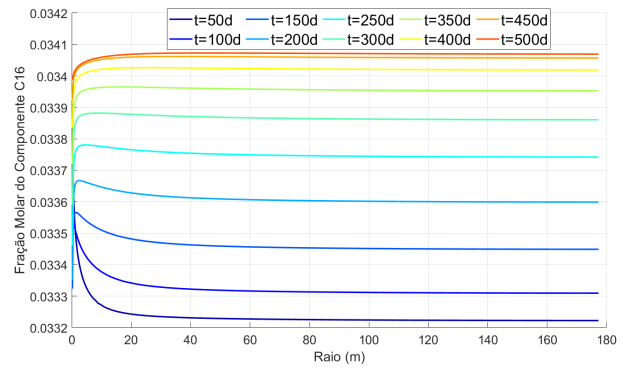

(5.12(b)) Modelo de Rede

Figura 5.12: Fração molar de $C_{16+}$ no condensado em função do tempo e do raio calculadas com ambos os modelos para $k=169 \mathrm{mD}$ e $v=100 \mathrm{~m} / \mathrm{d}$.

Além disso, a composição do fluido nas proximidades do poço ao final da simulação é apresentada na Tabela 5.4. De uma forma geral, ambos os modelos indicam que o gás produzido se torna progressivamente mais pobre em componentes pesados. Entretanto, a fração molar dos componentes pesados na mistura é menor com o modelo de rede, sendo outro indicativo do efeito positivo da velocidade.

Tabela 5.4: Composição do Fluido nas Proximidades do Poço ao Final da Simulação

\begin{tabular}{|c|ccc|ccc|}
\cline { 2 - 7 } \multicolumn{1}{c|}{} & \multicolumn{3}{c|}{ Modelo IFT } & \multicolumn{3}{c|}{ Modelo Rede } \\
\cline { 2 - 7 } \multicolumn{1}{c|}{} & $\mathrm{x}$ & $\mathrm{y}$ & $\mathrm{z}$ & $\mathrm{x}$ & $\mathrm{y}$ & $\mathrm{z}$ \\
\hline $\mathrm{CO}_{2}$ & 0,05335 & 0,07278 & 0,06940 & 0,05335 & 0,07278 & 0,06965 \\
$C 1$ & 0,39826 & 0,69157 & 0,64045 & 0,39824 & 0,69157 & 0,64432 \\
$C 2$ & 0,13096 & 0,12993 & 0,13011 & 0,13096 & 0,12993 & 0,13010 \\
$C 3$ & 0,09862 & 0,06529 & 0,07110 & 0,09862 & 0,06529 & 0,07066 \\
$C 6$ & 0,15344 & 0,03270 & 0,05374 & 0,15344 & 0,03269 & 0,05215 \\
$C 10$ & 0,13140 & 0,00739 & 0,02901 & 0,13140 & 0,00739 & 0,02737 \\
$C 16+$ & 0,03397 & 0,00034 & 0,00620 & 0,03399 & 0,00034 & 0,00576 \\
\hline
\end{tabular}

Conforme visto anteriormente, ambos os modelos de permeabilidade relativa de líquido são crescentes com a saturação, na faixa de saturação observada nesse caso $\left(S_{\text {liq }}<15 \%\right)$, como mostrado nas Figuras 3.2 e 3.3. Por isso, na Figura 5.13, é observado nas curvas de permeabilidade relativa de líquido um comportamento semelhante ao das curvas de saturação. Entretanto, vê-se também que, enquanto a permeabilidade relativa de líquido calculada com o modelo de rede atinge o máximo em 400 dias como a curva de saturação de líquido, a permeabilidade relativa calculada com o modelo IFT apresenta um máximo antecipado para 200 dias e, em seguida, é reduzida. 
Essa diferença aparece porque existem fenômenos diferentes afetando o comportamento da curva de permeabilidade relativa de líquido calculada com o modelo IFT. Inicialmente, há um aumento da saturação de condensado, o que leva a um aumento na permeabilidade relativa de líquido. Nessa situação inicial, o condensado que aparece é mais leve e a tensão interfacial não aumenta muito. A partir de um certo tempo, a saturação de líquido varia muito pouco, mas, como visto nas Figuras 5.12 a) e b), continua a aumentar a fração de componentes pesados no condensado. Nesse caso, a tensão interfacial começa a crescer bastante e isso leva a uma redução da permeabilidade relativa de líquido. Como a saturação de líquido é praticamente constante, esse efeito de redução da permeabilidade relativa se torna preponderante.

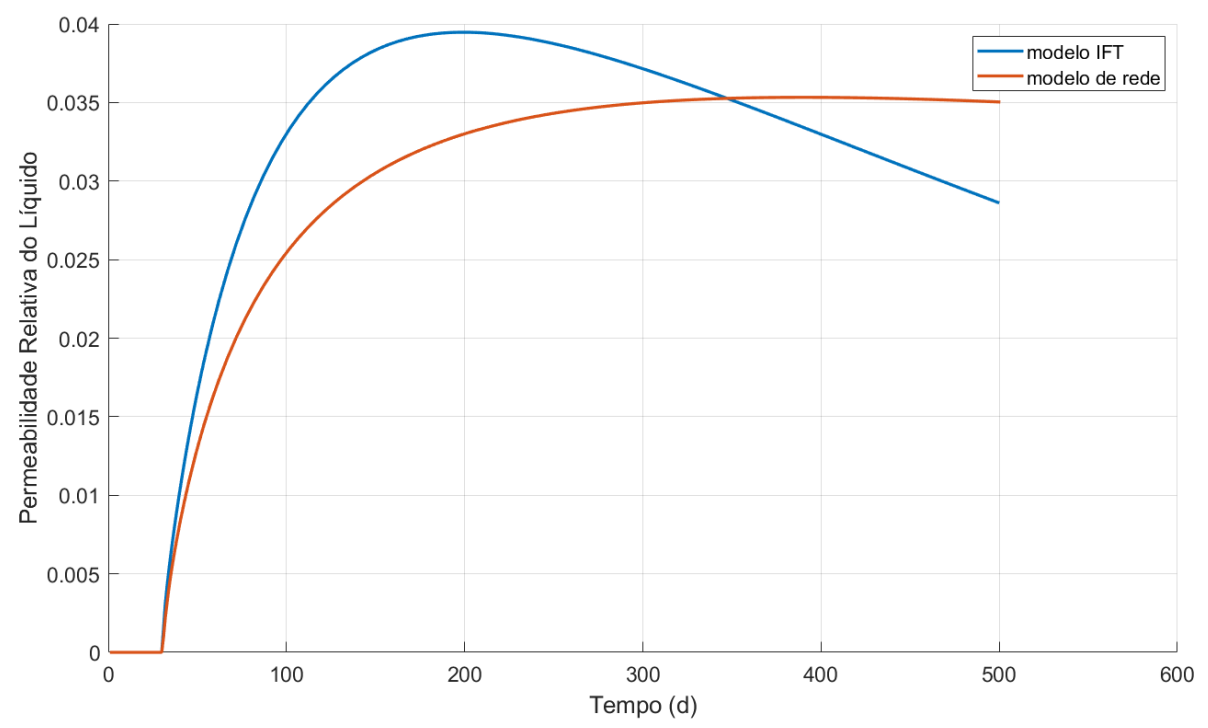

Figura 5.13: Permeabilidade relativa do líquido em função do tempo para $k=$ $169 m D$ e $v=100 m / d$.

Na Figura 5.14 é apresentada a permeabilidade de gás em função do tempo para os dois modelos e em dois pontos diferentes do reservatório: nas proximidades do poço $\left(r_{\text {well }}\right)$ e no final do reservatório $\left(r_{r e s}\right)$. Nela é possível ver que a permeabilidade relativa de gás ao longo do reservatório é praticamente constante com o modelo IFT para um mesmo instante de tempo. Isso ocorre porque, a partir de 32 dias, o condensado ocupa todo o reservatório e a sua composição não varia significativamente ao longo do reservatório. Por isso, a tensão interfacial varia pouco ao longo do reservatório, o que leva ao modelo IFT também variar pouco ao longo do reservatório.

A permeabilidade relativa de gás calculada com o modelo de rede, por outro lado, varia significativamente por levar em consideração o efeito da velocidade. Nesse caso, para velocidades mais baixas observadas longe do poço, 
o modelo IFT prevê permeabilidades relativas maiores que o modelo de rede, enquanto que para velocidades mais altas perto do poço, o modelo de rede passa a prever permeabilidades relativas maiores que o modelo IFT. Isso mostra a capacidade do modelo de rede de representar o efeito positivo da velocidade na permeabilidade relativa de gás.

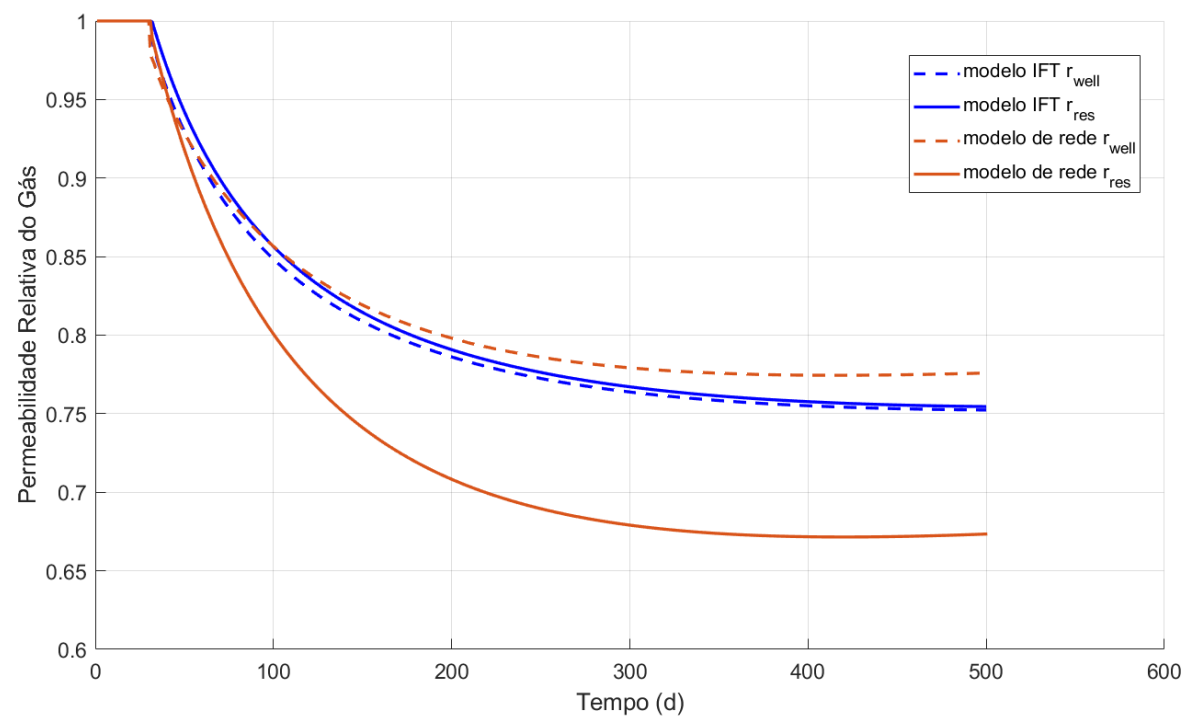

Figura 5.14: Permeabilidade relativa do gás em função do tempo para $k=$ $169 m D$ e $v=100 m / d$.

Na Figura 5.15, é apresentada a produção acumulada de gás em condições standard, à pressão $101.325 \mathrm{~Pa}$ e temperatura de $15^{\circ} \mathrm{C}$, em função do tempo. Nesse caso, a produção com o modelo IFT foi $6.363 .843 \mathrm{~m}^{3}$ e com o modelo de rede foi de $6.362 .458 \mathrm{~m}^{3}$. Assim, há uma pequena diferença de produção de gás utilizando os dois modelos (1.390 $\mathrm{m}^{3}$ para o modelo IFT). Para entender o motivo dessa pequena diferença entre os dois modelos, é analisado o quanto desse gás vem de gás em condições de reservatório e quanto vem de condensado em condições de reservatório.

A produção acumulada de gás oriundo de gás em condições de reservatório é apresentada na Figura 5.16, onde pode-se observar que a produção foi de $6,283 \times 10^{6} \mathrm{~m}^{3}$ para o modelo IFT e foi de $6,291 \times 10^{6} \mathrm{~m}^{3}$ para o modelo de rede. Essa diferença de $8.000 \mathrm{~m}^{3}$ a mais para o modelo de rede pode-se atribuir a maior permeabilidade relativa de gás do modelo de rede que do modelo IFT nas vizinhanças do poço, a qual não é tão significativa porque no restante do reservatório essa tendência é invertida como pode ser observado nas Figuras 5.14 e 5.17 . 


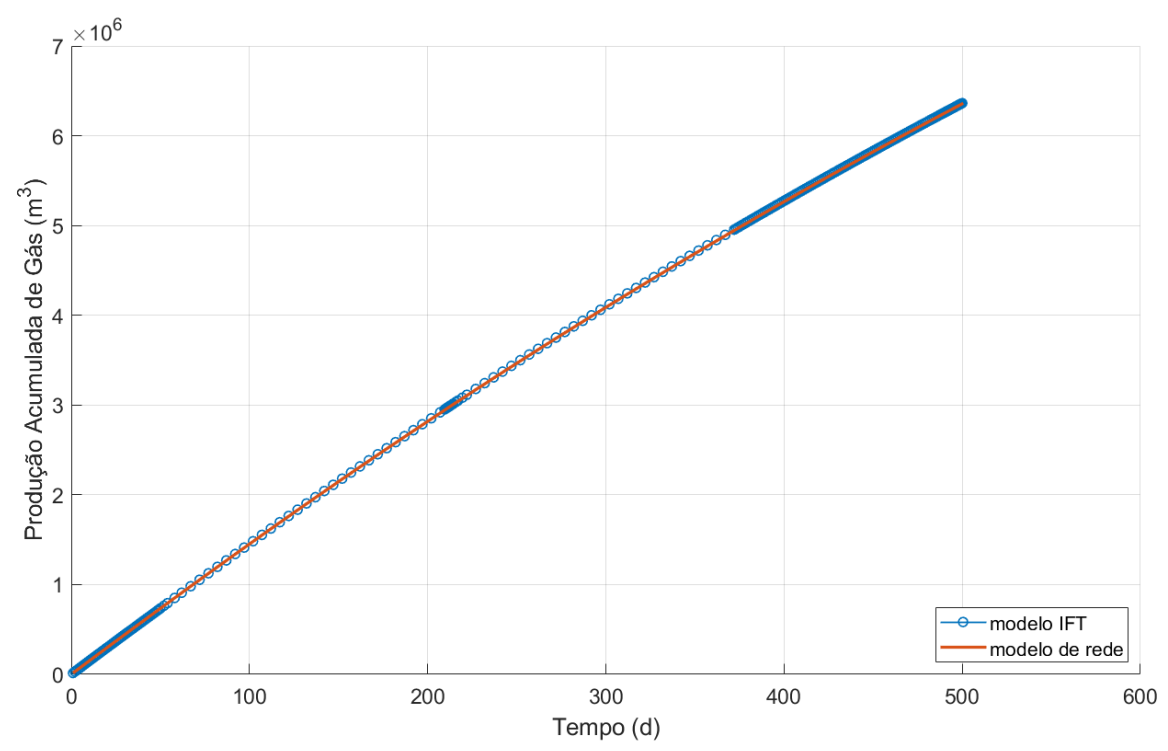

Figura 5.15: Produção acumulada de gás em condições standard em função do tempo para $k=169 \mathrm{mD}$ e $v=100 \mathrm{~m} / d$.

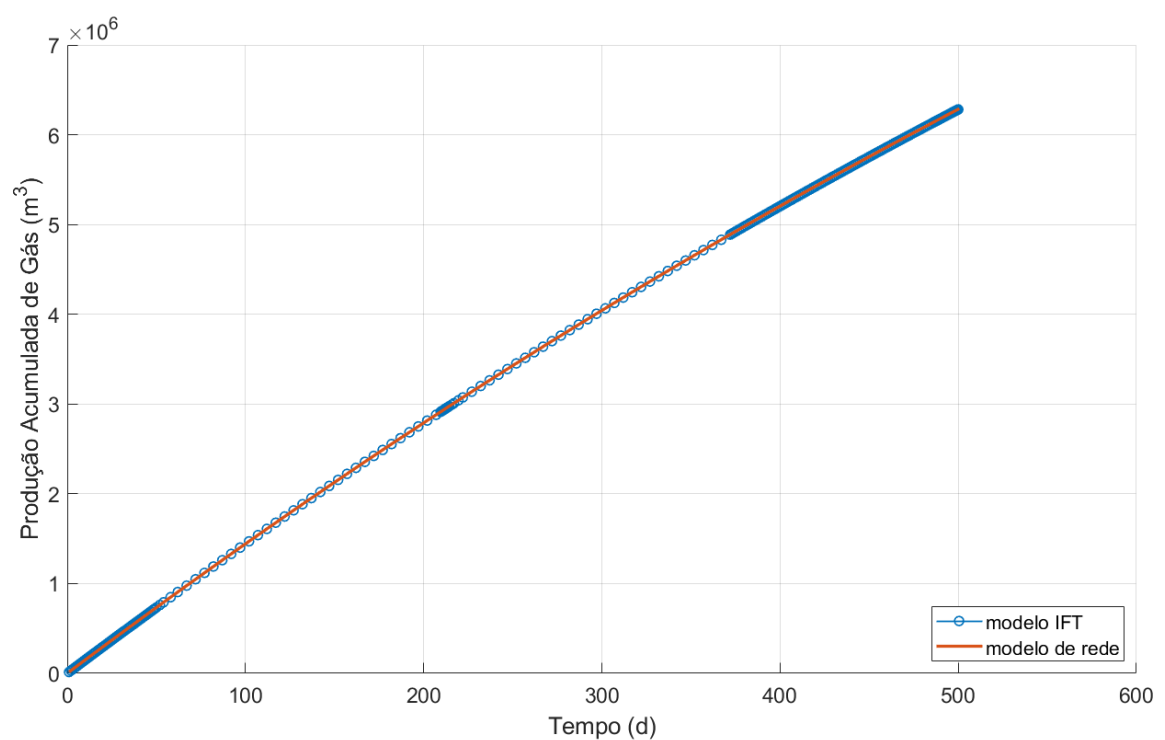

Figura 5.16: Produção acumulada de gás em condições standard vindo de gás em condições de reservatório em função do tempo para $k=169 m D$ e $v=$ $100 \mathrm{~m} / d$. 


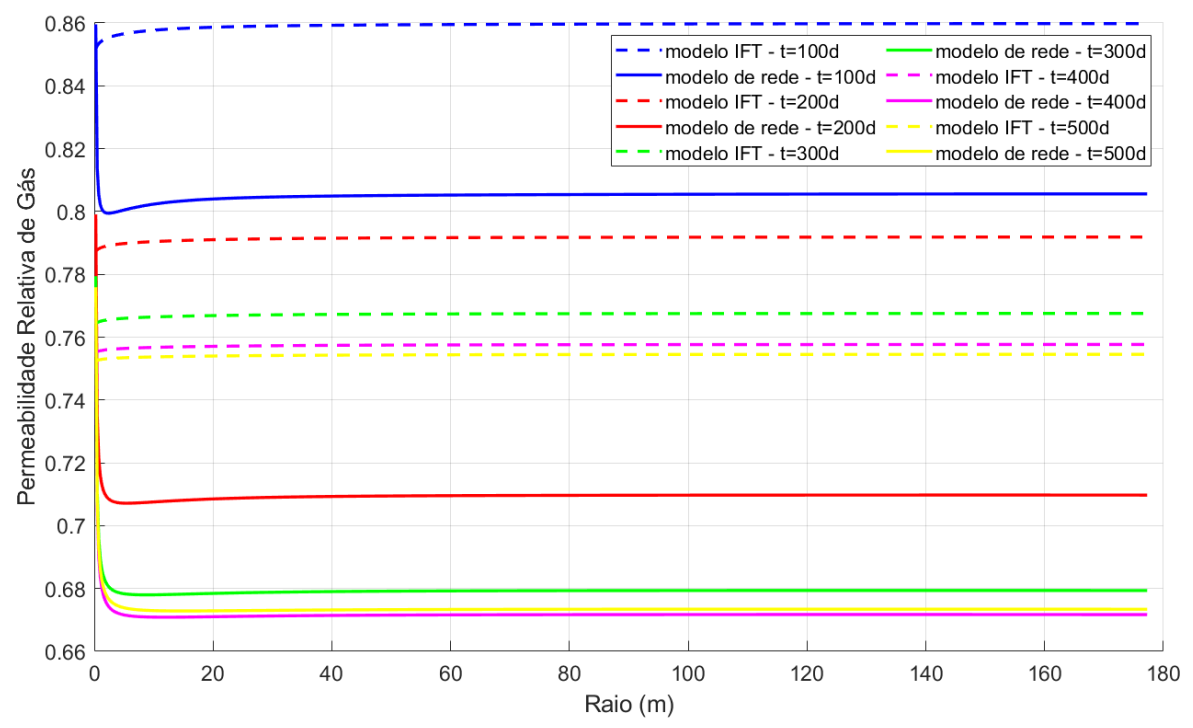

Figura 5.17: Permeabilidade relativa de gás em função do raio e do tempo para $k=169 \mathrm{~m} D$ e $v=100 \mathrm{~m} / d$.

Na Figura 5.18, é apresentada a produção de gás oriundo de condensado em condições de reservatório. É possível observar que a produção de gás, nesse caso, foi de $80.843 \mathrm{~m}^{3}$ para o modelo IFT e de $71.458 \mathrm{~m}^{3}$ para o modelo de rede. Essa diferença de $9.390 \mathrm{~m}^{3}$ a mais para o modelo IFT existe, porque a permeabilidade relativa de líquido do modelo IFT é maior que a do modelo de rede na maior parte da simulação (350 dias) tanto nas proximidades do poço, como pode ser observado na Figura 5.13, quanto no restante do reservatório, como pode ser observado na Figura 5.19. Inclusive, percebe-se também que a partir dos 350 dias, essa diferença entre a produção acumulada utilizando os dois modelos começa a diminuir, porque a partir desse ponto, a permeabilidade relativa de líquido passa a ser menor para o modelo IFT. 


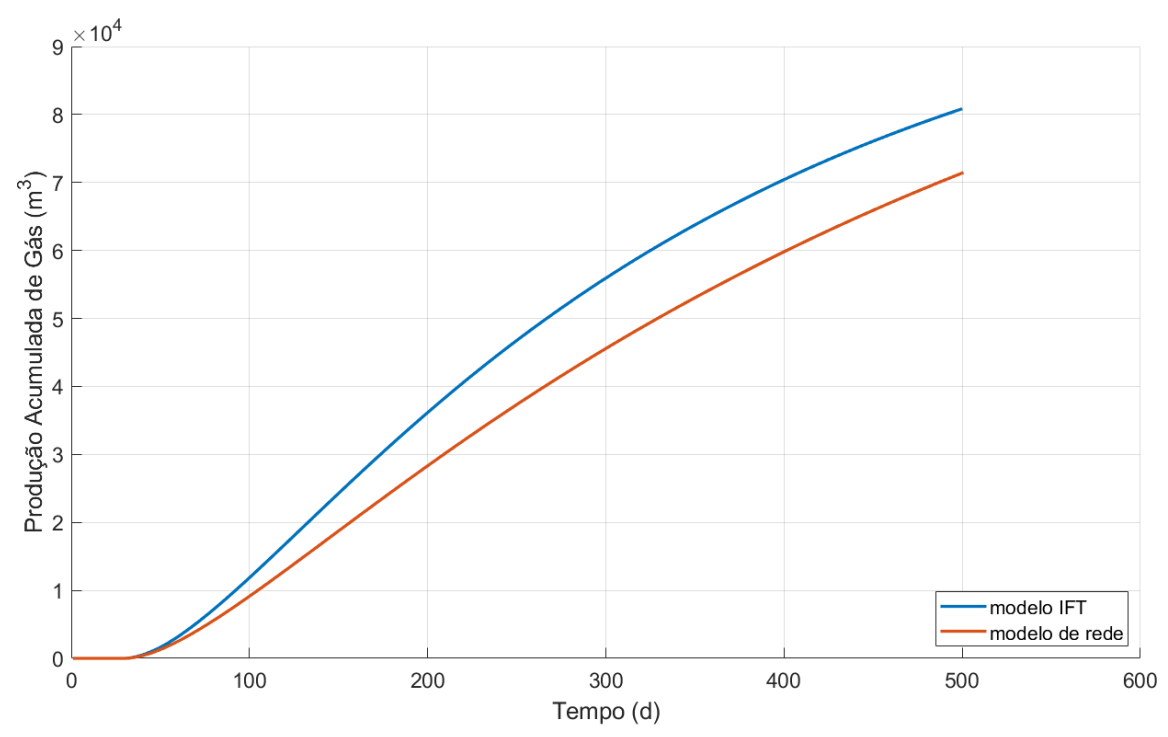

Figura 5.18: Produção acumulada de gás em condições standard vindo de condensado em condições de reservatório em função do tempo para $k=169 \mathrm{mD}$ e $v=100 \mathrm{~m} / d$.

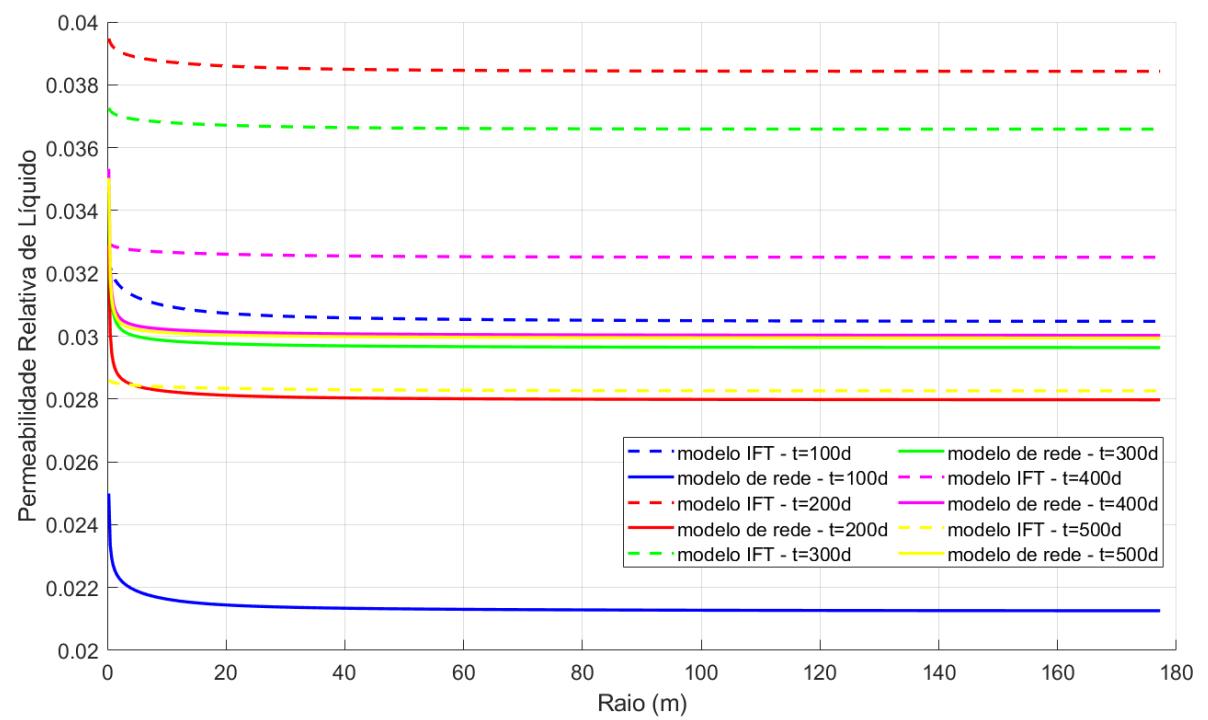

Figura 5.19: Permeabilidade relativa de líquido em função do raio e do tempo para $k=169 m D$ e $v=100 m / d$.

Na Figura 5.20, é apresentada a produção acumulada de condensado. Nela é possível perceber que, com o modelo IFT, produziu-se 1.321,4 $\mathrm{m}^{3}$ e, com o modelo de rede, produziu-se 1.307,6 $\mathrm{m}^{3}$. A diferença entre os dois modelos foi de $13,8 \mathrm{~m}^{3}$, ou seja, aproximadamente $1 \%$. Para entender o motivo dessa pequena diferença, é analisado o quanto desse condensado vem de gás 
em condições de reservatório e quanto vem de condensado em condições de reservatório.

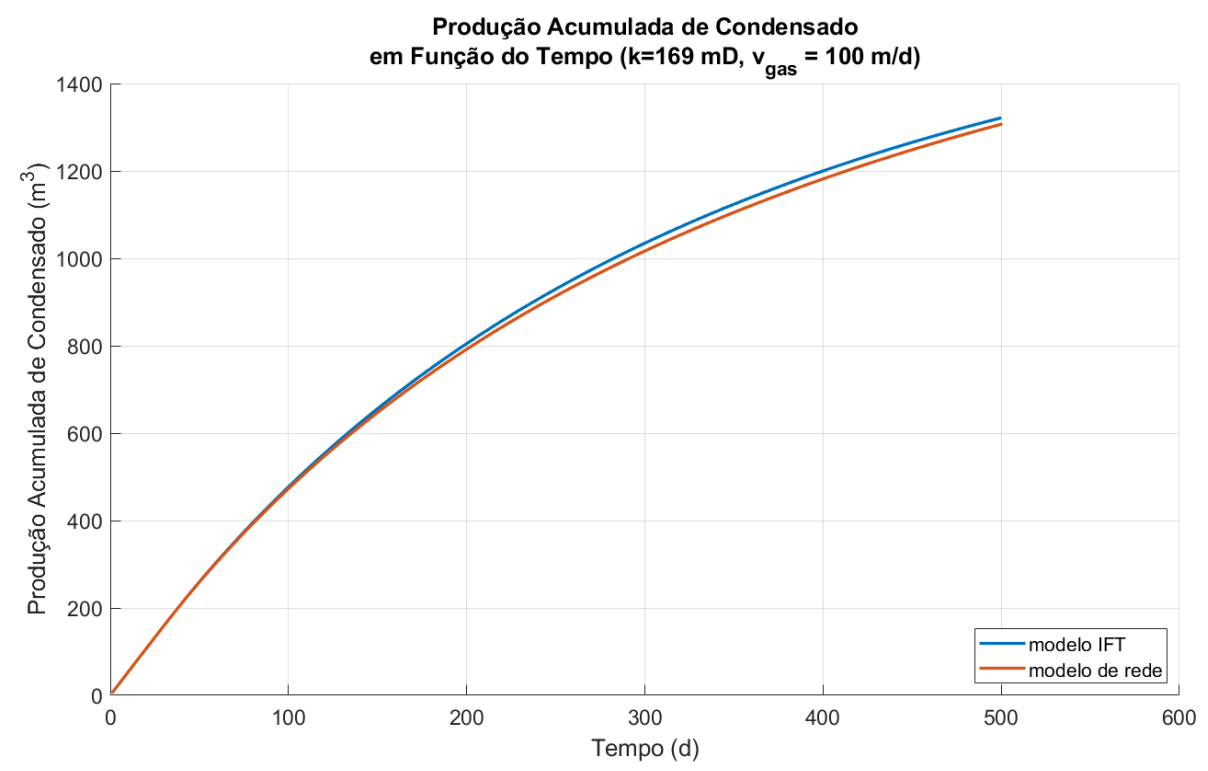

Figura 5.20: Produção acumulada de condensado em condições standard em função do tempo para $k=169 m D$ e $v=100 m / d$.

Pode-se ver na Figura 5.21 que a produção acumulada de condensado originado de gás em condições de reservatório foi de $1.149 \mathrm{~m}^{3}$ no modelo IFT e $1.151 \mathrm{~m}^{3}$ no modelo de rede em 500 dias. A diferença entre a previsão da produção de condensado em condições standard dos dois modelos foi de $2 \mathrm{~m}^{3}$ a mais para o modelo de rede. Mais uma vez, a hipótese que parece explicar essa diferença para o modelo de rede é que a permeabilidade relativa de gás com ele é maior que a do modelo IFT nas vizinhanças do poço, mas ela não é tão significativa porque no restante do reservatório essa tendência é invertida.

Prosseguindo, na Figura 5.22, encontra-se a produção acumulada de condensado originado de condensado em condições de reservatório. Essa produção foi de 172,4 $\mathrm{m}^{3}$ para o modelo IFT e de $156,6 \mathrm{~m}^{3}$ para o modelo de rede, totalizando uma diferença de $15,8 \mathrm{~m}^{3}$ ao final da simulação. Essa diferença entre os modelos ocorre e passa a diminuir depois dos 350 dias pelos mesmos motivos já citados: permeabilidade relativa de líquido ser maior para o modelo IFT ao longo do reservatório durante os primeiros 350 dias e essa tendência se inverter a partir desse tempo de simulação. 


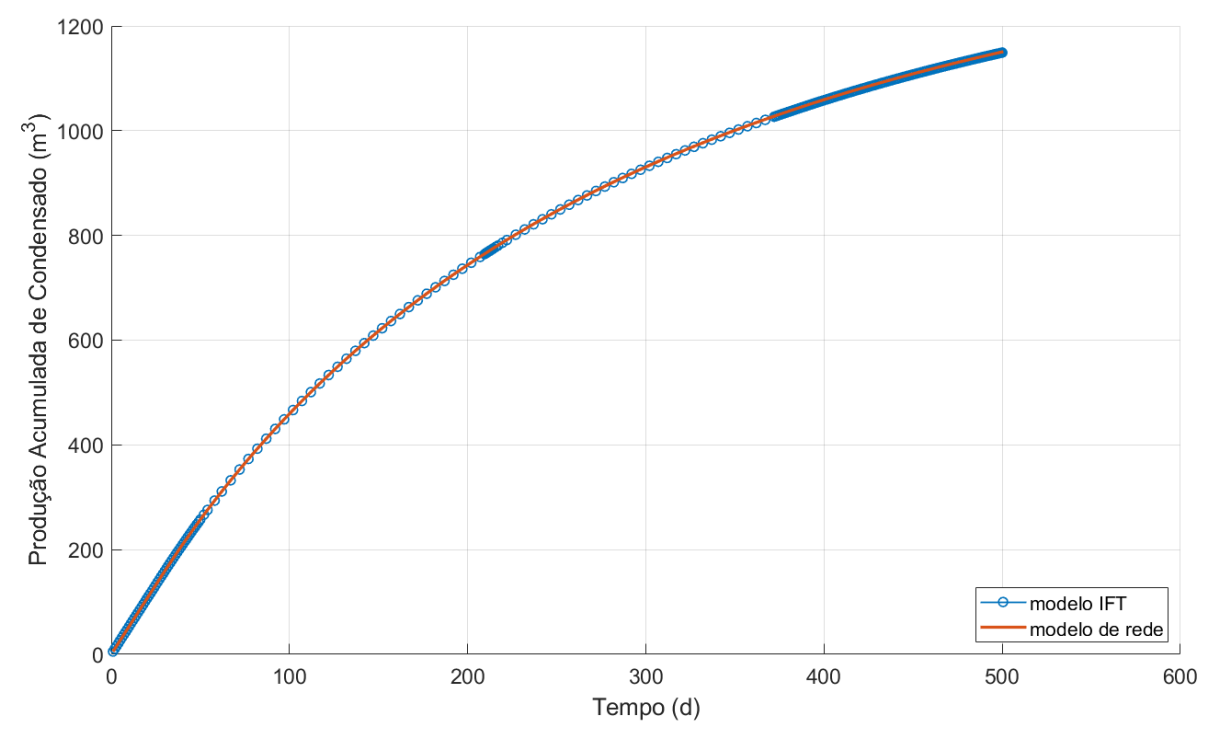

Figura 5.21: Produção acumulada de condensado em condições standard vindo de gás em condições de reservatório em função do tempo para $k=169 \mathrm{mD}$ e $v=100 \mathrm{~m} / \mathrm{d}$.

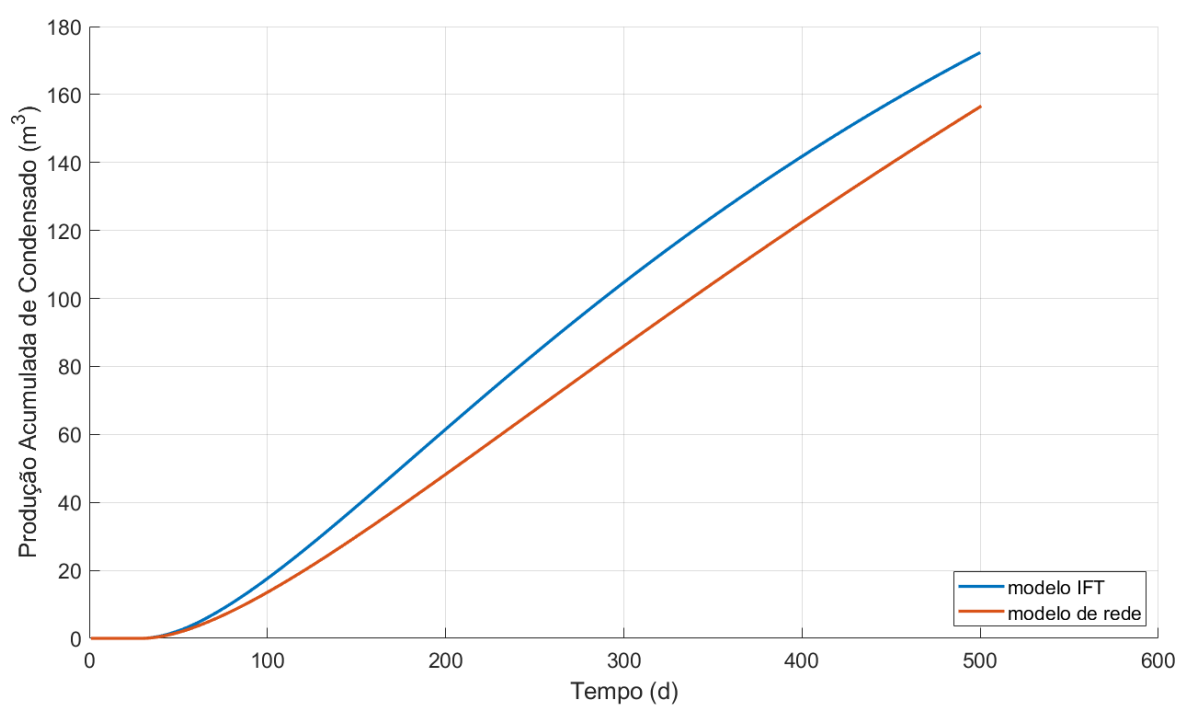

Figura 5.22: Produção acumulada de condensado em condições standard vindo de condensado em condições de reservatório em função do tempo para $k=$ $169 m D$ e $v=100 m / d$.

De uma forma geral, com a permeabilidade absoluta do meio relativamente alta (169 mD), não houve diferença significativa entre o uso dos dois modelos de permeabilidade relativa dentro do intervalo de pressão avaliado. 


\subsection{2}

\section{Resultados obtidos com $k=169 m D$ e $v=200 m / d$}

A seguir é apresentada a análise dos resultados da simulação com permeabilidade absoluta de $169 \mathrm{mD}$ e com a velocidade de $200 \mathrm{~m} / \mathrm{d}$. Com relação à formação do banco de condensado, o aumento na velocidade causou uma antecipação do início da condensação retrógrada, como pode-se ver na Figura 5.23. Com velocidade de $100 \mathrm{~m} / \mathrm{d}$, a condensação retrógrada inicia com 30 dias. Já com 200m/d, ela inicia com 15 dias, na metade do tempo, indicando que ao dobrar a velocidade, reduzimos para metade o tempo de início da condensação retrógrada.

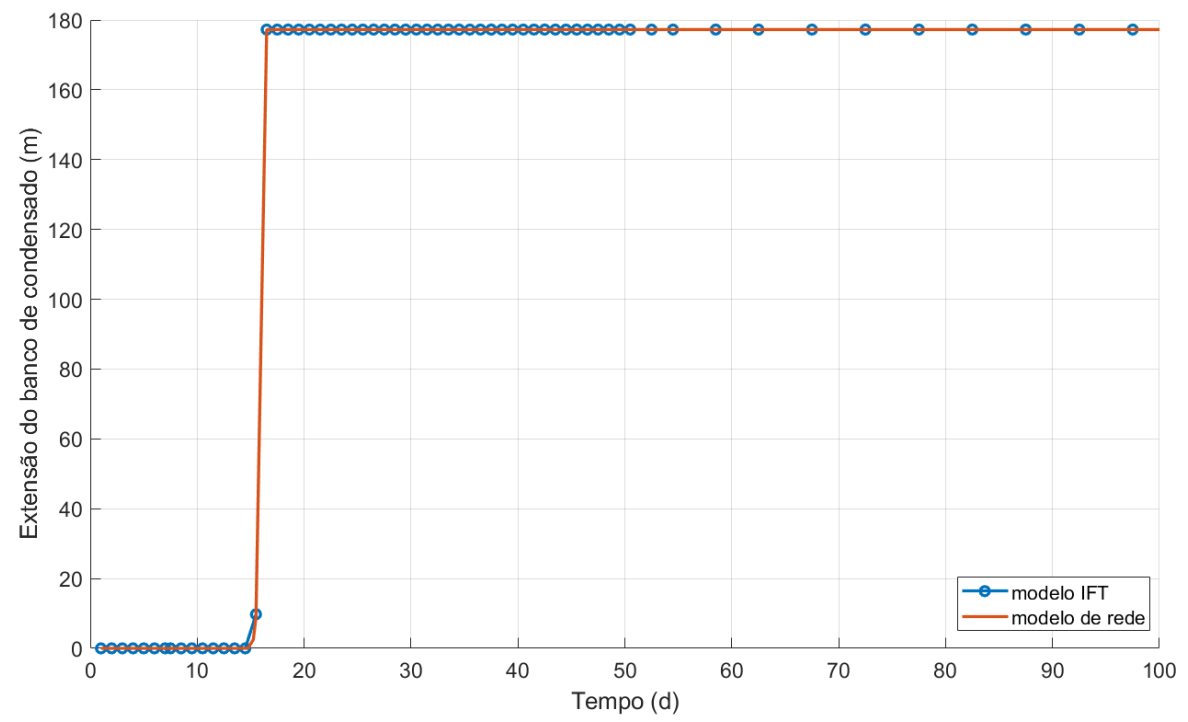

Figura 5.23: Extensão do banco de condensado em função do tempo para $k=$ $169 m D$ e $v=200 m / d$.

Com relação a saturação, é possível ver na Figura 5.24 que a saturação de condensado nas proximidades do poço continua maior no modelo IFT $(0,1395)$ que no modelo de rede $(0,1215)$. Entretanto, a diferença entre os modelos aumentou $84 \%$, de 0,0098 para 0,0180. Além disso, vê-se que a curva tem comportamento crescente até os 200 dias de simulação e começa a decrescer em seguida.

Outro ponto interessante é que comparado com o caso de velocidade igual a $100 \mathrm{~m} / \mathrm{d}$, a saturação de líquido cresce no modelo IFT e decresce no modelo de rede. Isso ocorre porque, sem considerar o efeito positivo da velocidade na permeabilidade relativa, no modelo IFT, o aumento de velocidade leva a um aumento do diferencial de pressão, o que leva o reservatório a pressões mais baixas mais rápido e, portanto, a uma saturação de líquido maior. Por outro 
lado, considerando o efeito positivo da velocidade, o aumento da velocidade leva o modelo de rede a varrer mais o condensado, levando a uma saturação de líquido menor.

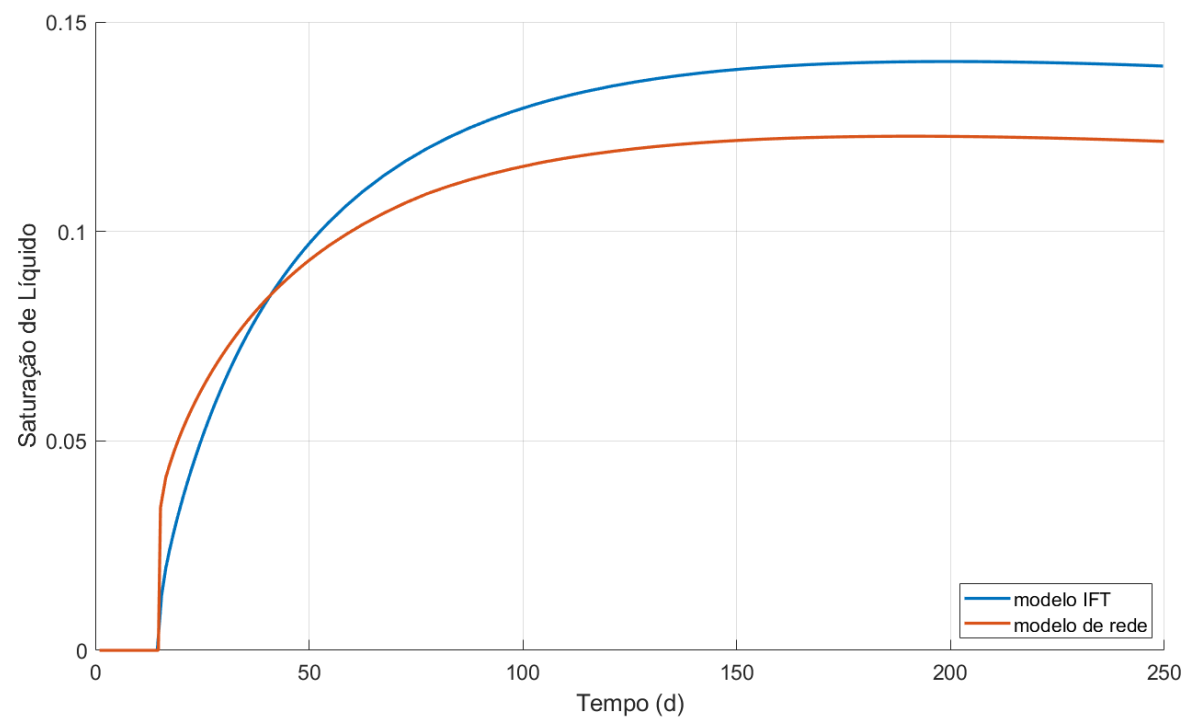

Figura 5.24: Saturação de líquido em função do tempo para $k=169 m D$ e $v$ $=200 \mathrm{~m} / \mathrm{d}$.

Na Figura 5.25 a) e b) é possível ver que a inversão da tendência da fração molar de componentes pesados é antecipada com ambos os modelos com relação ao caso de velocidade $100 \mathrm{~m} / \mathrm{d}$. O que acontece, neste caso, é que, no começo, há mais componentes pesados perto do poço, mas isso se inverte com o tempo, levando a menos componentes pesados perto do poço quando comparado com o caso de velocidade $100 \mathrm{~m} / \mathrm{d}$. Por causa disso, a tensão interfacial também apresenta uma redução quando comparado com o caso de velocidade igual a 100 m/d, como pode ser observado na Figura 5.26. 


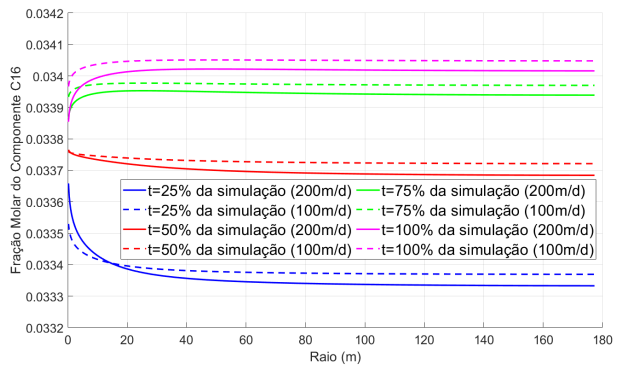

(5.25(a)) Modelo IFT

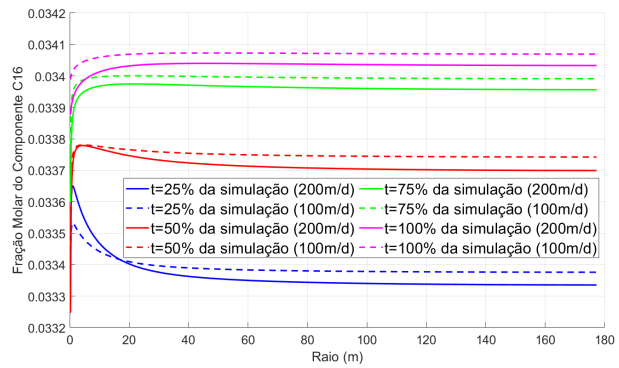

(5.25(b)) Modelo de Rede

Figura 5.25: Fração molar de $C_{16+}$ no condensado em função do tempo e do raio calculadas com ambos os modelos para $k=169 \mathrm{mD}$ e velocidades $v=$ $100 \mathrm{~m} / d$ e $v=200 \mathrm{~m} / d$.

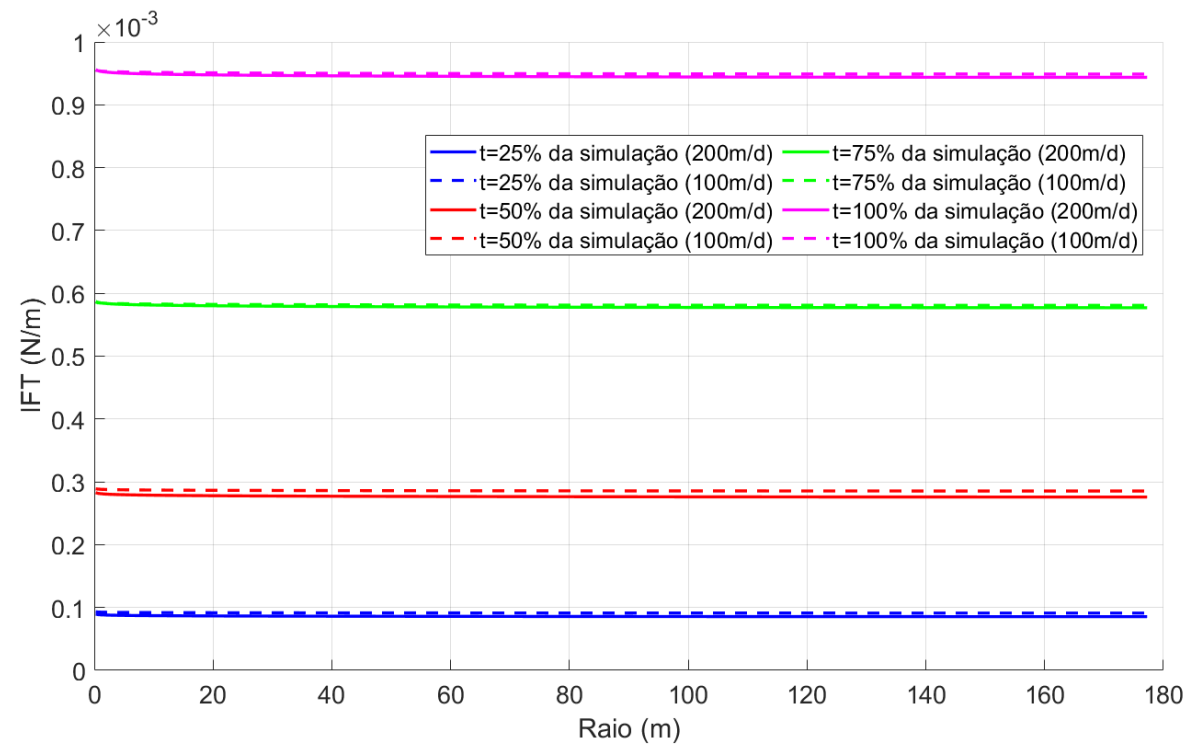

Figura 5.26: IFT calculado com Modelo IFT em função do raio e do tempo para $k=169 \mathrm{mD}$ e velocidades $v=100 \mathrm{~m} / d$ e $v=200 \mathrm{~m} / d$.

Na Figura 5.27, é possível ver que a permeabilidade relativa de líquido perto do poço no modelo de rede cresceu aproximadamente $14 \%$ se comparado com a velocidade de $100 \mathrm{~m} / \mathrm{d}$, enquanto que no modelo IFT esse crescimento é de apenas $2 \%$. O crescimento da permeabilidade relativa de líquido com o modelo IFT acontece justamente porque a saturação de líquido é maior e a tensão interfacial é menor conforme já apresentado nas Figuras 5.24 e 5.26. Já o crescimento de $14 \%$ da permeabilidade calculada com o modelo de rede advém dos efeitos positivos da velocidade no escoamento. Além disso, a permeabilidade relativa de líquido continua com comportamento semelhante ao caso de velocidade de $100 \mathrm{~m} / \mathrm{d}$. Ao dobrar a velocidade, pressões mais baixas 
mais rápido são atingidas em menor tempo. Com isso, a saturação de líquido cresce mais rapidamente e com a ela a permeabilidade relativa de líquido. Entretanto, para além do efeito da velocidade no campo de pressão, o modelo de rede leva em consideração o efeito positivo da velocidade, o que faz que com a taxa de crescimento da permeabilidade relativa de líquido seja ainda maior. Por isso, o ponto de máximo do modelo de IFT acontece na metade do tempo e este tem permeabilidades maiores apenas por aproximadamente um terço do tempo do caso anterior (128 dias).

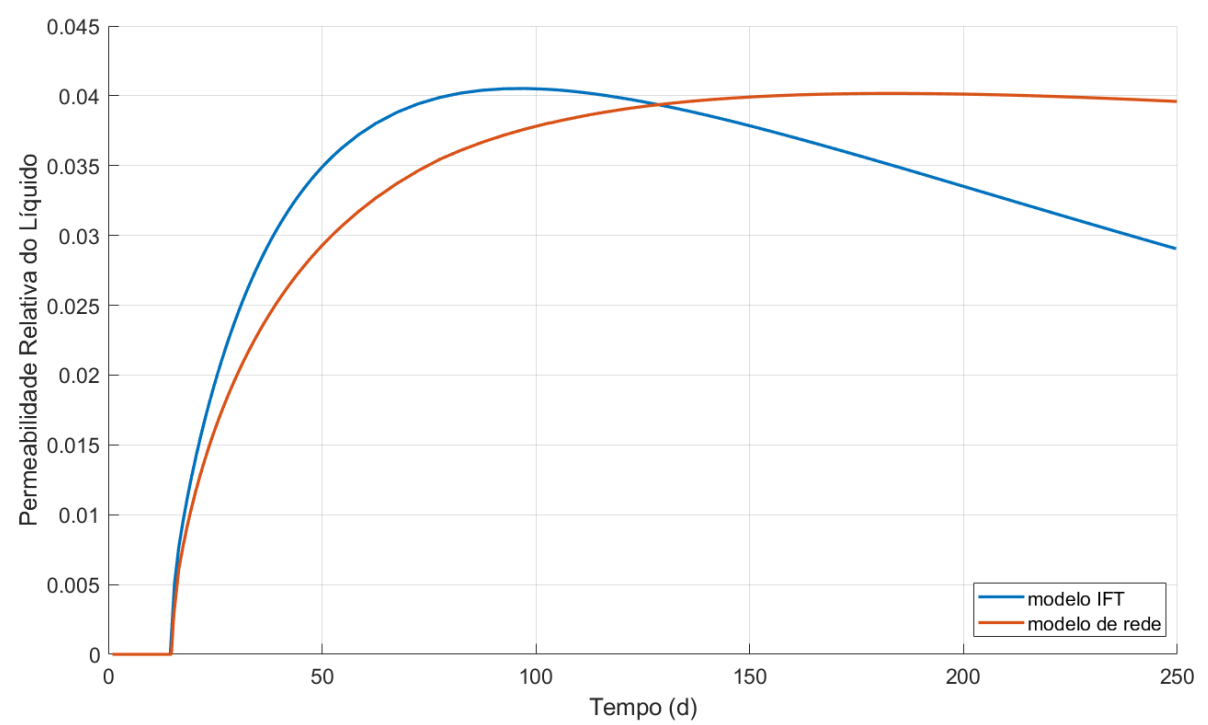

Figura 5.27: Permeabilidade relativa do líquido em função do tempo para $k=$ $169 \mathrm{mD}$ e $v=200 \mathrm{~m} / \mathrm{d}$.

O aumento de velocidade trouxe uma pequena redução na permeabilidade relativa de gás calculada pelo modelo IFT perto do poço $\left(r_{\text {well }}: 0,7524 @ 100 \mathrm{~m} / \mathrm{d}\right.$ $\rightarrow 0,7501 @ 200 \mathrm{~m} / \mathrm{d}$ ) e um aumento significativo na calculada pelo modelo de rede $\left(r_{\text {well }}: 0,7759 @ 100 \mathrm{~m} / \mathrm{d} \rightarrow 0,8632 @ 200 \mathrm{~m} / \mathrm{d}\right)$ como pode ser visto na Figura 5.28. Essa redução na permeabilidade relativa de gás no modelo IFT é causada pelo aumento da saturação de líquido, enquanto o aumento na permeabilidade calculada com o modelo de rede é causado pelo efeito positivo da velocidade e uma saturação de líquido menor no final da simulação.

Na Figura 5.29, é apresentada a produção acumulada de gás em condições standard em função do tempo. Nesse caso, a produção com o modelo IFT foi 6.346.800 $\mathrm{m}^{3}$ e com o modelo de rede foi de 6.343.530 $\mathrm{m}^{3}$. Assim, a diferença entre os dois modelos aumentou de $1.390 \mathrm{~m}^{3}$ para $3.270 \mathrm{~m}^{3}$ com o modelo IFT quando comparado ao caso com velocidade de $100 \mathrm{~m} / \mathrm{d}$. Logo o aumento na velocidade, também aumentou a diferença entre a produção acumulada de gás calculada com os dois modelos. Para entender o motivo dessa diferença entre 


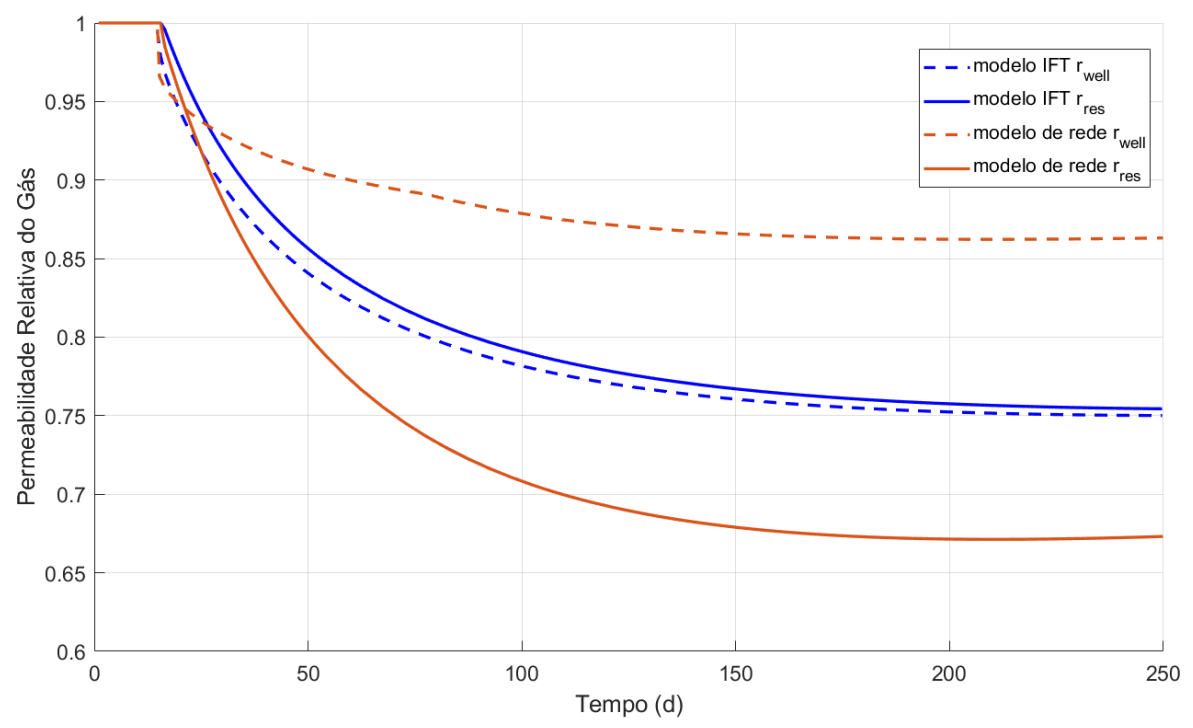

Figura 5.28: Permeabilidade relativa do gás em função do tempo para $k=$ $169 m D$ e $v=200 m / d$.

os dois modelos, mais uma vez, é analisado o quanto desse gás vem de gás em condições de reservatório e quanto vem de condensado em condições de reservatório.

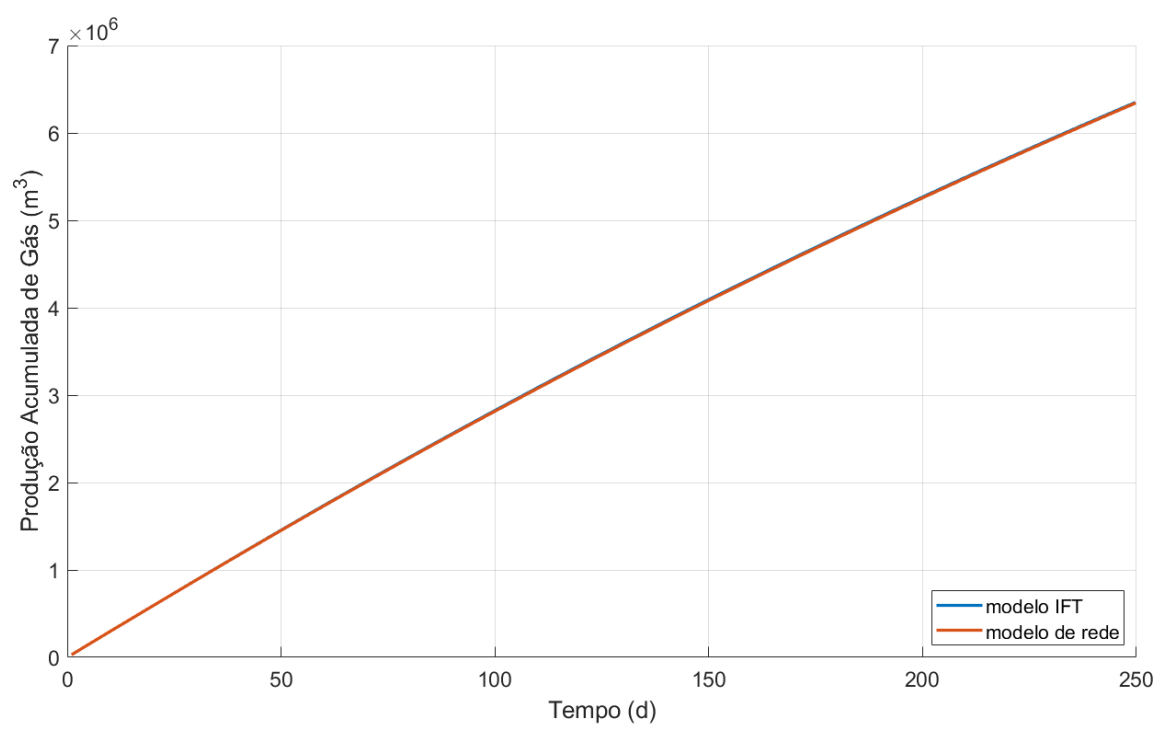

Figura 5.29: Produção acumulada de gás em condições standard em função do tempo para $k=169 \mathrm{mD}$ e $v=200 \mathrm{~m} / d$.

Na Figura 5.30, é apresentada a produção acumulada de gás oriundo de gás em condições de reservatório. Com a redução da permeabilidade relativa de gás nas vizinhanças do poço calculada com o modelo IFT em comparação 
ao caso de velocidade $100 \mathrm{~m} / \mathrm{d}$, a produção acumulada de gás vindo de gás ficou menor para o modelo IFT e foi de $6,263 \times 10^{6} \mathrm{~m}^{3}$. Por outro lado, apesar do aumento da permeabilidade relativa de gás nas vizinhanças do poço calculada com o modelo de rede em comparação ao caso de velocidade 100 $\mathrm{m} / \mathrm{d}$, como ela ainda é menor que a calculada pelo modelo IFT no restante do reservatório, como pode ser observado na Figura 5.31, a produção acumulada de gás vindo de gás também ficou menor para o modelo de rede e foi de $6,269 \times 10^{6} \mathrm{~m}^{3}$. Essa redução ocorre porque a saturação de líquido ao longo do reservatório ficou maior para esse caso com ambos os modelos, como pode ser visto nas Figuras 5.32 e 5.33. Entretanto, o aumento da permeabilidade relativa de gás nas proximidades do poço com o modelo de rede trouxe uma redução na diferença da produção acumulada de gás entre os dois modelos de $8.000 \mathrm{~m}^{3}$ para $6.000 \mathrm{~m}^{3}$.

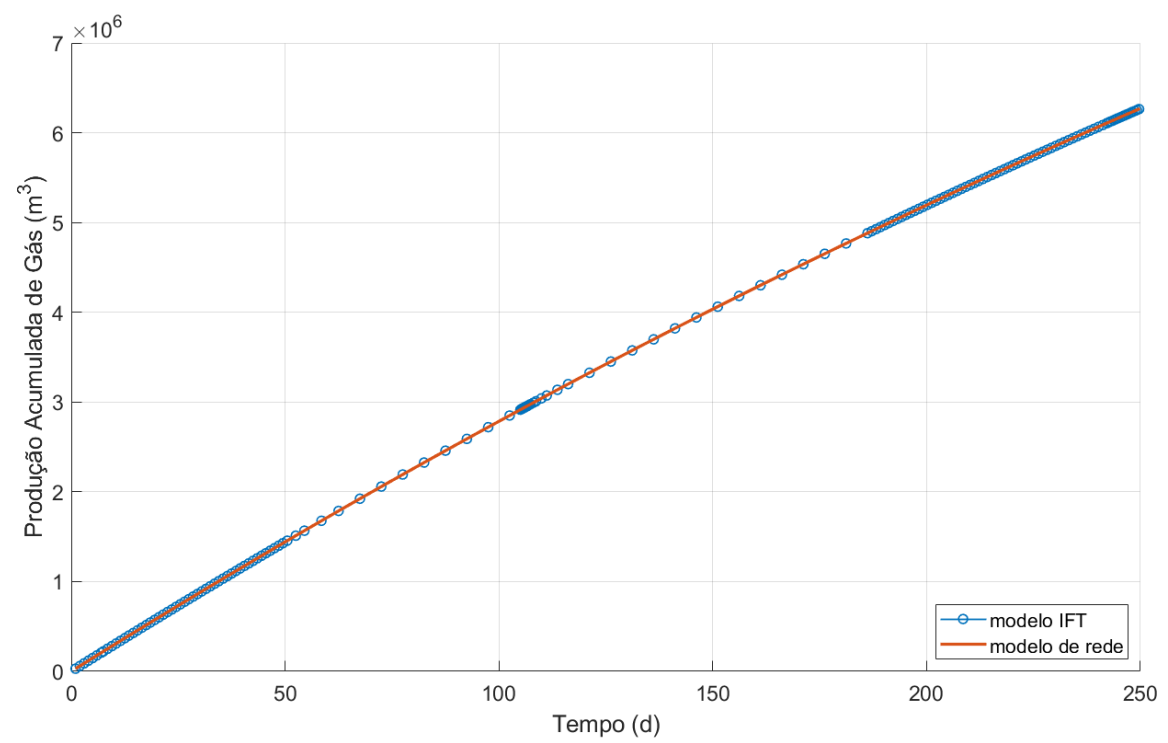

Figura 5.30: Produção acumulada de gás em condições standard vindo de gás em condições de reservatório em função do tempo para $k=169 m D$ e $v=$ $200 \mathrm{~m} / d$. 


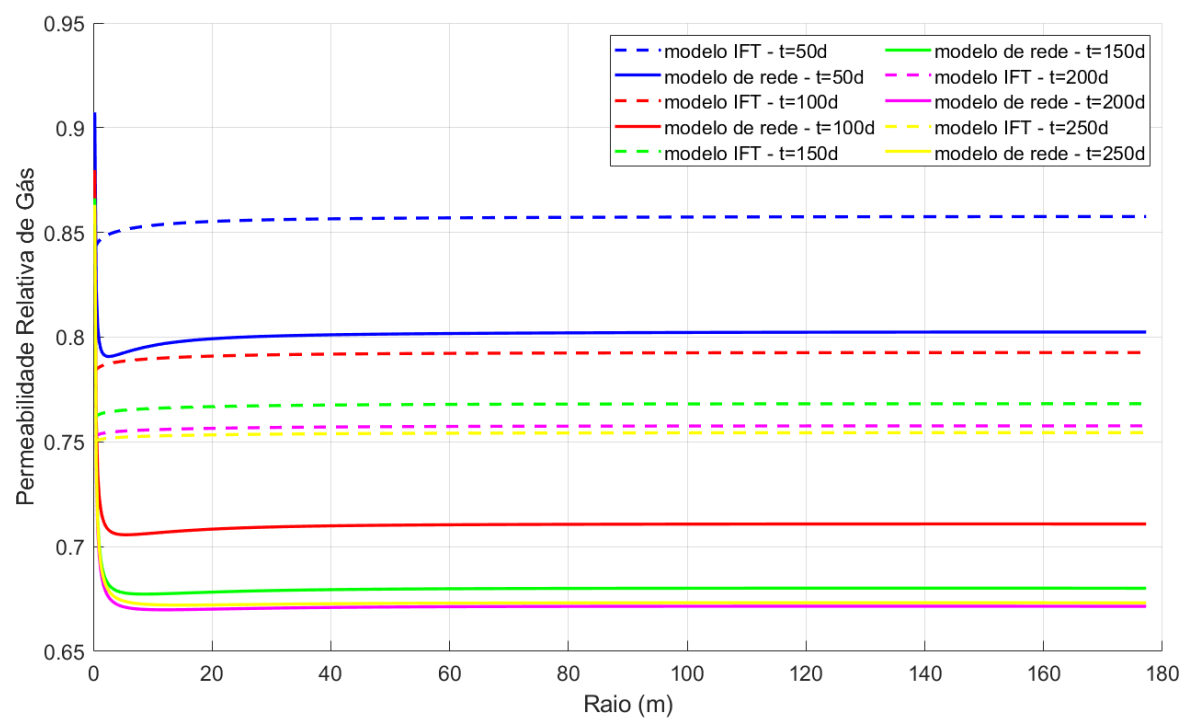

Figura 5.31: Permeabilidade relativa de gás em função do raio e do tempo para $k=169 \mathrm{~m} D$ e $v=200 \mathrm{~m} / d$.

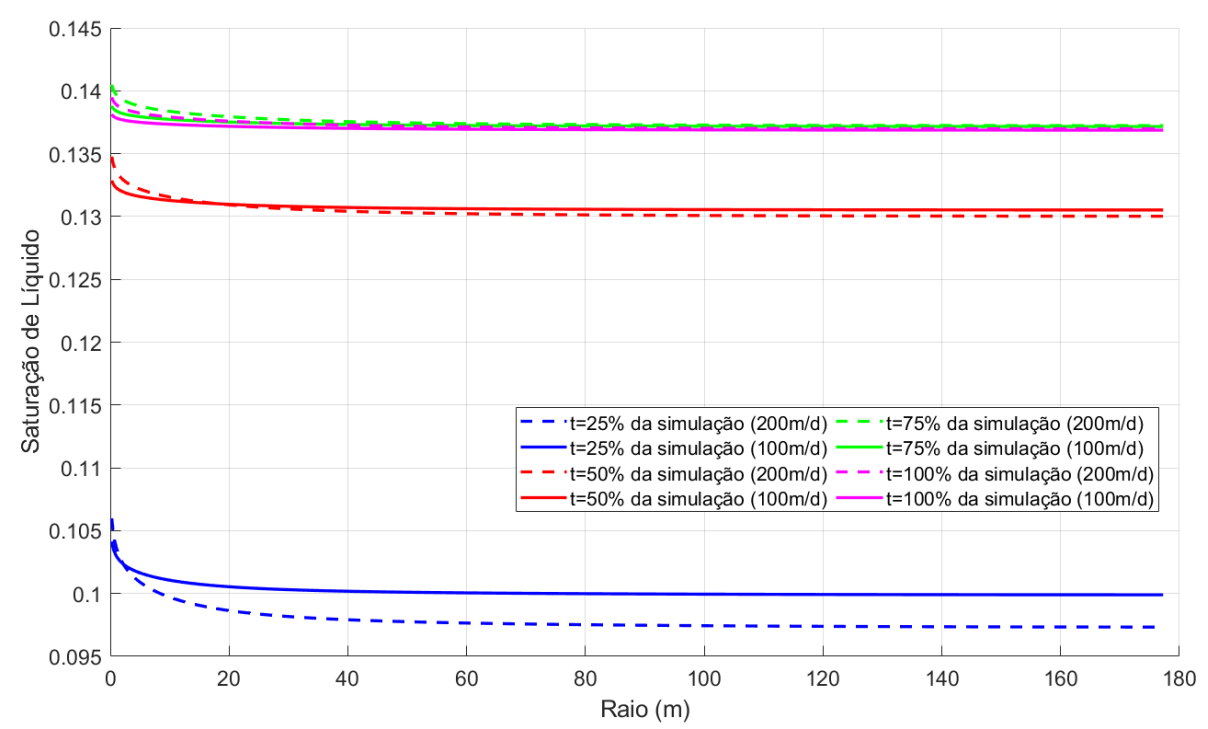

Figura 5.32: Saturação de líquido com Modelo IFT em função do raio e do tempo para $k=169 \mathrm{mD}$ e velocidades $v=100 \mathrm{~m} / d$ e $v=200 \mathrm{~m} / \mathrm{d}$. 


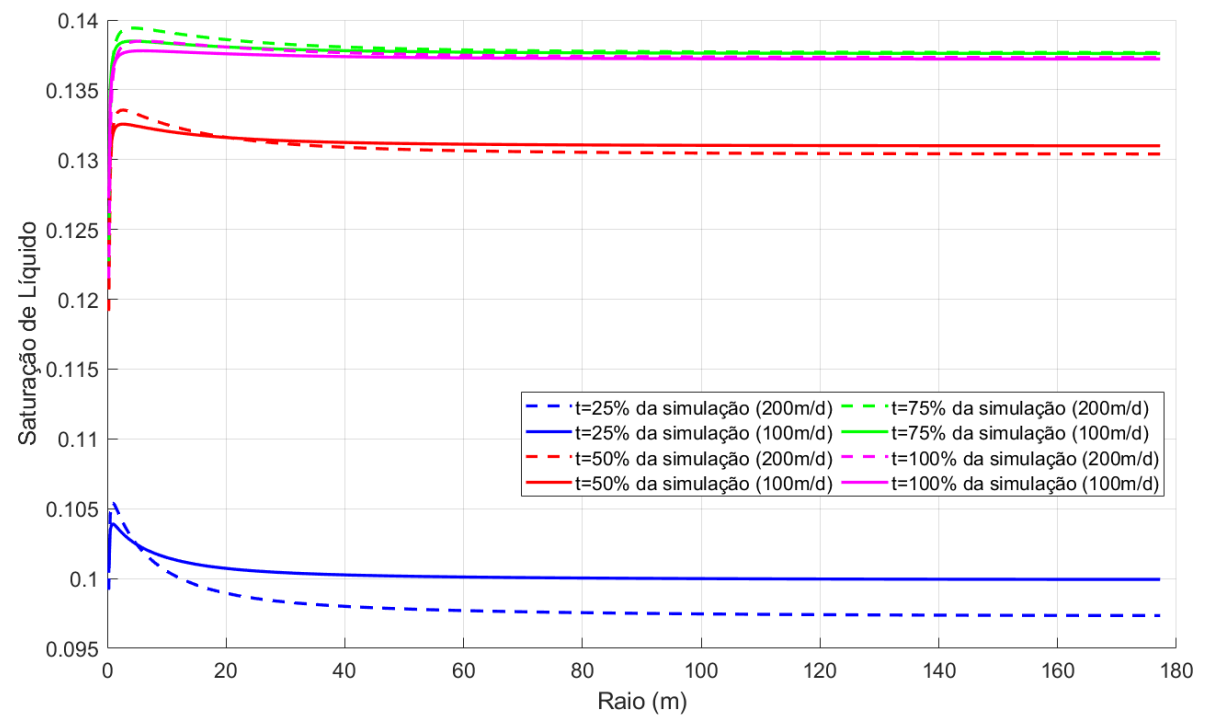

Figura 5.33: Saturação de líquido com Modelo de Rede em função do raio e do tempo para $k=169 \mathrm{mD}$ e velocidades $v=100 \mathrm{~m} / d$ e $v=200 \mathrm{~m} / d$.

Prosseguindo, na Figura 5.34, é apresentada a produção de gás oriundo de condensado em condições de reservatório. Como as permeabilidades relativas de líquido são maiores com ambos os modelos, a produção acumulada de gás oriundo de condensado é maior para os dois modelos: $83.800 \mathrm{~m}^{3}$ para o modelo IFT e $74.530 \mathrm{~m}^{3}$ para o modelo de rede. A diferença entre a produção dos dois modelos cai de $9.390 \mathrm{~m}^{3}$ para $9.270 \mathrm{~m}^{3}$, porque o modelo de rede teve um maior crescimento da permeabilidade relativa de líquido com a velocidade que o modelo IFT.

Na Figura 5.35, é apresentada a produção acumulada de condensado. Nela é possível perceber que, com o modelo IFT, produziu-se $1.316,3 \mathrm{~m}^{3} \mathrm{e}$, com o modelo de rede, produziu-se 1.307,2 $\mathrm{m}^{3}$. Vê-se que houve uma redução na diferença de produção calculada pelo dois modelos (de $13,8 \mathrm{~m}^{3}$ para $9,1 \mathrm{~m}^{3}$ ) e houve uma redução na produção de condensado de uma forma geral $\left(5,1 \mathrm{~m}^{3}\right.$ para o modelo IFT e $0,4 \mathrm{~m}^{3}$ para o modelo de rede). Para entender o motivo dessa diferença, é analisado quanto desse condensado vem de gás em condições de reservatório e quanto vem de condensado em condições de reservatório. 


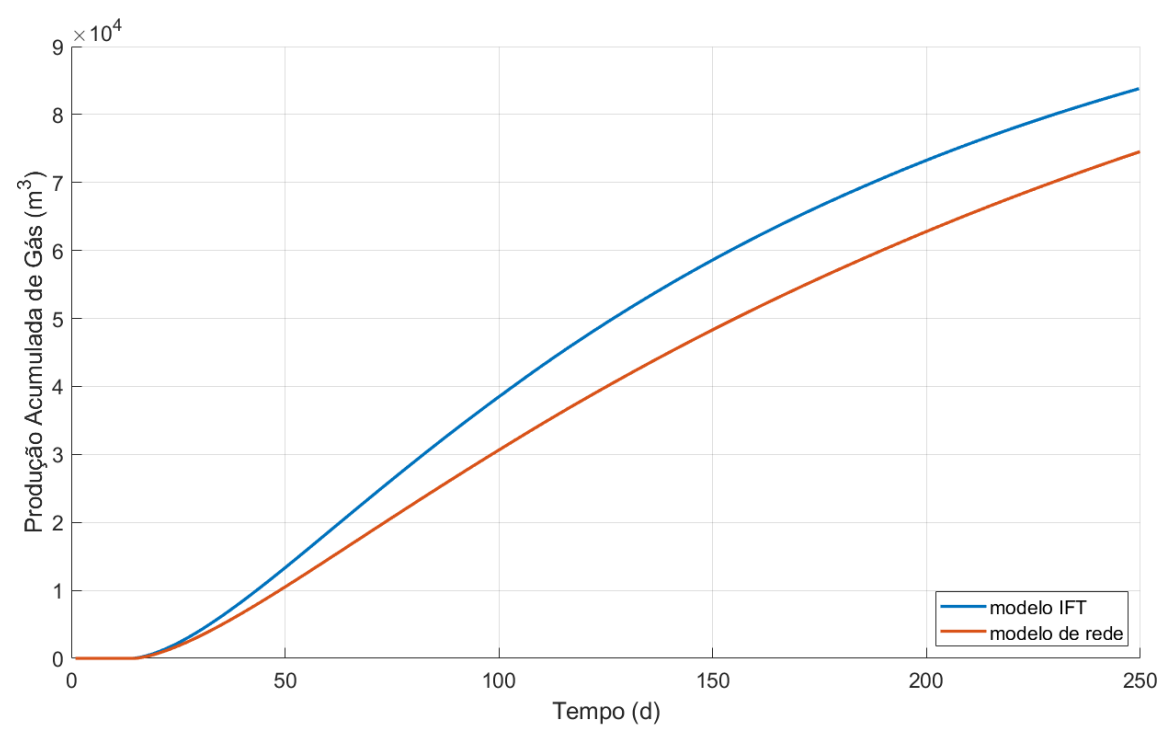

Figura 5.34: Produção acumulada de gás em condições standard vindo de condensado em condições de reservatório em função do tempo para $k=169 \mathrm{mD}$ e $v=200 \mathrm{~m} / d$.

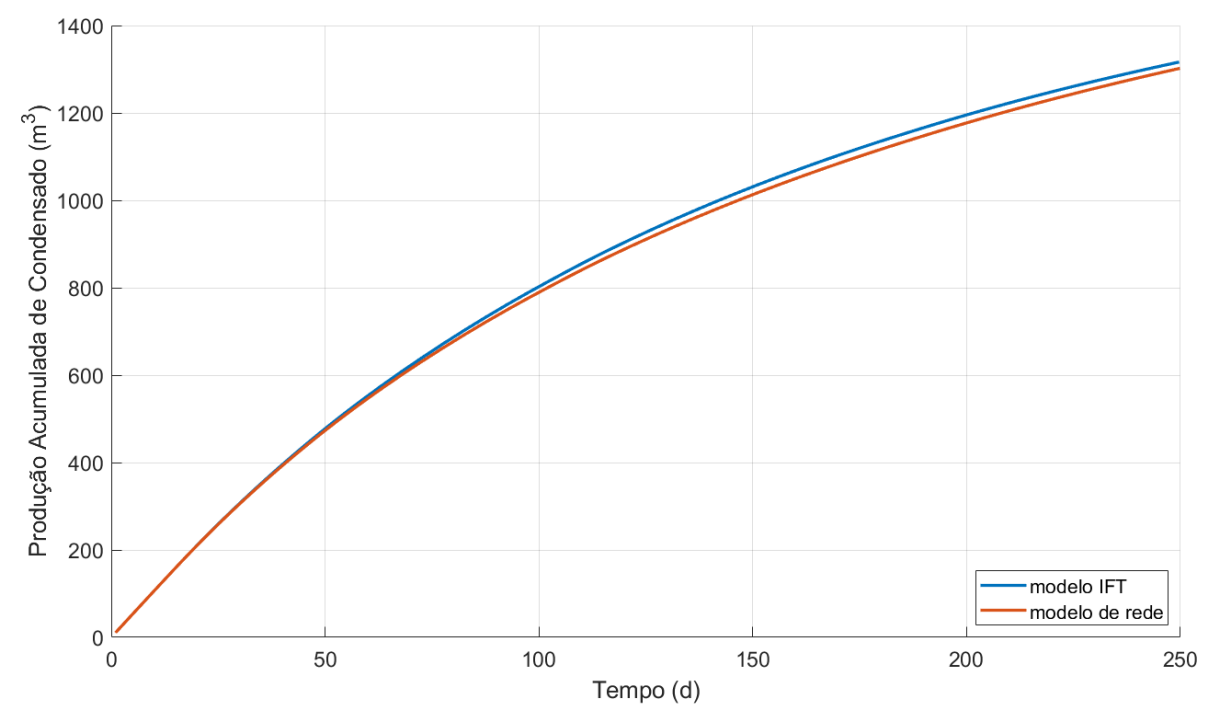

Figura 5.35: Produção acumulada de condensado em condições standard em função do tempo para $k=169 \mathrm{mD}$ e $v=200 \mathrm{~m} / d$.

Pode-se ver na Figura 5.36 que a produção acumulada de condensado originado de gás em condições de reservatório foi menor para os dois modelos: $1.139 \mathrm{~m}^{3}$ para o modelo de rede e $1.138 \mathrm{~m}^{3}$ para o modelo IFT. A produção de gás, de uma forma geral, decresceu porque a permeabilidade relativa de gás decresceu com ambos os modelos, exceto com o modelo de rede nas proximidades do poço. 


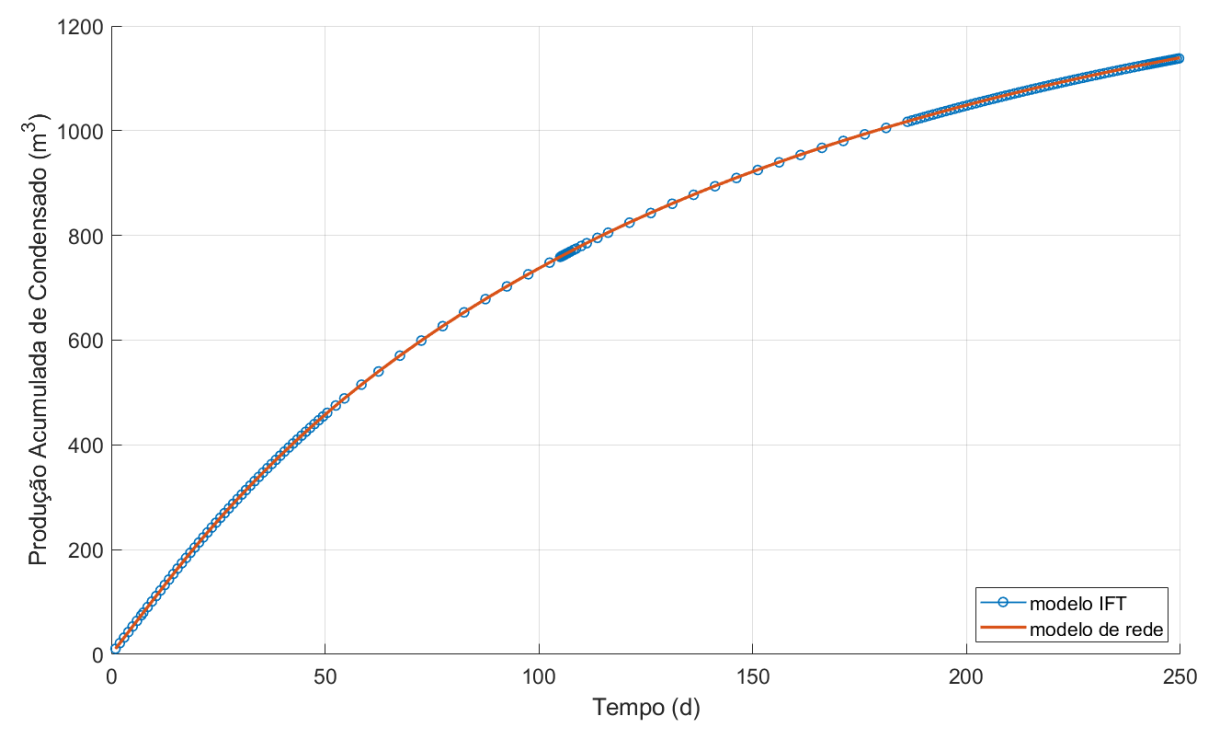

Figura 5.36: Produção acumulada de condensado em condições standard vindo de gás em condições de reservatório em função do tempo para $k=169 \mathrm{mD}$ e $v=200 \mathrm{~m} / d$.

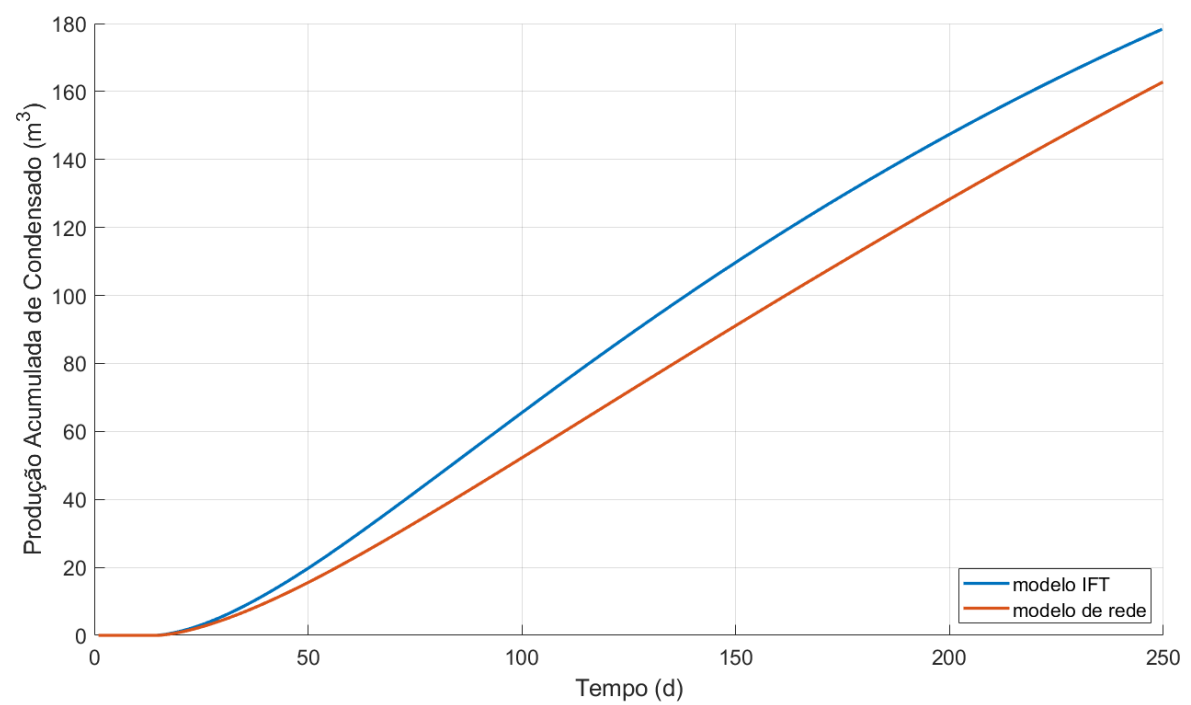

Figura 5.37: Produção acumulada de condensado em condições standard vindo de condensado em condições de reservatório em função do tempo para $k=$ $169 m D$ e $v=200 m / d$.

Prosseguindo, na Figura 5.37, encontra-se a produção acumulada de condensado originado de condensado. Essa produção foi maior do que a obtida com velocidade igual a $100 \mathrm{~m} / \mathrm{d}$ : 178,3 $\mathrm{m}^{3}$ para o modelo IFT e 168,2 $\mathrm{m}^{3}$ para o modelo de rede. Esse aumento ocorre porque a permeabilidade relativa de líquido nas proximidades do poço é maior para os dois modelos com a 
velocidade igual a $200 \mathrm{~m} / \mathrm{d}$. Além disso, a diferença entre os modelos cai de $15,8 \mathrm{~m}^{3}$ para $10,1 \mathrm{~m}^{3}$ justamente porque a permeabilidade de líquido cresce mais com o modelo de rede do que com o modelo IFT.

Mais uma vez, de uma forma geral, com a permeabilidade relativamente alta (169 mD), mesmo com uma velocidade maior, não houve diferença significativa entre o uso dos dois modelos de permeabilidade relativa dentro do intervalo de pressão avaliado. Além disso, é possível perceber que mesmo usando um modelo que leva em consideração o efeito positivo da velocidade, ao aumentar de $100 \mathrm{~m} / \mathrm{d}$ para $200 \mathrm{~m} / \mathrm{d}$, houve uma redução na produção. Isso ocorre provavelmente porque a pressão cai mais ao longo do reservatório gerando mais líquido.

\subsection{3}

\section{Resultados obtidos com $k=5 m D$ e $v=100 m / d$}

A seguir, é apresentada a análise dos resultados da simulação com permeabilidade absoluta de $5 \mathrm{mD}$ e com velocidade de $100 \mathrm{~m} / \mathrm{d}$. Na Figura 5.38, é possível ver que, com a permeabilidade absoluta reduzida, os modelos iniciam a formação de condensado desde o começo da simulação e o condensado atinge o fim do reservatório em 34 dias. Isso acontece porque, com a permeabilidade absoluta consideravelmente reduzida, a queda de pressão nas vizinhanças do poço se torna muito mais significativa. Além disso, a perturbação de pressão do poço demora mais a chegar no fim do reservatório e, por isso, a prolongação do banco de condensado até o final do reservatório é mais demorada. Continuam não sendo observadas diferenças significativas entre os modelos IFT e o de rede.

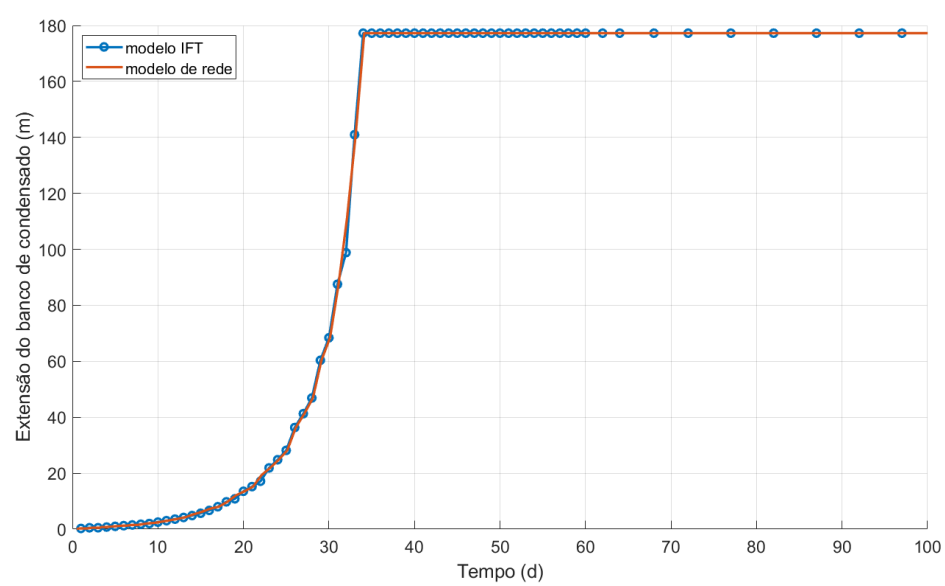

Figura 5.38: Extensão do banco de condensado em função do tempo para $k=$ $5 m D$ e $v=100 m / d$. 
Na Figura 5.39, é possível ver um comportamento similar ao observado anteriormente nas curvas de saturação de líquido calculadas com os dois modelos. Entretanto, uma diferença visível é que tanto o crescimento quanto a redução estão muito mais acentuados com o modelo de rede que com o modelo IFT. Isso ocorre porque o crescimento da permeabilidade relativa de líquido com a saturação de líquido é diferente entre os dois modelos, como pode ser visto na Figura 5.40. Nela, observa-se que, na faixa de saturação analisada $\left(S_{l i q}<30 \%\right)$ e durante maior parte da simulação, a permeabilidade relativa de líquido é maior com o modelo IFT do que com o modelo de rede, o que explica o maior acúmulo de condensado com o modelo de rede.

Além disso, de uma forma geral, com a redução da permeabilidade absoluta, era esperado que a saturação de líquido aumentasse nas proximidades do poço para ambos os modelos, já que, com a vazão constante, há um gradiente de pressão maior nas proximidades do poço, e isso também pode ser visto na Figura 5.39. A saturação de líquido perto do poço com o modelo IFT foi de 0,1786 e com o modelo de rede foi de 0,1856 no final do período analisado.

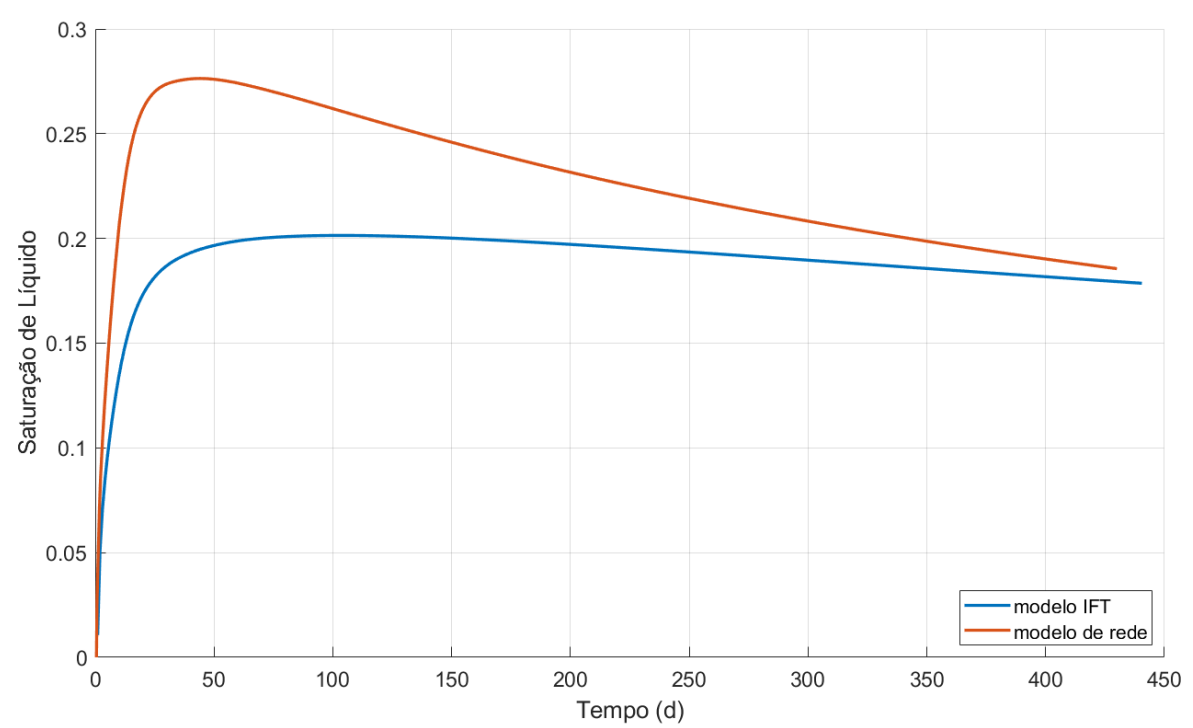

Figura 5.39: Saturação de líquido em função do tempo para $k=5 m D$ e $v=$ $100 \mathrm{~m} / \mathrm{d}$. 


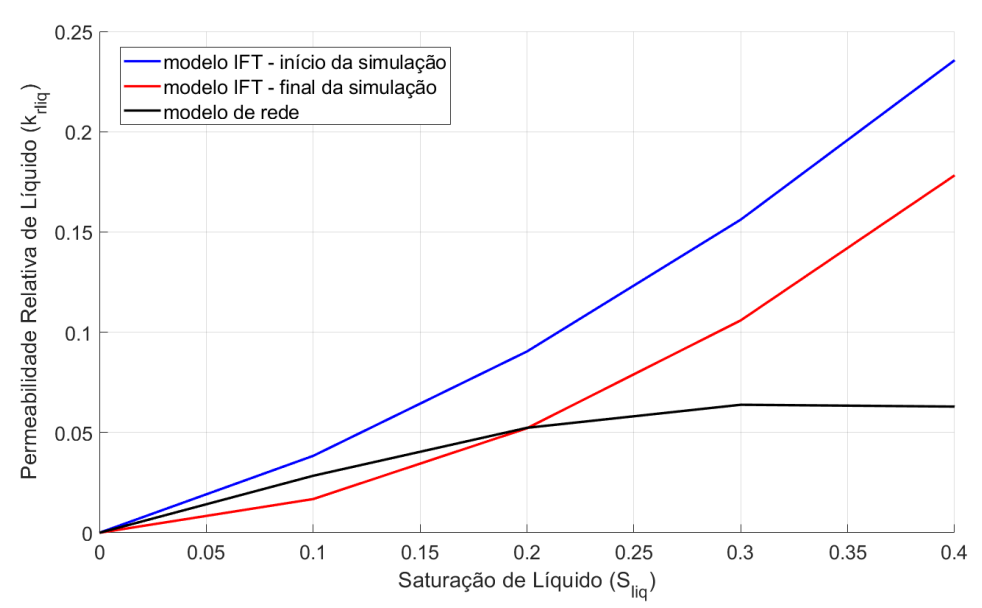

Figura 5.40: Curvas de permeabilidade relativa de líquido com os dois modelos para $v=100 \mathrm{~m} / \mathrm{d}$.

Na Figura 5.41, é possível ver também um comportamento similar ao observado anteriormente, nas curvas de permeabilidade relativa de líquido perto do poço, em função do tempo, calculadas com os dois modelos. Apesar disso, o modelo de rede apresenta um decrescimento mais acentuado do que antes e isso ocorre por causa da redução mais acentuada na saturação de líquido vista anteriormente. Um outro ponto a ser observado é o aumento na permeabilidade relativa de líquido com o modelo IFT ( $r_{\text {well }}: 0,02865 @ 169 \mathrm{mD}$ $\rightarrow 0,0441 @ 5 \mathrm{mD})$ e com o modelo de rede $\left(r_{\text {well }}: 0,03504 @ 169 \mathrm{mD} \rightarrow 0,04656\right.$ @ $5 \mathrm{mD})$, consequência direta do aumento da saturação de líquido.

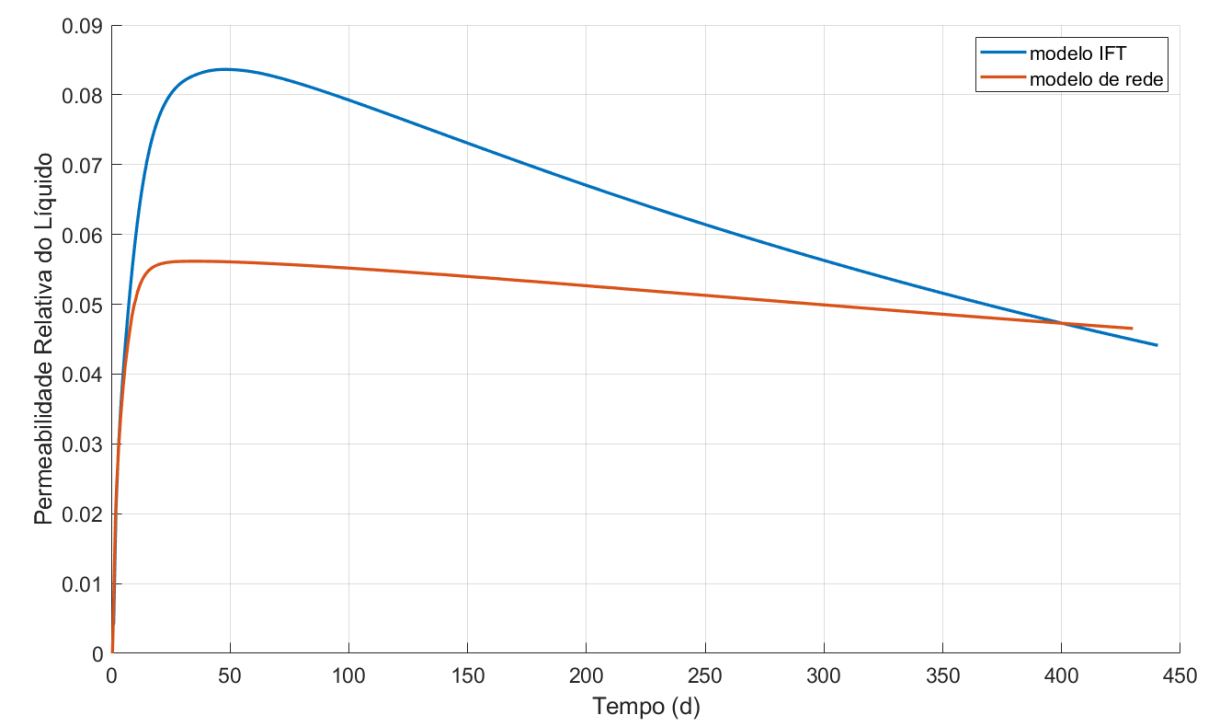

Figura 5.41: Permeabilidade relativa do líquido em função do tempo para $k=$ $5 m D$ e $v=100 m / d$. 
A redução na permeabilidade absoluta trouxe também uma redução na permeabilidade relativa de gás calculada pelo modelo IFT $\left(r_{\text {well }}: 0,7524\right.$ $@ 169 \mathrm{mD} \rightarrow 0,6869 @ 5 \mathrm{mD})$ e pelo modelo de rede $\left(r_{\text {well }}: 0,7759 @ 129 \mathrm{mD} \rightarrow\right.$ 0,6304) como pode ser visto na Figura 5.42. Nela, também é possível perceber um comportamento distinto com o modelo de rede: a curva é decrescente, atinge um ponto de mínimo e cresce. Isso é um reflexo do aumento da velocidade e do aumento rápido da saturação de líquido seguido de decrescimento lento que já foi previamente discutido. Observa-se também, na Figura 5.42, que a permeabilidade relativa de gás calculada com o modelo de rede é menor que a calculada com o modelo IFT, inclusive nas vizinhanças do poço, diferente do caso com permeabilidade absoluta $169 \mathrm{mD}$. Logo, com esse valor de permeabilidade absoluta, o efeito positivo da velocidade não levou a valores superiores de permeabilidade relativa de gás.

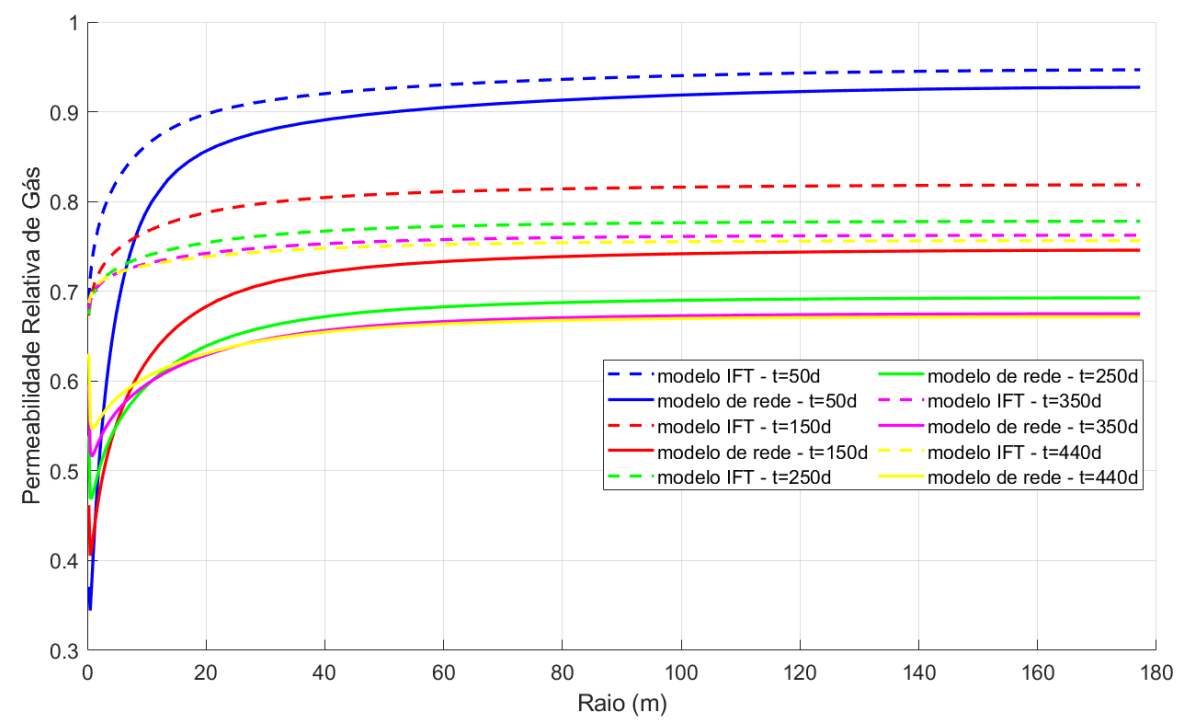

Figura 5.42: Permeabilidade do gás em função do tempo para $k=5 m D$ e $v=$ $100 \mathrm{~m} / \mathrm{d}$.

Na Figura 5.43, é apresentada a produção acumulada de gás em condições standard em função do tempo. Nesse caso, a produção com o modelo IFT foi 5.575.000 $\mathrm{m}^{3}$ e com o modelo de rede foi de $5.417 .300 \mathrm{~m}^{3}$ em relação ao caso de maior permeabilidade. Assim, a diferença entre os dois modelos aumentou de $1.390 \mathrm{~m}^{3}$ para $157.700 \mathrm{~m}^{3}$ sendo superior com o modelo IFT. Logo, a redução na permeabilidade absoluta evidenciou mais a diferença entre a produção acumulada de gás calculada com os dois modelos. Além disso, ela trouxe uma grande redução na produção de ambos os modelos, aproximadamente $790.000 \mathrm{~m}^{3}$ a menos do que o caso com permeabilidade absoluta de $169 \mathrm{mD}$. Para entender o motivo dessa diferença entre os dois modelos, mais uma vez, é 
analisado quanto desse gás vem de gás em condições de reservatório e quanto vem de condensado em condições de reservatório.

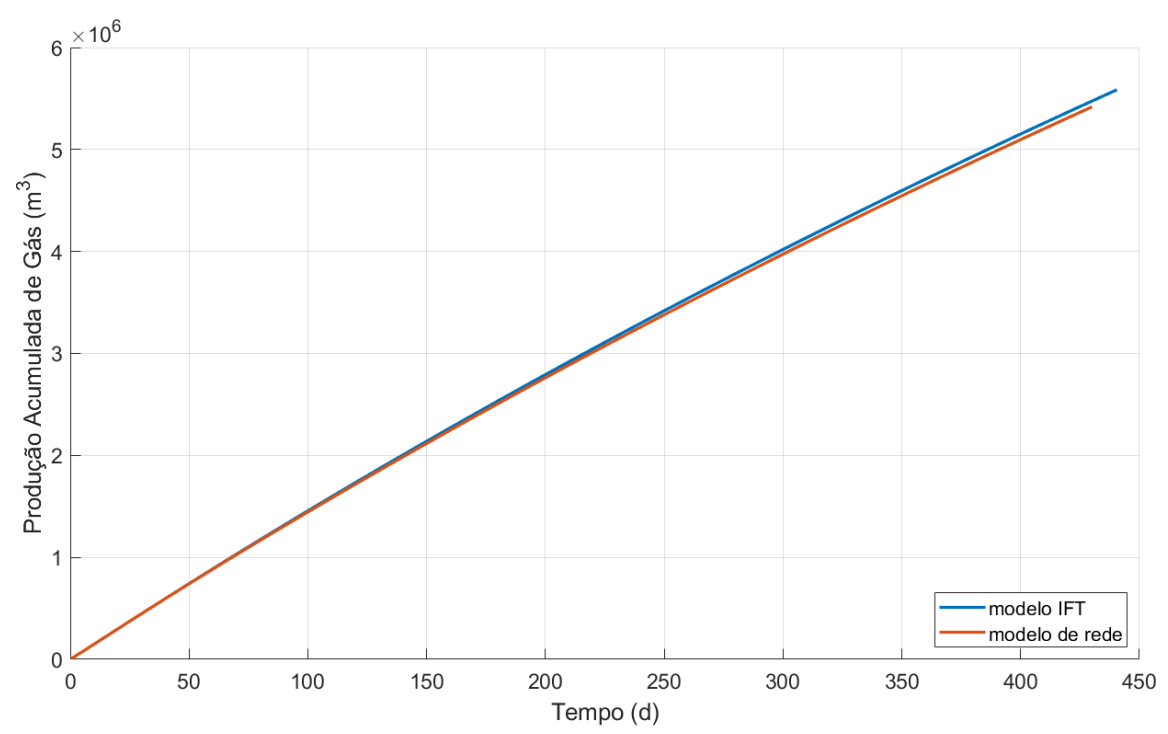

Figura 5.43: Produção acumulada de gás em condições standard em função do tempo para $k=5 m D$ e $v=100 m / d$.

Na Figura 5.44, é apresentada a produção acumulada de gás oriundo de gás em condições de reservatório. Com a redução na permeabilidade relativa de gás para ambos os modelos, houve uma redução da produção de gás oriundo de gás: com o modelo IFT a produção foi de 5,402 × $10^{6} \mathrm{~m}^{3}$ e com o modelo de rede a produção foi de $5,234 \times 10^{6} \mathrm{~m}^{3}$. Uma diferença clara é que, neste caso, o modelo IFT produz mais, diferentemente do caso com permeabilidade absoluta $169 \mathrm{mD}$. Isso ocorre justamente porque a permeabilidade relativa de gás com o modelo de rede é menor que a calculada com o modelo IFT em todo o reservatório, como foi visto anteriormente.

Outro ponto que merece destaque é que a diferença entre a previsão da produção de gás em condições standard dos dois modelos aumentou bastante: de $8.000 \mathrm{~m}^{3}$ a mais com o modelo de rede para $168.000 \mathrm{~m}^{3}$ a mais com o modelo IFT, justamente porque o bloqueio por condensado é bem mais acentuado com o modelo de rede. Esses resultados indicam que, para campos com permeabilidade absoluta reduzida, a escolha de modelos de curvas de permeabilidade relativa de IFT pode afetar significativamente as estimativas de produção. 


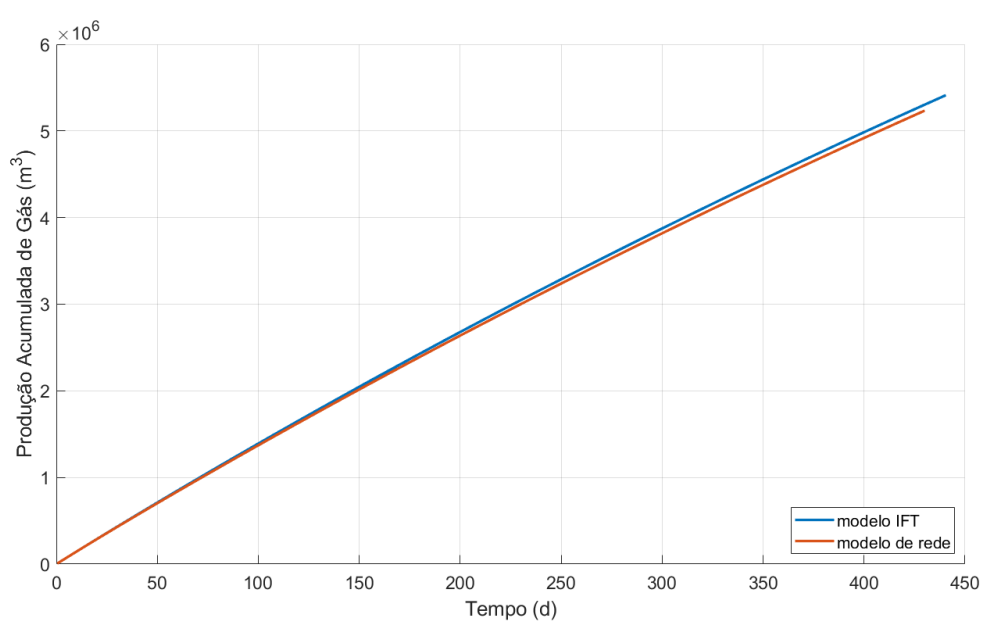

Figura 5.44: Produção acumulada de gás em condições standard vindo de gás em condições de reservatório em função do tempo para $k=5 \mathrm{mD}$ e $v=100 \mathrm{~m} / \mathrm{d}$.

Prosseguindo, na Figura 5.45, é apresentada a produção de gás oriundo de condensado em condições de reservatório. Como as permeabilidades relativas de líquido são maiores com ambos os modelos, a produção de acumulada de gás oriundo de condensado é também maior para os dois modelos: $173.000 \mathrm{~m}^{3}$ para o modelo IFT e $183.300 \mathrm{~m}^{3}$ para o modelo de rede. A diferença entre a produção dos dois modelos aumenta de $9.390 \mathrm{~m}^{3}$ a mais com o modelo IFT para 10.300 $\mathrm{m}^{3}$ a mais com o modelo de rede, porque o modelo de rede apresenta uma permeabilidade relativa de líquido bem maior que a calculada com o modelo IFT em praticamente toda a simulação.

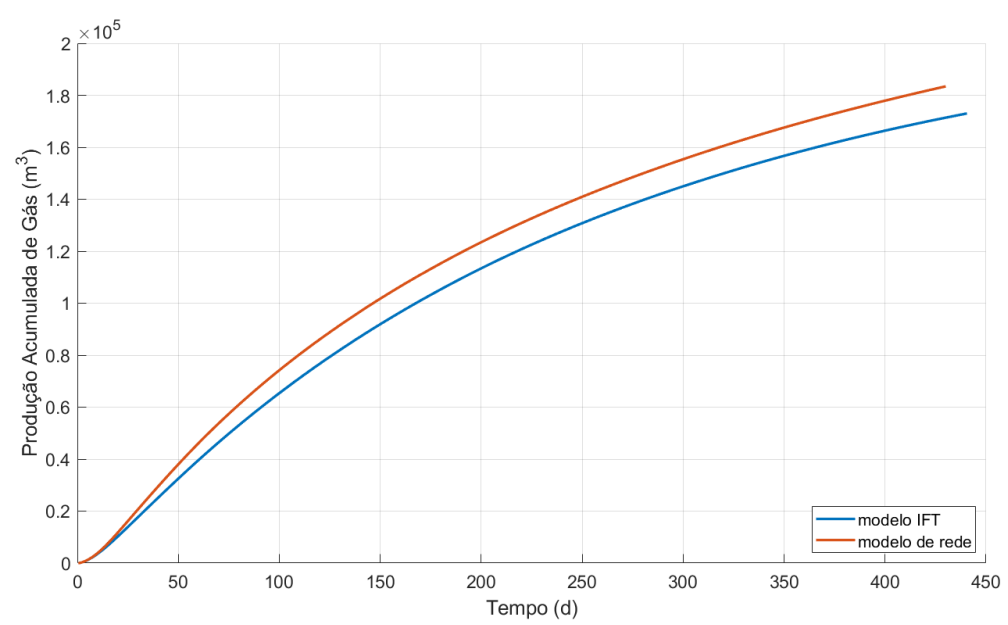

Figura 5.45: Produção acumulada de gás em condições standard vindo de condensado em condições de reservatório em função do tempo para $k=5 \mathrm{mD}$ e $v=100 \mathrm{~m} / d$. 
Na Figura 5.46, é apresentada a produção acumulada de condensado. Nela é possível perceber que, com o modelo IFT, produziu-se $1.220 \mathrm{~m}^{3} \mathrm{e}, \mathrm{com}$ o modelo de rede, produziu-se $1.181 \mathrm{~m}^{3}$. Percebe-se que houve um aumento da diferença entre os modelos de $13,8 \mathrm{~m}^{3}$ para $38 \mathrm{~m}^{3}$ para o modelo IFT. Para entender o motivo dessa diferença, é analisado o quanto desse condensado vem de gás em condições de reservatório e quanto vem de condensado em condições de reservatório.

Pode-se ver na Figura 5.47 que a produção acumulada de condensado originado de gás em condições de reservatório foi menor para ambos os modelos: $864 \mathrm{~m}^{3}$ no modelo IFT e $795 \mathrm{~m}^{3}$ no modelo de rede em 440 dias. Neste caso, o modelo IFT também acaba produzindo mais que o modelo de rede porque permeabilidade relativa de gás calculada com o modelo IFT é maior que a calculada com o modelo de rede, exceto nas proximidades do poço. Há também um aumento na diferença entre a previsão da produção dos dois modelos: de 2 $\mathrm{m}^{3}$ com o modelo de rede para $69 \mathrm{~m}^{3}$ com o modelo IFT, justamente por conta da limitação já citada no crescimento da permeabilidade relativa de líquido com a saturação de líquido para o modelo de rede.

Prosseguindo, na Figura 5.48, encontra-se a produção acumulada de condensado originado de condensado em condições de reservatório. Essa produção foi maior para ambos os modelos: $356 \mathrm{~m}^{3}$ para o modelo IFT e de $386 \mathrm{~m}^{3}$ para o modelo de rede. O aumento dessa diferença de $15,8 \mathrm{~m}^{3}$ a mais com o modelo IFT para $31 \mathrm{~m}^{3}$ a mais com o modelo de rede é reflexo da permeabilidade relativa de líquido com o modelo de rede ser bem maior praticamente durante toda a simulação.

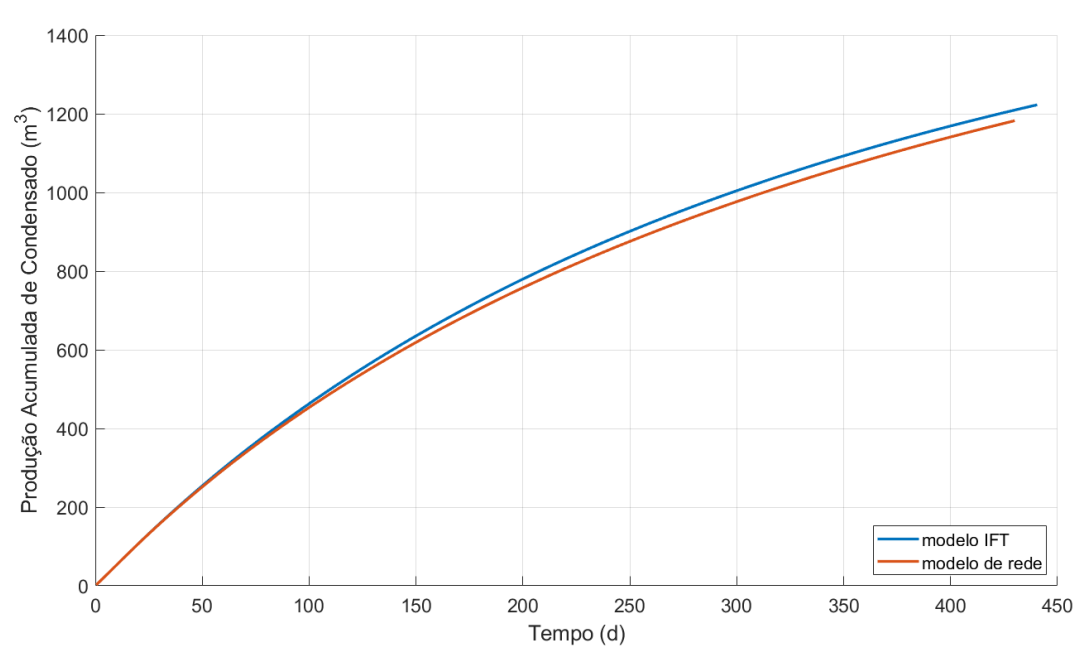

Figura 5.46: Produção acumulada de condensado em condições standard vindo de condensado em condições de reservatório em função do tempo para $k=5 \mathrm{mD}$ e $v=100 \mathrm{~m} / d$. 


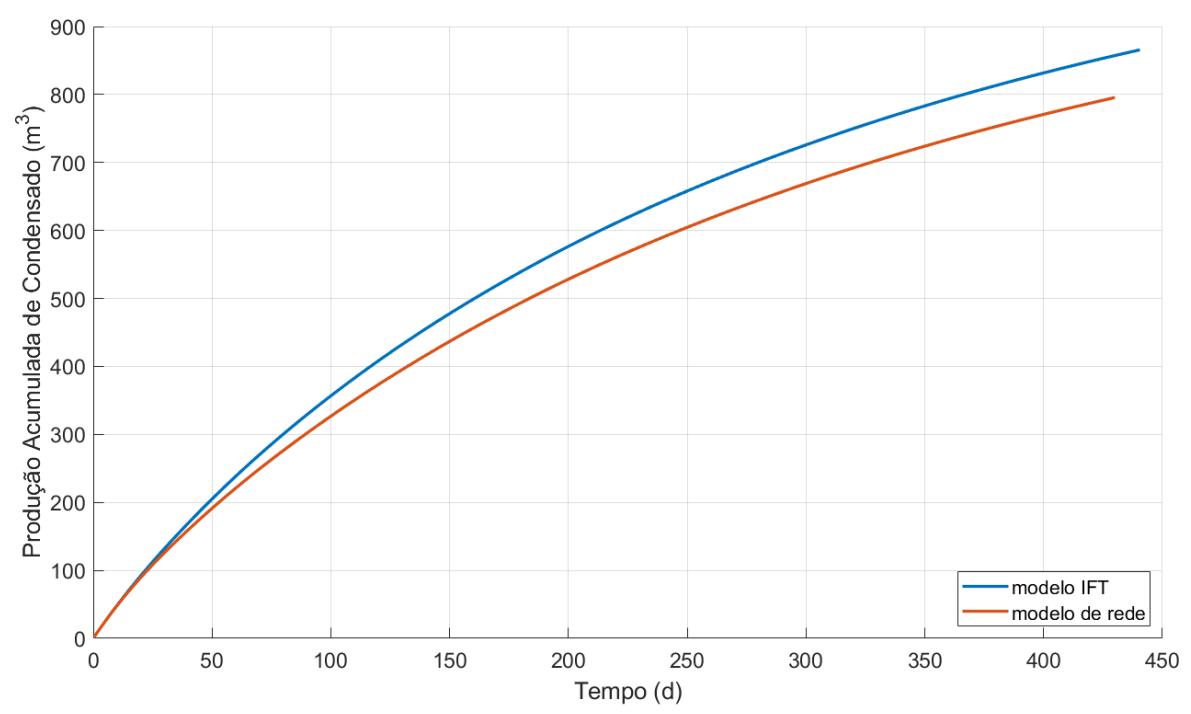

Figura 5.47: Produção acumulada de condensado em condições standard vindo de gás em condições de reservatório em função do tempo para $k=5 m D$ e $v$ $=100 \mathrm{~m} / \mathrm{d}$.

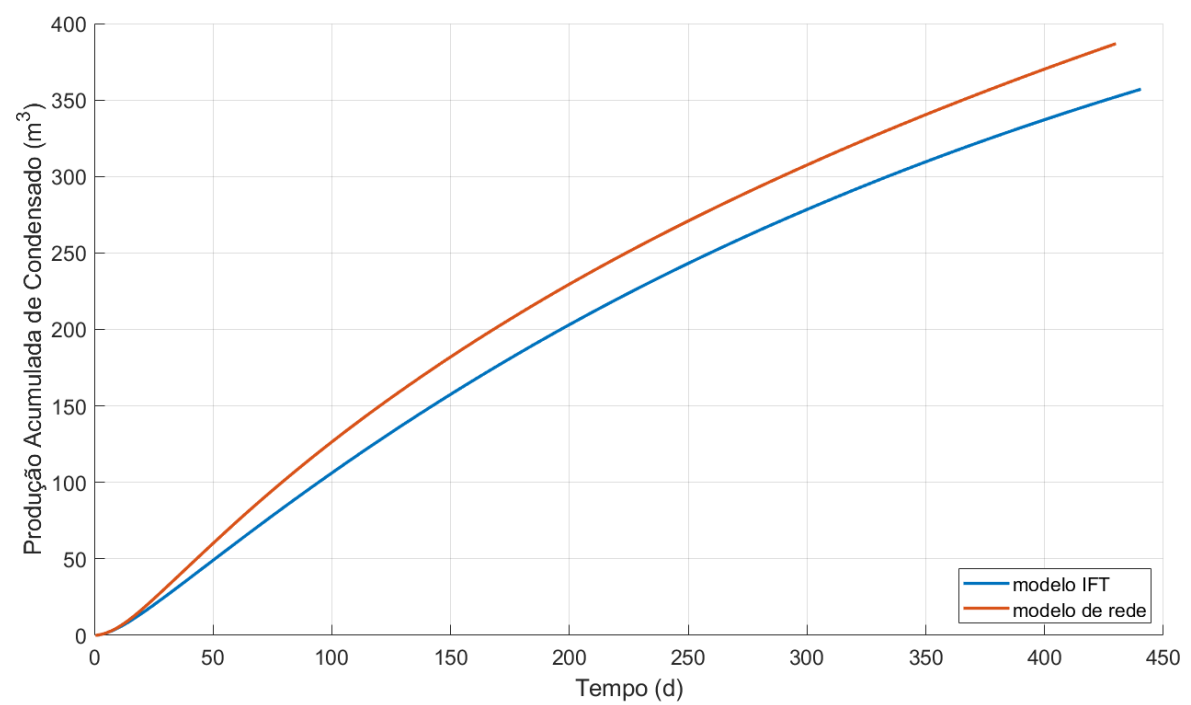

Figura 5.48: Produção acumulada de condensado em condições standard vindo de condensado em condições de reservatório em função do tempo para $k=5 \mathrm{mD}$ e $v=100 \mathrm{~m} / d$.

Portanto, é possível perceber que, com uma baixa permeabilidade absoluta do meio $(5 \mathrm{mD})$, houve diferença significativa entre o uso dos dois modelos de permeabilidade relativa dentro do intervalo de pressão avaliado. Assim, à medida que a permeabilidade absoluta é reduzida, o efeito do modelo de permeabilidade relativa fica mais significativo. 


\subsection{4}

Resultados obtidos com $k=5 m D$ e $v=200 m / d$

A seguir é apresentada a análise dos resultados da simulação com permeabilidade absoluta de $5 \mathrm{mD}$ e com a velocidade de $200 \mathrm{~m} / \mathrm{d}$. Com relação à formação do banco de condensado, o aumento na velocidade antecipou sua extensão até o final do reservatório, como pode-se ver na Figura 5.49. Com velocidade de $100 \mathrm{~m} / \mathrm{d}$, a condensação retrógrada chega ao fim do reservatório em 34 dias. Já com 200 m/d, ela chega ao fim com 20 dias. Além disso, é possível perceber uma diferença mais significativa entre o desenvolvimento do banco de condensado com os dois modelos.

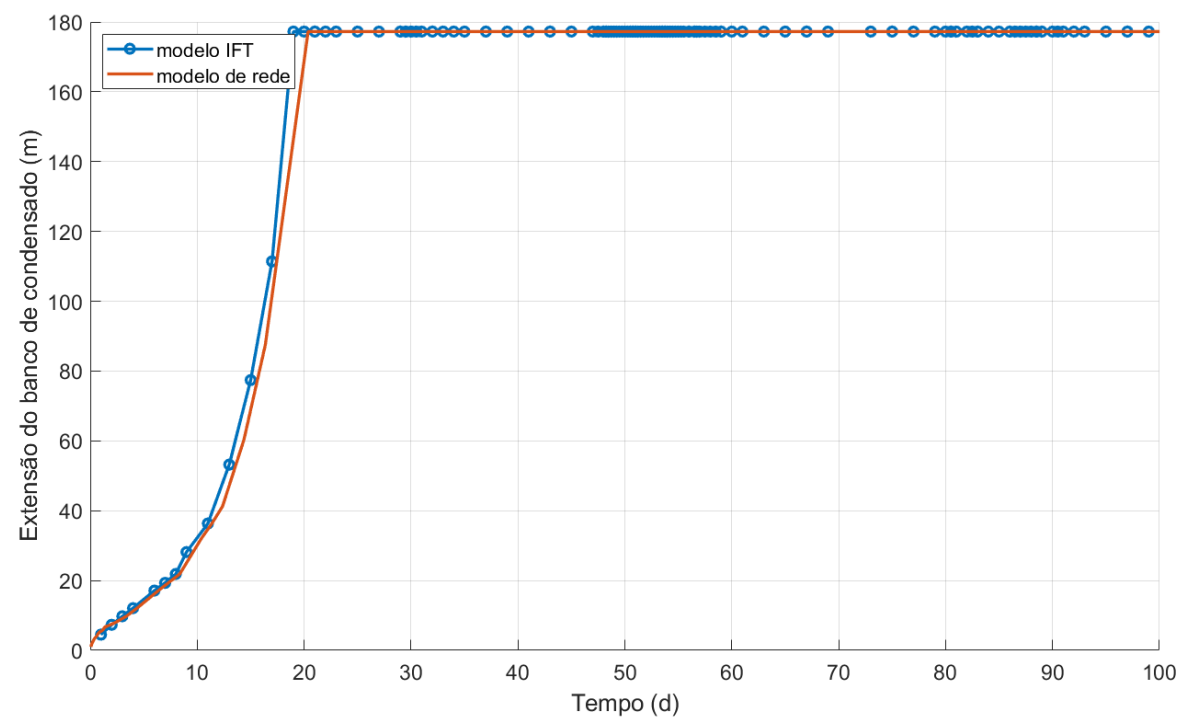

Figura 5.49: Produção acumulada de condensado em função do tempo para $k$ $=5 m D$ e $v=200 m / d$.

Nas Figuras 5.50 e 5.51, é possível observar um comportamento similar ao observado no caso anterior, com velocidade de escoamento de gás igual a $100 \mathrm{~m} /$ d. Entretanto, com a única diferença que, com uma velocidade maior, na faixa de saturação analisada $\left(S_{l i q}<40 \%\right)$ e durante a maior parte da simulação, a permeabilidade de líquido é ainda maior com o modelo IFT do que com o modelo de rede, o que explica o maior acúmulo de condensado com o modelo de rede. Esse comportamento pode ser observado na Figura 5.52. 


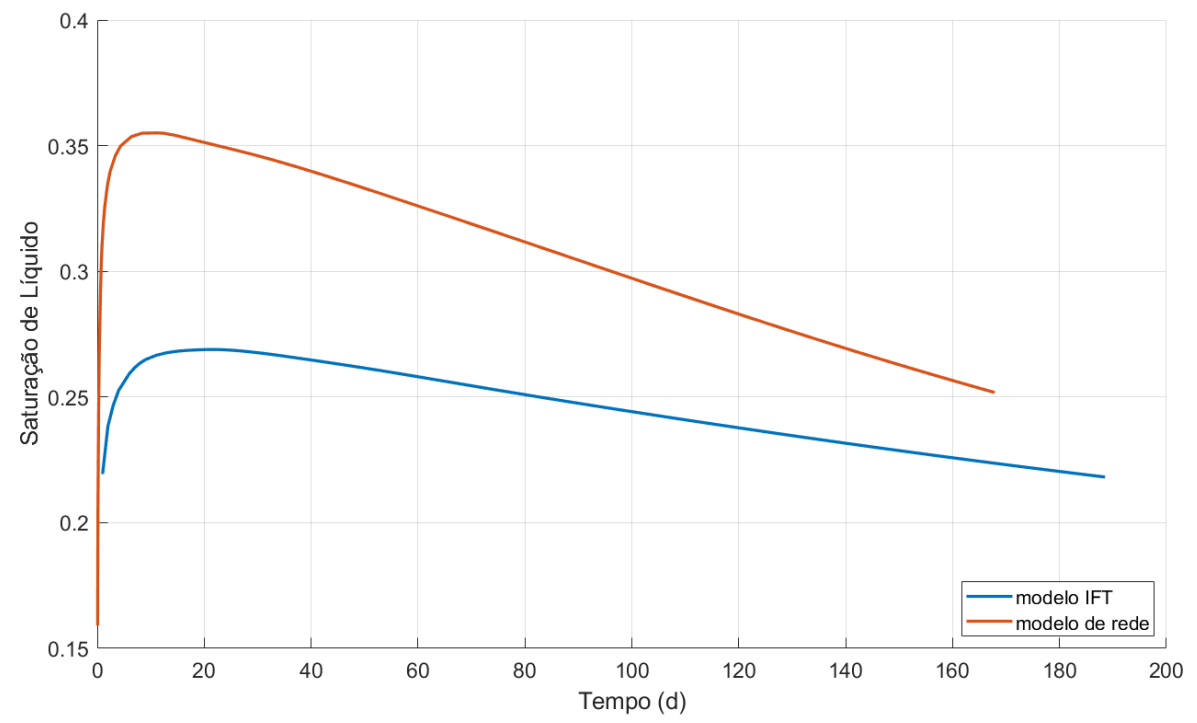

Figura 5.50: Saturação de líquido em função do tempo para $k=5 m D$ e $v=$ $200 \mathrm{~m} / d$.

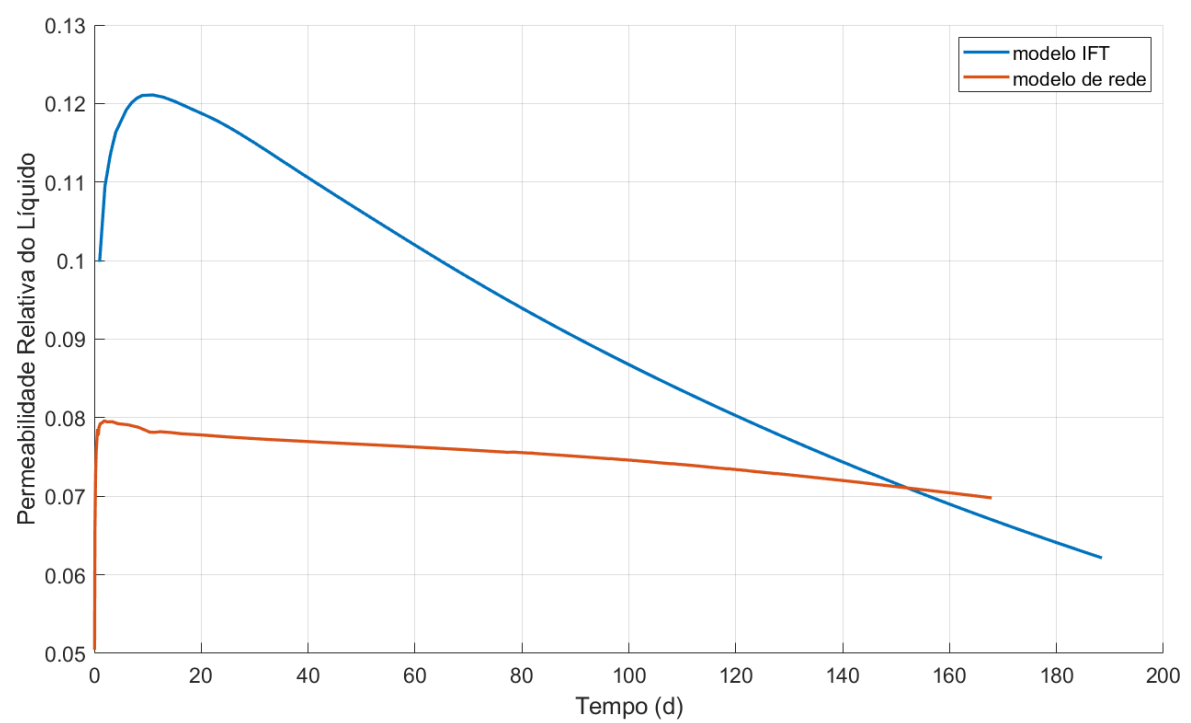

Figura 5.51: Permeabilidade relativa de líquido em função do tempo para $k=$ $5 m D$ e $v=200 m / d$. 


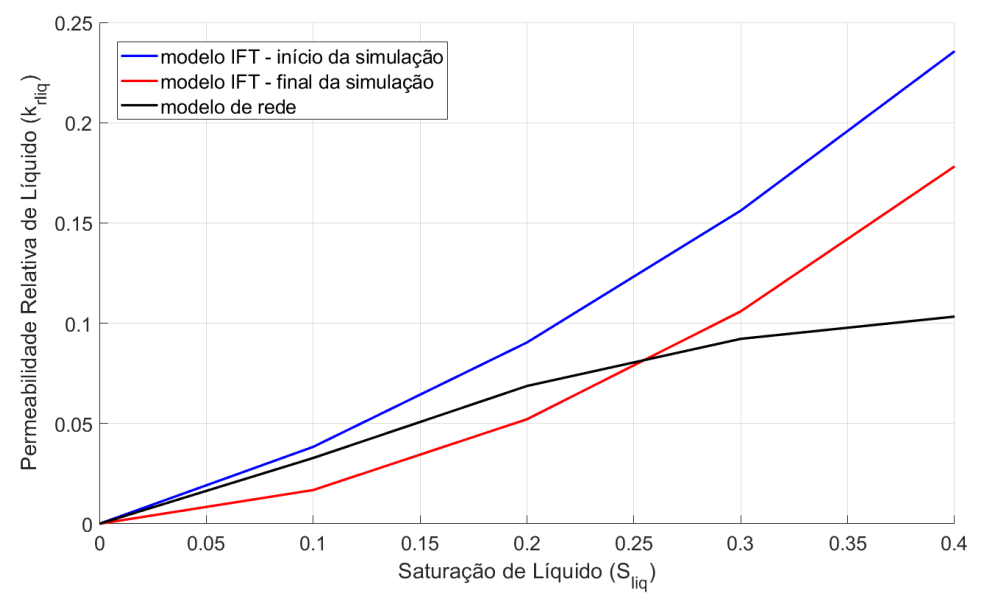

Figura 5.52: Curvas de permeabilidade relativa de líquido com os dois modelos para $v=200 \mathrm{~m} / \mathrm{d}$.

O aumento da velocidade mais uma vez trouxe uma redução na permeabilidade relativa de gás calculada pelo modelo IFT ( $r_{\text {well }}: 0,6869 @ 100 \mathrm{~m} / \mathrm{d}$ $\rightarrow$ 0,6258@200m/d) e, dessa vez, também trouxe uma redução na permeabilidade calculada pelo modelo de rede $\left(r_{\text {well }}: 0,6304 @ 100 \mathrm{~m} / \mathrm{d} \rightarrow 0,5487\right.$ @200m/d) como pode ser observado na Figura 5.53. Essa redução na permeabilidade relativa de gás calculada com o modelo de rede ocorre porque o efeito do aumento da saturação de líquido, devido a queda de pressão mais rápida, é maior que o efeito do aumento de velocidade na curva de permeabilidade relativa de gás.

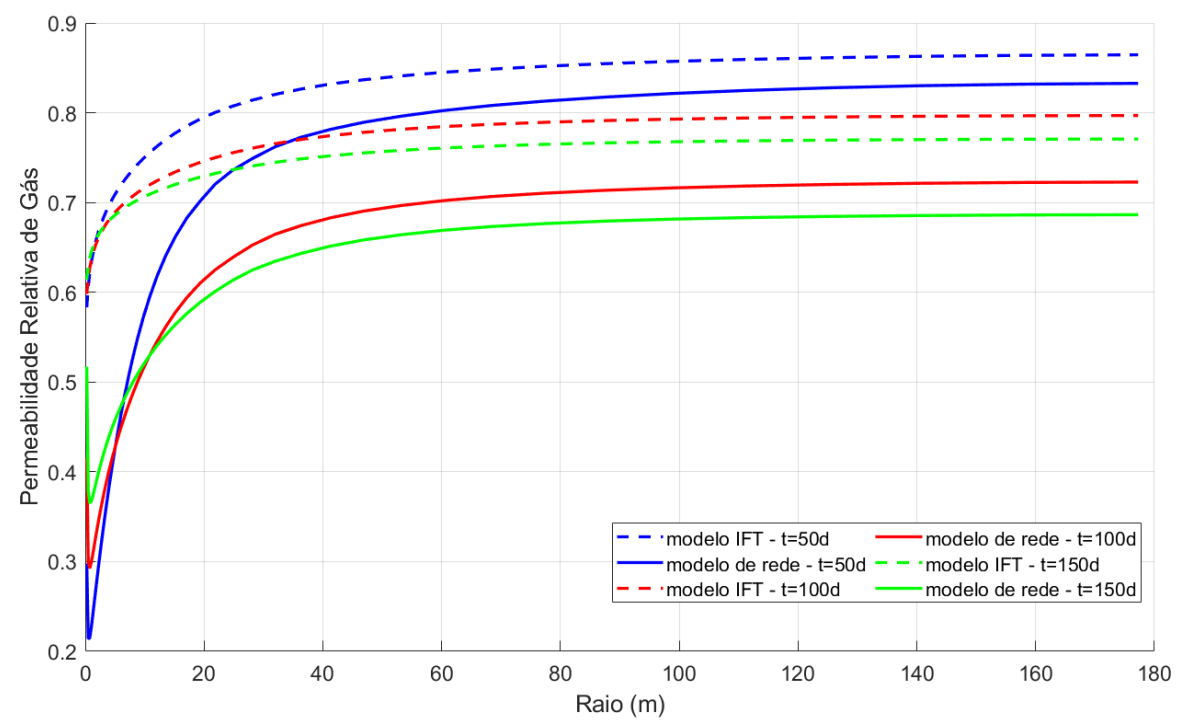

Figura 5.53: Permeabilidade relativa de gás em função do tempo para $k=$ $5 m D$ e $v=200 m / d$. 
Na Figura 5.54, é apresentada a produção acumulada de gás em condições standard em função do tempo. Nesse caso, a produção com o modelo IFT foi 4.718.400 $\mathrm{m}^{3}$ e com o modelo de rede foi de 4.050.200 $\mathrm{m}^{3}$. Assim, vê-se que a diferença de produção entre os modelos passou de $157.700 \mathrm{~m}^{3}$ para $668.200 \mathrm{~m}^{3} \mathrm{a}$ mais com o modelo IFT. Logo, o aumento na velocidade, evidenciou ainda mais a diferença entre a produção acumulada de gás calculada com os dois modelos com uma permeabilidade absoluta menor. Diferentemente dos casos anteriores, houve uma diferença significativa entre o tempo de produção dos dois modelos: a simulação com o modelo IFT atinge a pressão final com 190 dias enquanto a simulação com o modelo de rede atinge com 170 dias. Para entender melhor essas diferenças entre os dois modelos, é analisado quanto desse gás vem de gás em condições de reservatório e quanto vem de condensado em condições de reservatório.

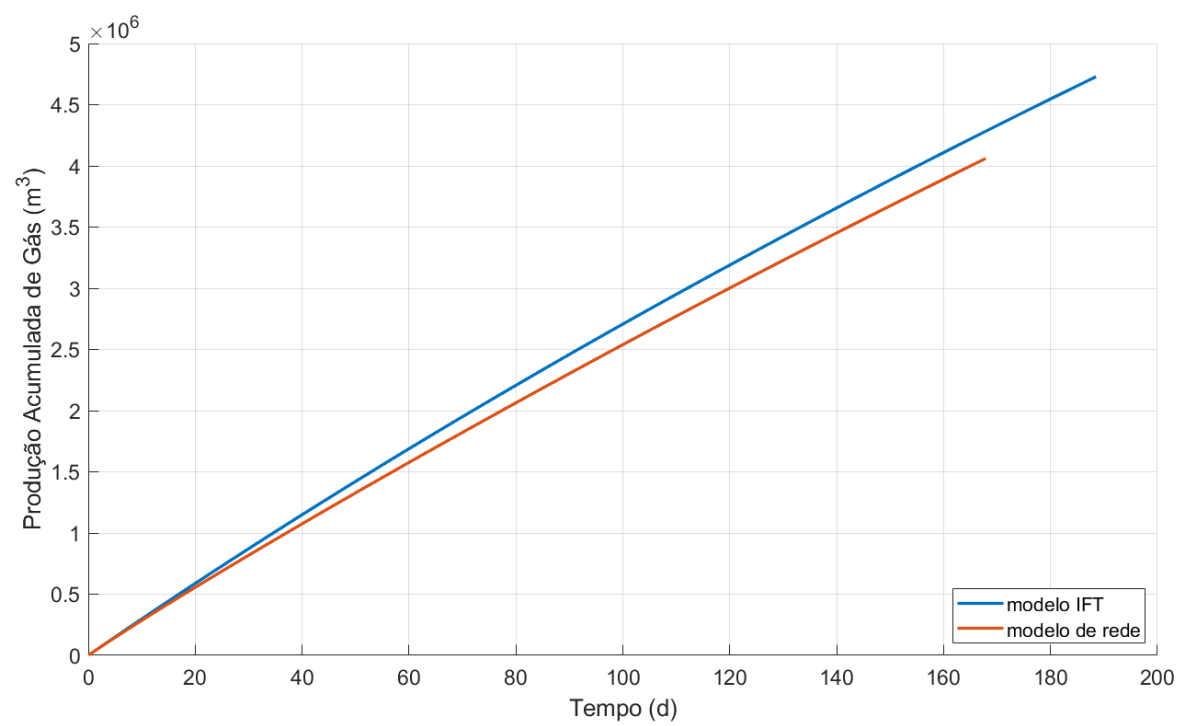

Figura 5.54: Produção acumulada de gás em condições standard em função do tempo para $k=5 m D$ e $v=200 m / d$.

Na Figura 5.55, é apresentada a produção acumulada de gás oriundo de gás em condições de reservatório. Com a redução na permeabilidade relativa de gás para ambos os modelos, houve uma redução da produção de gás oriundo de gás: com o modelo IFT a produção foi de $4,5 \times 10^{6} \mathrm{~m}^{3}$ e com o modelo de rede a produção foi de $3,822 \times 10^{6} \mathrm{~m}^{3}$. Mais uma vez, o modelo IFT produz mais que o modelo de rede. Um ponto que merece destaque é que a diferença entre a previsão da produção de gás em condições standard dos dois modelos aumentou ainda mais: de $168.000 \mathrm{~m}^{3}$ para $678.000 \mathrm{~m}^{3}$ a mais com o modelo IFT, justamente porque o bloqueio por condensado é ainda mais acentuado com o modelo de rede que no caso anterior. 


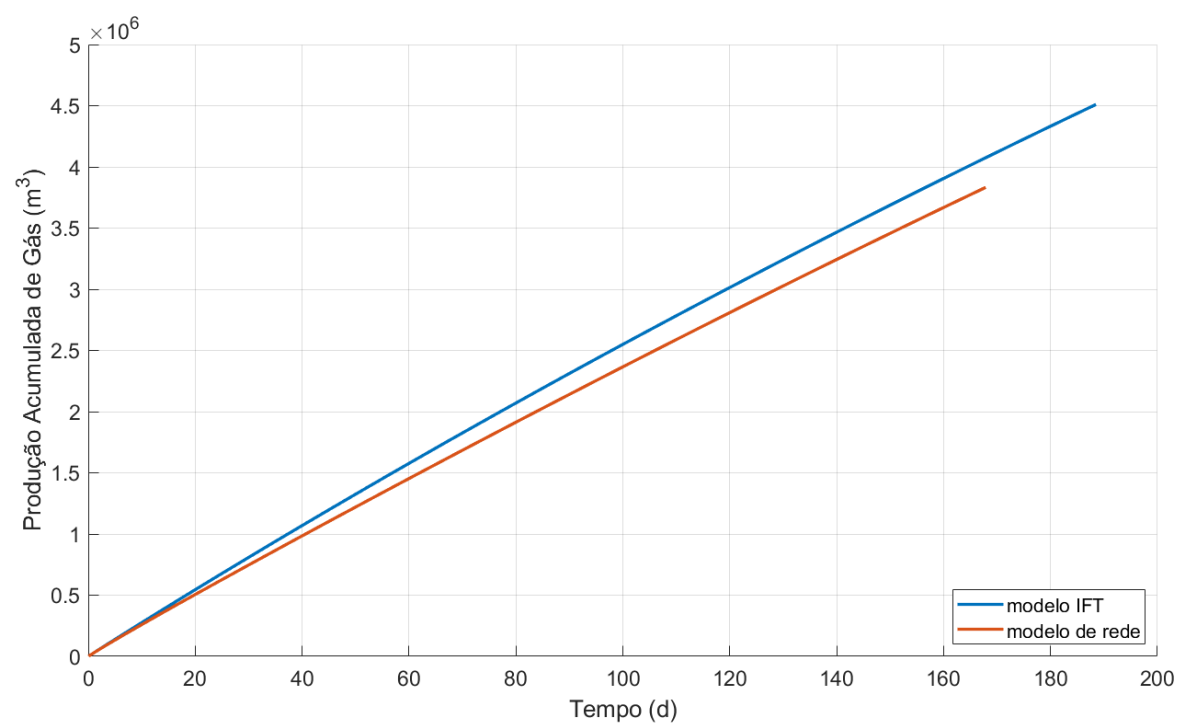

Figura 5.55: Produção acumulada de gás em condições standard vindo de gás em condições de reservatório em função do tempo para $k=5 \mathrm{mD}$ e $v=200 \mathrm{~m} / \mathrm{d}$.

Prosseguindo, na Figura 5.56, é apresentada a produção de gás oriundo de condensado em condições de reservatório. Como as permeabilidades relativas de líquido são maiores com ambos os modelos, a produção de acumulada de gás oriundo de condensado é também maior para os dois modelos: $218.400 \mathrm{~m}^{3}$ para o modelo IFT e $228.200 \mathrm{~m}^{3}$ para o modelo de rede. A diferença entre a produção dos dois modelos reduz de $10.300 \mathrm{~m}^{3}$ para $9.800 \mathrm{~m}^{3}$ a mais com o modelo de rede, porque o modelo de rede teve um maior crescimento da permeabilidade relativa de líquido com velocidade que o modelo IFT.

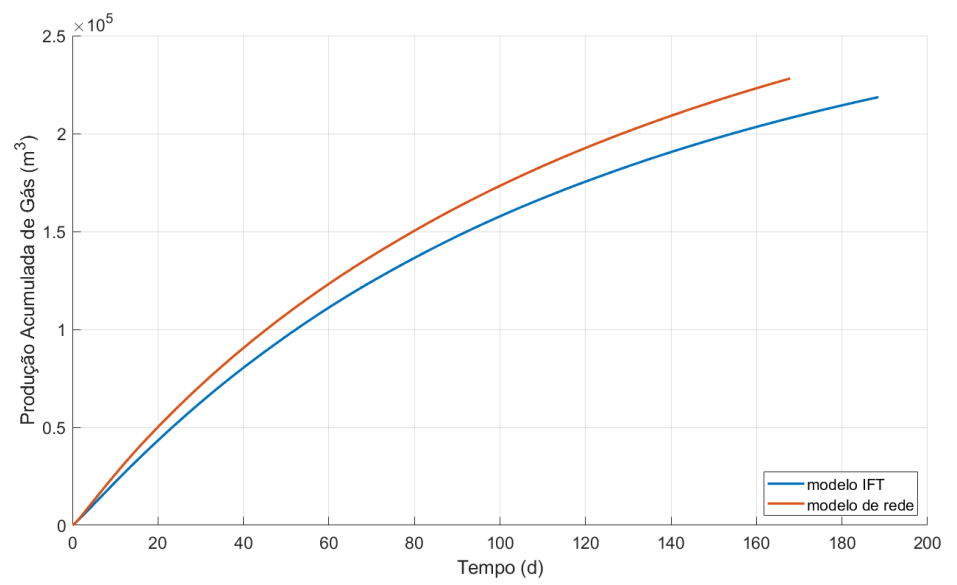

Figura 5.56: Produção acumulada de gás em condições standard vindo de condensado em condições de reservatório em função do tempo para $k=5 \mathrm{mD}$ e $v=200 \mathrm{~m} / d$. 
Na Figura 5.57, é apresentada a produção acumulada de condensado. Nela é possível perceber que, com o modelo IFT, produziu-se $1100 \mathrm{~m}^{3}$ e, com o modelo de rede, produziu-se $988 \mathrm{~m}^{3}$. Percebe-se que houve um aumento da diferença entre os modelos de $38 \mathrm{~m}^{3}$ para $118 \mathrm{~m}^{3}$ para o modelo IFT. Para entender o motivo dessa diferença, é analisado o quanto desse condensado vem de gás em condições de reservatório e quanto vem de condensado em condições de reservatório.

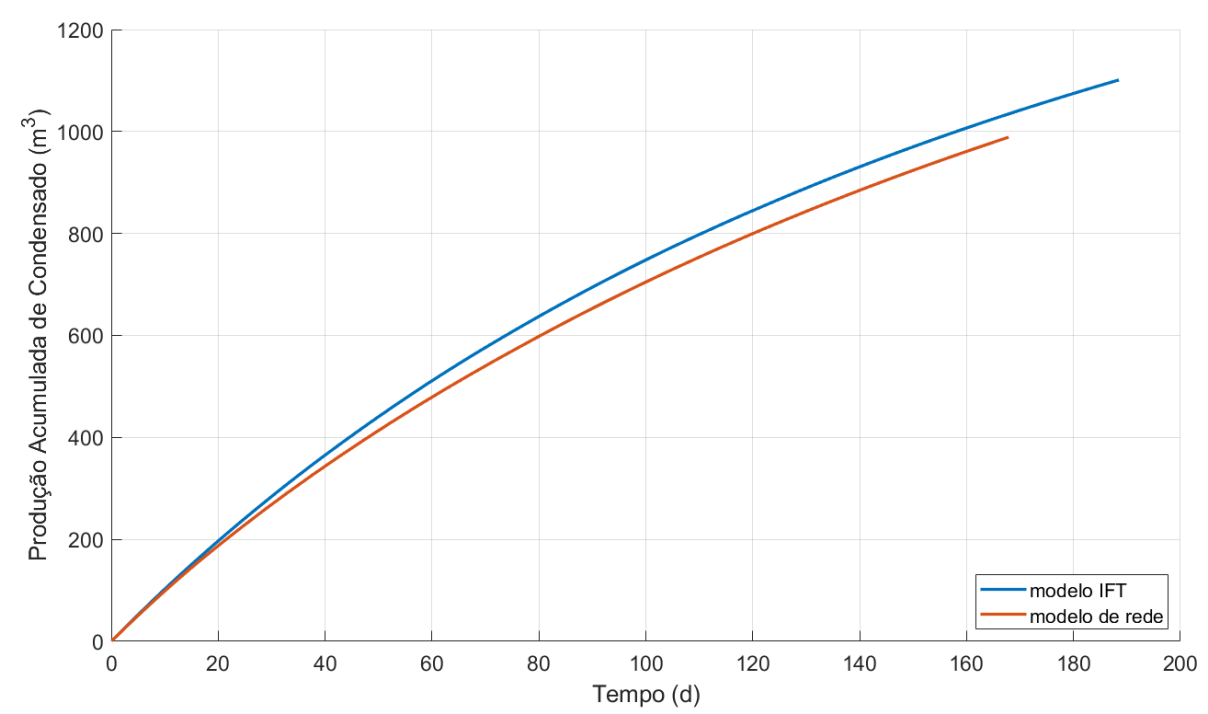

Figura 5.57: Produção acumulada de condensado em condições standard em função do tempo para $k=169 m D$ e $v=100 m / d$.

Pode-se ver na Figura 5.58 que a produção acumulada de condensado originado de gás em condições de reservatório foi ainda menor para ambos os modelos: $617 \mathrm{~m}^{3}$ no modelo IFT e $421 \mathrm{~m}^{3}$ no modelo de rede. Há um aumento na diferença entre a previsão da produção dos dois modelos: de $69 \mathrm{~m}^{3}$ para 196 $\mathrm{m}^{3}$ com o modelo IFT, porque houve uma menor redução na permeabilidade relativa de gás com o modelo IFT que com o modelo de rede.

Prosseguindo, na Figura 5.59, encontra-se a produção acumulada de condensado originado de condensado em condições de reservatório. Essa produção foi maior para ambos os modelos: $483 \mathrm{~m}^{3}$ para o modelo IFT e de $567 \mathrm{~m}^{3}$ para o modelo de rede. $\mathrm{O}$ aumento dessa diferença de $31 \mathrm{~m}^{3}$ para $84 \mathrm{~m}^{3}$ a mais com o modelo de rede é reflexo da permeabilidade relativa de líquido atingir valores maiores com o modelo IFT dentro da faixa de saturação de líquido analisada, conforme apresentado na Figura 5.52. 


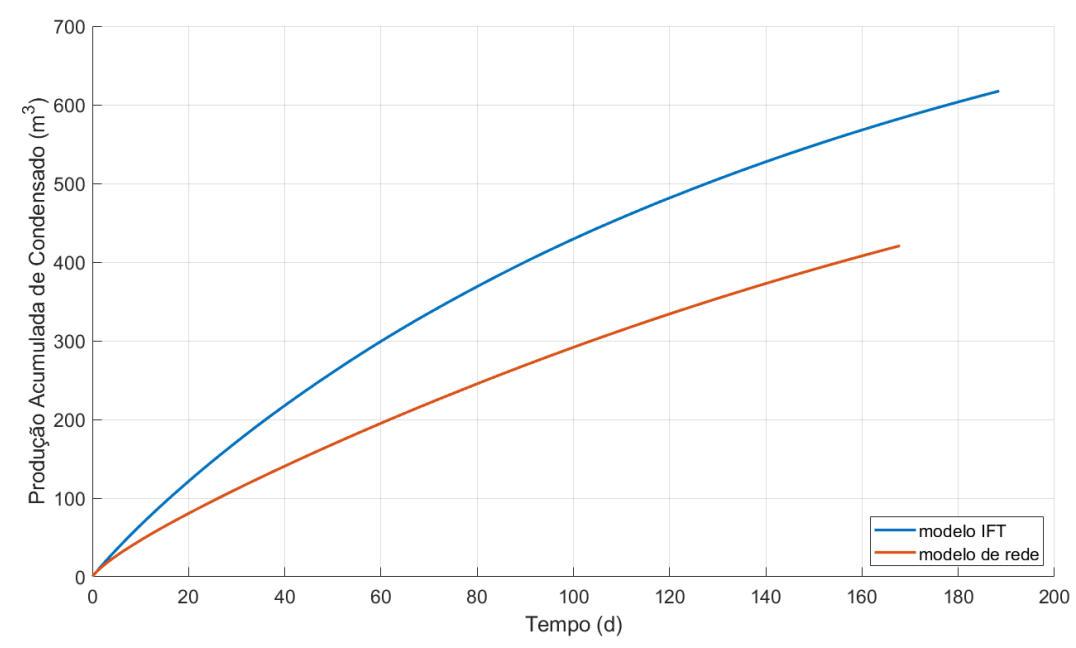

Figura 5.58: Produção acumulada de condensado em condições standard vindo de gás em condições de reservatório em função do tempo para $k=5 m D$ e $v$ $=200 \mathrm{~m} / \mathrm{d}$.

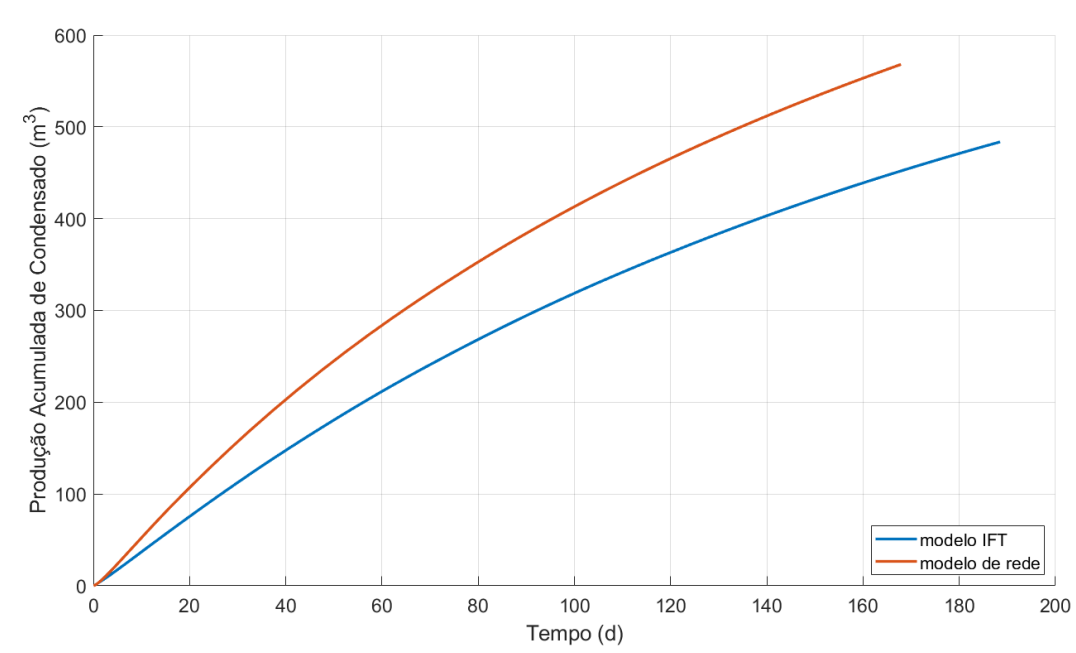

Figura 5.59: Produção acumulada de condensado em condições standard vindo de condensado em condições de reservatório em função do tempo para $k=5 \mathrm{mD}$ e $v=200 \mathrm{~m} / d$.

Portanto, é possível perceber que, com uma baixa permeabilidade absoluta do meio $(5 \mathrm{mD})$, um aumento de velocidade de escoamento traz uma diferença ainda mais significativa entre o uso dos dois modelos de permeabilidade relativa dentro do intervalo de pressão avaliado. Além disso, mesmo usando um modelo que leva em consideração o efeito positivo da velocidade, ao aumentar a velocidade de $100 \mathrm{~m} / \mathrm{d}$ para $200 \mathrm{~m} / \mathrm{d}$, houve uma redução na produção. 


\subsection{5}

\section{Resumo dos Resultados}

Para facilitar a comparação entre os resultados obtidos com diferentes permeabilidades absolutas, diferentes velocidades e diferentes modelos de permeabilidade relativa utilizados por este trabalho, a produção acumulada de gás e condensado para todos os casos se encontram resumidas nas Tabelas 5.5 e 5.6 .

Tabela 5.5: Produção Acumulada de Gás ao Final das Simulações

\begin{tabular}{|c|c|c|c|}
\cline { 3 - 4 } \multicolumn{2}{c|}{} & \multicolumn{2}{c|}{$\begin{array}{c}\text { Produção Acumulada } \\
\text { de Gás }\left(m^{3}\right)\end{array}$} \\
\hline \multirow{2}{*}{$\mathbf{k}(\mathbf{m D})$} & $\mathbf{v} \mathbf{( m / d )}$ & Modelo IFT & Modelo Rede \\
\hline \multirow{2}{*}{169} & 100 & 6.363 .843 & 6.362 .458 \\
\cline { 2 - 4 } & 200 & 6.346 .800 & 6.343 .530 \\
\hline \multirow{2}{*}{5} & 100 & 5.575 .000 & 5.417 .300 \\
\cline { 2 - 4 } & 200 & 4.718 .400 & 4.050 .200 \\
\hline
\end{tabular}

Tabela 5.6: Produção Acumulada de Condensado ao Final das Simulações

\begin{tabular}{|c|c|c|c|}
\cline { 3 - 4 } \multicolumn{2}{c|}{} & \multicolumn{2}{c|}{$\begin{array}{c}\text { Produção Acumulada } \\
\text { de Condensado }\left(\mathrm{m}^{3}\right)\end{array}$} \\
\hline \multirow{2}{*}{$\mathbf{k}(\mathbf{m D})$} & $\mathbf{v} \mathbf{( m / d )}$ & Modelo IFT & Modelo Rede \\
\hline \multirow{2}{*}{169} & 100 & $1.321,4$ & $1.307,6$ \\
\cline { 2 - 4 } & 200 & $1.316,3$ & $1.307,2$ \\
\hline \multirow{2}{*}{5} & 100 & $1.220,0$ & $1.181,0$ \\
\cline { 2 - 4 } & 200 & $1.100,0$ & 988,0 \\
\hline
\end{tabular}




\section{Conclusão}

Neste trabalho foi desenvolvido um simulador de reservatório composicional unidimensional com formulação totalmente implícita, cujas variáveis primárias são pressão e número de moles de cada componente. O simulador é usado para analisar a evolução da saturação das fases, pressão ao redor do poço e volume produzido de gás e condensado.

A simulação foi validada comparando a resposta de pressão com a solução exata para o caso monofásico, quando o gás escoa com pressão acima da pressão de orvalho.

O comportamento do reservatório foi obtido usando diferentes curvas de permeabilidade relativa. O primeiro conjunto (IFT) foi baseado nas correlações empíricas propostas por Hartman \& Cullick [21]. O segundo conjunto de curvas de permeabilidade relativas foi baseado nos resultados de simulação de rede de poros por Reis e Carvalho [27]. Curvas de permeabilidade relativa baseadas na simulação na escala de poros descrevem melhor os diferentes fenômenos que ocorrem na escala de poros. Para entender os efeitos do modelo de permeabilidade relativa na perda de produtividade de um poço em decorrência da formação e acúmulo de condensado na sua vizinhança, são simulados quatro casos variando a permeabilidade absoluta $(169 \mathrm{mD}, 5 \mathrm{mD})$ e a velocidade de escoamento de gás $(100 \mathrm{~m} / \mathrm{d}, 200 \mathrm{~m} / \mathrm{d})$.

Primeiramente, é percebido que, com permeabilidade absoluta do meio relativamente alta $(169 \mathrm{mD})$ e velocidade de $100 \mathrm{~m} / \mathrm{d}$, não há diferença significativa de produção acumulada de gás e de condensado com o uso dos dois modelos de permeabilidade relativa dentro do intervalo de pressão avaliado. Ao aumentar a velocidade, mantendo a permeabilidade absoluta, também não há uma diferença significativa entre os dois modelos dentro do intervalo de pressão avaliado. Além disso, é possível perceber que mesmo usando um modelo que leva em consideração o efeito positivo da velocidade, ao aumentar a velocidade, houve uma redução na produção. Isso ocorre provavelmente porque a pressão cai mais ao longo do reservatório gerando mais líquido.

Ao reduzir a permeabilidade absoluta do meio $(5 \mathrm{mD})$ e mantendo a velocidade em $100 \mathrm{~m} / \mathrm{d}$, já pode se perceber que houve uma diferença significativa entre o uso dos dois modelos dentro do intervalo de pressão 
avaliado. Neste caso, utilizando o modelo IFT, prevê-se $157.700 \mathrm{~m}^{3}$ a mais de gás produzido e $38 \mathrm{~m}^{3}$ a mais de condensado produzido. Aumentando a velocidade para $200 \mathrm{~m} / \mathrm{d}$, essa diferença entre o uso dos dois modelos se torna ainda mais significativa $\left(668.200 \mathrm{~m}^{3}\right.$ a mais de gás produzido e $118 \mathrm{~m}^{3}$ a mais de condensado produzido).

Esses resultados indicam que, para campos com permeabilidade absoluta reduzida, a escolha de modelos de curvas de permeabilidade relativa baseadas em correlações empíricas, e que não descrevem de forma adequada os fenômenos, que ocorrem na escala de poros pode comprometer significativamente as estimativas de produção.

\section{1}

\section{Sugestões para trabalhos futuros}

As curvas de permeabilidade relativa baseadas no modelo de rede consideram que o condensado molha perfeitamente a parede do espaço poroso. A primeira melhoria sugerida seria um modelo mais generalista considerando outros ângulos de contato nas curvas de permeabilidade, conforme descrito em Reis e Carvalho em [27].

Como proposta para trabalho futuro, pode-se considerar também a inclusão dos efeitos da gravidade e da compressibilidade da rocha. É também interessante adicionar ao modelo a água, somente em fase líquida e com apenas um componente como nos softwares comerciais.

Outra melhoria importante consiste na expansão do modelo de 1D para $2 \mathrm{D}$ e 3D, a fim de representar melhor o meio poroso e o fluxo de fluidos. Além disso, vale ressaltar que o modelo radial atual de um poço vertical pode ser atualizado para um poço bidimensional do tipo S ou J, a fim de explorar mais a geometria ao redor do poço e da perturbação de pressão no campo de gás condensado.

Uma melhoria na equação de estado consiste no uso da formulação de 1978 da equação de Peng \& Robinson, que é considerada como mais adequada para a predição de componentes pesados, como o condensado.

Com relação ao meio poroso, uma sugestão é investigar o dano no reservatório em cenários de tight gas, com ou sem fraturamento natural.

Outra sugestão é analisar o efeito da composição do fluido presente no reservatório. Gases com maior percentual de componentes pesados (Rich gas) levam a uma maior quantidade de fase líquida formada para pressões abaixo da pressão de orvalho do que gases com baixa fração molar de componentes pesados (Lean Gas). Essa variação da saturação de líquido devido a composição 
do fluido pode alterar de forma significativa o escoamento das duas fases no espaço poroso. 


\section{Referências bibliográficas}

[1] SOPRANO, ARTHUR BESSEN. Estudo e implementação de um modelo composicional para a simulação de reservatórios de petróleo. Dissertação de mestrado em engenharia mecânica, Universidade Federal de Santa Catarina, Santa Catarina, 2013.

[2] BASÍlIO, LORRAN; SOUSA, SERGIO; PEIXOTO, FERNANDO. Ferramentas numérico-computacionais para análise do comportamento de reservatórios de petróleo. Monografia de graduação em engenharia de petróleo, Universidade Federal Fluminense, Nitéroi, 2012.

[3] GOMES, HAMILTON PIMENTEL. Modelo composicional de reservatorios com formulação totalmente implicita. Dissertação de mestrado em engenharia mecânica, Universidade Estadual de Campinas, Campinas, 1990.

[4] SANTOS, MARCOS PAULO PEREIRA C DOS. Modelo de rede de capilares para o estudo do escoamento de gás retrógrado em meios porosos. Dissertação de mestrado em engenharia mecânica, PUCRio, Rio de Janeiro, 2017.

[5] ENAUTA. Enciclopédia og - extração de Óleo e gás, 2019. Disponível em: <https://www.enauta.com.br/wp-content/uploads/sites/134/ 2019/07/01_ENA_OIL_GAS_fm.pdf >. Acesso em: Maio de 2020.

[6] KNIAZEFF, VLADIMIR J.; NAVILLE, S. A. . Two-phase flow of volatile hydrocarbons. Society of Petroleum Engineers Journal, 05:37-44, 1965.

[7] ROEBUCK JR., I. F.; HENDERSON, G.E.; DOUGLAS JR., JIM; FORD, W.T.. The compositional reservoir simulator: Case $\mathbf{i}$ - the linear model. Society of Petroleum Engineers Journal, 09:115-130, 1969.

[8] NOLEN, J. S.. Numerical simulation of compositional phenomena in petroleum reservoirs. In: SPE SYMPOSIUM ON NUMERICAL SIMULATION OF RESERVOIR PERFORMANCE, Texas, USA), 1973.

[9] FUSSELL, L. T. ;FUSSELL, D.D.. An iterative technique for compositional reservoir models. Society of Petroleum Engineers Journal, 19:211-220, 1979. 
[10] PeTroblogger. Arun gas field, 2009. Disponível em: <https:// www. ingenieriadepetroleo.com/arun-gas-field/>. Acesso em: Maio de 2020.

[11] PRABODH, P. AND YAN, F. AND HANIFATU, A. AND ZULKARNAIN, K. AND MARK, A. AND HIDAYAT, D.. The arun gas field in indonesia: Resource management of a mature field. In: SPE ASIA PACIFIC CONFERENCE ON INTEGRATED MODELLING FOR ASSET MANAGEMENT, Kuala Lumpur, Malaysia, 2004.

[12] ARPS, J.J.. Analysis of Decline Curves. Transactions of the AIME, p. 228-247, 1945.

[13] WHITSON, C. H.; FEVANG $\varnothing$. AND S/EVAREID, A.. Gas condensate relative permeability for well calculations. Transport in Porous Media, 52:279-311, 2003.

[14] WHITSON, C. H. AND FEVANG Ø. . Modeling gas-condensate well deliverability. SPE Reservoir Engineering, 11:221-230, 1996.

[15] GUITERAS, O. H. J.. Metodologia de análise global para o desenvolvimento de um campo de gás natural. Dissertação de mestrado em engenharia mecânica, PUC-Rio, Rio de Janeiro, 2003.

[16] HAVLENA, D. AND ODEH, A. S.. The material balance as an equation of a straight line. Journal of Petroleum Technology, p. 896-900, 1963.

[17] REIS, P. K. P. AND CARVALHO, M. S.. Pore-scale analysis of condensate blockage mitigation by wettability alteration. Energies, 13:27-47, 2020.

[18] BEAR, J.. Dynamics of Fluids in Porous Media. Dover Publications, New York, 1972.

[19] MUCCINO, J. C. AND GRAY, W. G. AND FERRAND, L. A.. Toward an improved understanding of multiphase flow in porous media. Reviews of Geophysics, 36:401-422, 1998.

[20] ROSA, A. J.; CARVALhO, R. S. AND XAVIER J. A. D.. Engenharia de Reservatório de Petróleo. Interciência, 2006.

[21] HARTMAN, K J. AND CULLICK, A. S.. Oil recovery by gas displacement at low interfacial tension. Journal of Petroleum Science and Engineering, 10(3):197-210, 1994. 
[22] LI, K. AND FIROOZABADI, A.. Phenomenological modeling of critical condensate saturation and relative permeabilities in gas/condensate systems. Society of Petroleum Engineers Journal, 5:138$147,2000$.

[23] FANG, F.; FIROOZABADI, A.; ABBASZADEH, M. AND RADKE, C.. A phenomenological modeling of critical condensate saturation. In: SPE ANNUAL FALL MEETING AND CONFERENCE EXHIBITION, Denver, Colorado, 1996.

[24] THOMAS, F.B. AND BENNION, D.B. AND ANDERSEN, G.. Gas condensate reservoir performance. Journal of Canadian Petroleum Technology, 48:18-24, 2009.

[25] SILVA, D. Y. C. A.. Análise e comparação dos esforços em colunas de produção com completação convencional e biengastada de poços de petróleo. Trabalho de conclusão de curso de graduação em engenharia de petróleo, Universidade Católica de Petrópolis, Petrópolis, 2017.

[26] NEMETH, L.K. AND KENNEDY, H.T.. A correlation of dewpoint pressure with fluid composition and temperature. Society of Petroleum Engineers Journal, 7:99-104, 1967.

[27] REIS, P. K. P. AND CARVALHO, M. S.. Compositional pore-network modeling of gas-condensate flow: Effects of interfacial tension and flow velocity. International Journal of Multiphase Flow, 2020.

[28] REIS, P. K. P.. Development and applications of a pore-network model for gas-condensate flow. Tese de doutorado do departamento de engenharia mecânica, Pontifícia Universidade Católica do Rio de Janeiro (PUC-Rio), Rio de Janeiro, 2021.

[29] SHI, C.. Flow behavior of gas-condensate wells. Phd thesis of energy resources engineering department, Stanford University, California, 2009.

[30] PENG, D. AND ROBINSON, D.. New two-constant equation of state. Industrial Engineering Chemistry Fundamentals, 15:59-64, 1976.

[31] DONG, H.. Micro-CT Imaging and Pore Network Extraction. Phd thesis of earth science and engineering department, Imperial College London, London, 2007.

[32] PATANKAR, S.V.. Numerical Heat Transfer and Fluid Flow. Hemisphere Publishing Corporation, United States of America, 1st edition, 1980. 
[33] SANNI, M.. Petroleum Engineering: Principles, Calculations, and Workflows. Wiley, Washington, 1st edition, 2009.

[34] GOLPARVAR, AMIR; ZHOU, Y.; WU, KEJIAN; MA, JINGSHENG AND YU, ZHIXIN. Conception and significance of the parachor. Nature, 196:890-891, 1962.

[35] LØVOLL, G.; MÉHEUST, Y.; MÅLØY, K. J.; AKER, E. AND SCHMITTBUHL, J.. Competition of gravity, capillary and viscous forces during drainage in a two-dimensional porous medium, a pore scale study. Energy, 30:861-872, 2005.

[36] G.D. HENDERSON AND A. DANESH AND D.H. TEHRANI AND J.M. PEDEN. The effect of velocity and interfacial tension on relative permeability of gas condensate fluids in the wellbore region. Journal of Petroleum Science and Engineering, 17:265-273, 1997.

[37] COATS, KEITH H.. An equation of state compositional model. Society of Petroleum Engineers Journal, 20:363-376, 1980.

[38] BLOM, S.M.P. AND HAGOORT, J. . How to include the capillary number in gas condensate relative permeability functions? SPE Annual Technical Conference and Exhibition, All Days, 1998.

[39] POPE, G.A.; WU, W.; NARAYANASWAMY, G.; DELSHAD, M.; SHARMA, M.M. AND WANG, P.. Modeling relative permeability effects in gascondensate reservoirs with a new trapping model. SPE Reservoir Evaluation Engineering, 3:171-178, 2000.

[40] FUSSELL, D.D. AND YANOSIK, J.L.. An iterative sequence for phaseequilibria calculations incorporating the redlich-kwong equation of state. Society of Petroleum Engineers Journal, 18:173-182, 1978.

[41] COLLINS, D.A.; NGHIEM, L.X.; LI, Y-K. AND GRABONSTOTTER, J.E.. An efficient approach to adaptive- implicit compositional simulation with an equation of state. SPE Reservoir Engineering, 7:259-264, 1992.

[42] WEINAUG, C. F. AND KATZ, D. L.. Surface tensions of methanepropane mixtures. Industrial Engineering Chemistry, 35:239-246, 1943.

[43] CHANG, Y.. Development and Application of an Equation of State Compositional Simulator. Ph.D. thesis, University of Texas, Austin, 1990. 
[44] SANTOS, LUIZ OTAVIO SCHMALL DOS. Development aof Multiformulation Compositional Simulator. Ph.D. thesis, University of Texas, Austin, 2013.

[45] MICHELSEN, M. L. . The isothermal flash problem. part i. stability. 9:1-19, 1982.

[46] LOHRENZ, J.; BRAY, B. G. AND CLARK, C. R.. Calculating viscosities of reservoir fluids from their compositions. 16:1171-1176, 1964.

[47] WONG, T.W. \& AZIZ, K.. Considerations in the development of multipurpose reservoir simualtion models. First and Second International Forum on Reservoir Simulation Models, p. 12-16, 1988.

[48] WILSON G. M.. A modified redlich-kwong equation of state, application to general physical data calculations. 65th National AIChE Meeting, p. 12-16, 1969.

[49] SHI, JUNTAI AND LI, X. AND ZHOU, J. AND LI, Q. AND WU, KELIU. Deliverability prediction of gas condensate wells based on statistics. Petroleum Science and Technology, 2013.

[50] LLOYD, P.. Productivity of gas condensate fields below the dew point: A north sea case study. Master's thesis, 2011.

[51] ALI, J.K. AND MCGAULEY, P.J. AND WILSON, C.J.. The effects of high-velocity flow and pvt changes near the wellbore on condensate well performance. SPE Annual Technical Conference and Exhibition, p. 16, 1997.

[52] AGHAEI, A.. Analyzing full micro-ct image of a berea sandstone mini plug and the associated challenges. Thermo Fisher Scientific, p. 6, 2019.

[53] AHMED, T.. Reservoir Engineering Handbook. Gulf Professional Publishing, Massachusetts, 5th edition, 2018.

[54] ERTEKIN, T. AND ABOU-KASSEM, J.H. AND KING, G.R.. Basic Applied Reservoir Simulation. Society of Petroleum Engineers, Texas, 5th edition, 2001. 
A

\section{Equações Numéricas do Jacobiano}

Começando com o resíduo $R_{N}^{t}$ e a equação da conservação, derivando-a com relação a $P$, tem-se:

$$
0-\Delta t\left(\frac{\partial\left(T_{f}^{\tau}\right)_{f c, i+1}}{\partial P^{t}}-\frac{\partial\left(T_{f}^{\tau}\right)_{f c, i}}{\partial P^{t}}\right)=0
$$

Lembrando que $\left(T_{f}^{\tau}\right)_{f c, i+1}$ depende apenas de $P_{i+1}$ e $P_{i}$, enquanto $\left(T_{f}^{\tau}\right)_{f c, i}$ depende apenas de $P_{i-1}$ e $P_{i}$, tem-se que essas derivadas se resumem às seguintes expressões:

$$
\begin{aligned}
\frac{\partial\left(T_{f}^{\tau}\right)_{f c, i+1}}{\partial P_{i}^{t}} & =\frac{2 \pi h r_{f c, i+1}}{\phi}\left[\frac{\partial\left(m_{k}^{\tau}\right)_{f c, i+1}}{\partial P_{i}^{t}}\left(\frac{P_{i+1}^{t}-P_{i}^{t}}{d r_{f c, i+1}}\right)-\left(m_{k}^{\tau}\right)_{f c, i+1} \frac{1}{d r_{f c, i+1}}\right] \\
\frac{\partial\left(T_{f}^{\tau}\right)_{f c, i}}{\partial P_{i}^{t}} & =\frac{2 \pi h r_{f c, i}}{\phi}\left[\frac{\partial\left(m_{k}^{\tau}\right)_{f c, i}}{\partial P_{i}^{t}}\left(\frac{P_{i}^{t}-P_{i-1}^{t}}{d r_{f c, i}}\right)+\left(m_{k}^{\tau}\right)_{f c, i} \frac{1}{d r_{f c, i}}\right] \\
\frac{\partial\left(T_{f}^{\tau}\right)_{f c, i+1}}{\partial P_{i+1}^{t}} & =\frac{2 \pi h r_{f c, i+1}}{\phi}\left[\frac{\partial\left(m_{k}^{\tau}\right)_{f c, i+1}}{\partial P_{i+1}^{t}}\left(\frac{P_{i+1}^{t}-P_{i}^{t}}{d r_{f c, i+1}}\right)-\left(m_{k}^{\tau}\right)_{f c, i+1} \frac{1}{d r_{f c, i+1}}\right]
\end{aligned}
$$

$$
\frac{\partial\left(T_{f}^{\tau}\right)_{f c, i}}{\partial P_{i-1}^{t}}=\frac{2 \pi h r_{f c, i}}{\phi}\left[\frac{\partial\left(m_{k}^{\tau}\right)_{f c, i}}{\partial P_{i-1}^{t}}\left(\frac{P_{i}^{t}-P_{i-1}^{t}}{d r_{f c, i}}\right)-\left(m_{k}^{\tau}\right)_{f c, i} \frac{1}{d r_{f c, i}}\right]
$$

Vê-se que para determinar essas derivadas apresentadas nas Equações A-2 a A-5, é preciso encontrar expressões para as derivadas das mobilidades nas faces e para as derivadas da derivada da pressão. Elas estão apresentadas a seguir:

$$
\begin{gathered}
\frac{\partial\left(m_{k}^{\tau}\right)_{f c, i+1}}{\partial P_{i}^{t}}=2 \frac{\partial m_{k}^{\tau}(i)}{\partial P_{i}^{t}}\left(\frac{\left(m_{k}^{\tau}(i)\right)^{2}}{\left(m_{k}^{\tau}(i)+m_{k}^{\tau}(i+1)\right)^{2}}\right) \\
\frac{\partial\left(m_{k}^{\tau}\right)_{f c, i+1}}{\partial P_{i+1}^{t}}=2 \frac{\partial m_{k}^{\tau}(i+1)}{\partial P_{i+1}^{t}}\left(\frac{\left(m_{k}^{\tau}(i+1)\right)^{2}}{\left(m_{k}^{\tau}(i)+m_{k}^{\tau}(i+1)\right)^{2}}\right) \\
\frac{\partial\left(m_{k}^{\tau}\right)_{f c, i}}{\partial P_{i}^{t}}=2 \frac{\partial m_{k}^{\tau}(i)}{\partial P_{i}^{t}}\left(\frac{\left(m_{k}^{\tau}(i)\right)^{2}}{\left(m_{k}^{\tau}(i)+m_{k}^{\tau}(i-1)\right)^{2}}\right) \\
\frac{\partial\left(m_{k}^{\tau}\right)_{f c, i}}{\partial P_{i-1}^{t}}=2 \frac{\partial m_{k}^{\tau}(i-1)}{\partial P_{i-1}^{t}}\left(\frac{\left(m_{k}^{\tau}(i-1)\right)^{2}}{\left(m_{k}^{\tau}(i)+m_{k}^{\tau}(i-1)\right)^{2}}\right)
\end{gathered}
$$


Para calcular as derivadas apresentadas nas Equações A-6 a A-9, é preciso encontrar a derivada da mobilidade no volume de controle em função da pressão no volume de controle. Calcula-se essa derivada a seguir:

$$
\begin{aligned}
\frac{\partial m_{k}}{\partial P} & =\frac{\partial x}{\partial P} \frac{k k_{r l i q} \xi_{l i q}}{\mu_{l i q}}+x \frac{\partial \xi_{l i q}}{\partial P} \frac{k k_{r l i q}}{\mu_{l i q}}+x \xi_{l i q} \frac{\partial k_{r l i q}}{\partial P} \frac{k}{\mu_{l i q}}-x \frac{k k_{r l i q} \xi_{l i q}}{\mu_{l i q}^{2}} \frac{\partial \mu_{l i q}}{\partial P} \\
+ & \frac{\partial y}{\partial P} \frac{k k_{r g a s} \xi_{\text {gas }}}{\mu_{\text {gas }}}+y \frac{\partial \xi_{\text {gas }}}{\partial P} \frac{k k_{r g a s}}{\mu_{\text {gas }}}+y \xi_{\text {gas }} \frac{\partial k_{r g a s}}{\partial P} \frac{k}{\mu_{\text {gas }}}-y \frac{k k_{r g a s} \xi_{\text {gas }}}{\mu_{\text {gas }}^{2}} \frac{\partial \mu_{\text {gas }}}{\partial P}
\end{aligned}
$$

As últimas duas derivadas que precisam ser determinadas analiticamente são para essa parte do Jacobiano são as derivadas das densidades molares de gás e líquido, pois todas as outras tem suas expressões apresentadas em [4], [43], [44] e [47]. Assim, tem-se que:

$$
\begin{aligned}
\frac{\partial \xi_{\text {liq }, i}^{\tau}}{\partial P_{i}^{t}} & =-\left(\xi_{\text {liq }, i}^{\tau}\right)^{2}\left(\frac{\partial Z_{\text {liq,i }}^{\tau}}{\partial P_{i}^{t}} \frac{R T_{i}}{P_{i}^{t}}-\frac{Z_{\text {liq }, i}^{\tau} R T_{i}}{\left(P_{i}^{t}\right)^{2}}-\sum_{k=1}^{n_{c}} \frac{\partial x_{i}^{k, t}}{\partial P_{i}^{t}} \nu_{k}\right) \\
\frac{\partial \xi_{\text {gas }, i}^{\tau}}{\partial P_{i}^{t}} & =-\left(\xi_{\text {gas }, i}^{\tau}\right)^{2}\left(\frac{\partial Z_{\text {gas }, i}^{\tau}}{\partial P_{i}^{t}} \frac{R T_{i}}{P_{i}^{t}}-\frac{Z_{\text {gas }}^{t} R T_{i}}{\left(P_{i}^{t}\right)^{2}}-\sum_{k=1}^{n_{c}} \frac{\partial y_{i}^{k, t}}{\partial P_{i}^{t}} \nu_{k}\right)
\end{aligned}
$$

Prosseguindo, agora com o resíduo $R_{V}^{t}$ e a equação da consistência dos volumes, derivando-a com relação a $P$, tem-se:

$$
0-\frac{N_{l i q, i}^{t}}{\partial P_{i}^{t}} \xi_{\text {liq }, i}^{\tau}+\frac{N_{l i q, i}^{t}}{\left(\xi_{\text {liq }, i}^{\tau}\right)^{2}} \frac{\partial \xi_{\text {liq }, i}^{\tau}}{\partial P_{i}^{t}}-\frac{N_{\text {gas }, i}^{t}}{\partial P_{i}^{t}} \xi_{\text {gas }, i}^{\tau}+\frac{N_{\text {gas }, i}^{t}}{\left(\xi_{\text {gas }, i}^{\tau}\right)^{2}} \frac{\partial \xi_{\text {gas }, i}^{\tau}}{\partial P_{i}^{t}}=0
$$

Como já foram calculadas as expressões das derivadas das densidades molares de líquido e gás, resta calcular as derivadas de $N_{l i q}$ e $N_{\text {gas }}$ :

$$
\begin{aligned}
\frac{N_{\text {liq, } i}^{t}}{\partial P_{i}^{t}} & =\frac{\partial \mathcal{L}_{i}^{\tau}}{\partial P_{i}^{t}} \sum_{k=1}^{n_{c}} N_{i}^{k, t} \\
\frac{N_{\text {gas }, i}^{t}}{\partial P_{i}^{t}} & =-\frac{\partial \mathcal{L}_{i}^{\tau}}{\partial P_{i}^{t}} \sum_{k=1}^{n_{c}} N_{i}^{k, t}
\end{aligned}
$$

Agora é importante retomar as condições de contorno e adaptar as equações encontradas para o primeiro e o último volumes de controle. Começando com o primeiro volume de controle, que tem uma vazão do poço $Q_{\text {well }}$ tem-se as seguintes modificações: 


$$
\begin{gathered}
\frac{\partial\left(m_{k}^{\tau}\right)_{f c, 1}}{\partial P_{1}^{t}}=\frac{\partial m_{k}(1)^{t}}{\partial P_{1}^{t}} \\
\frac{\partial\left(m_{k}^{\tau}\right)_{f c, 1}}{\partial P_{0}^{t}}=0 \\
\frac{\partial}{\partial P_{1}^{t}}\left(\frac{\partial P^{t}}{\partial r}\right)_{f c, 1}=\frac{Q_{\text {well }}}{k\left[2 \pi r_{1} h\right]} \frac{1}{k_{r g a s, 1}} \frac{\partial \mu_{\text {gas }, 1}}{\partial P_{1}^{t}}-\frac{Q_{\text {well }}}{k\left[2 \pi r_{1} h\right]} \frac{\mu_{\text {gas }, 1}}{k_{r g a s, 1}^{2}} \frac{\partial k_{r g a s, 1}}{\partial P_{1}^{t}} \\
\frac{\partial}{\partial P_{0}^{t}}\left(\frac{\partial P^{t}}{\partial r}\right)_{f c, 1}=0
\end{gathered}
$$

Por outro lado, para o último volume de controle, de forma geral, tem-se as seguintes modificações nas derivadas da mobilidade:

$$
\begin{gathered}
\frac{\partial\left(m_{k}^{\tau}\right)_{f c, N_{\text {cells }}+1}}{\partial P_{N_{\text {cells }}}^{t}}=\frac{\partial m_{k}^{\tau}\left(N_{\text {cells }}\right)}{\partial P_{N_{\text {cells }}}^{t}} \\
\frac{\partial\left(m_{k}^{\tau}\right)_{f c, N_{\text {cells }}+1}}{\partial P_{N_{\text {cells }}+1}^{t}}=0 \\
\frac{\partial}{\partial P_{N_{\text {cells }}+1}^{t}}\left(\frac{\partial P^{t}}{\partial r}\right)_{f c, N_{\text {cells }}+1}=0
\end{gathered}
$$

Quando a pressão do reservatório $P_{\text {res }}$ é especificada, tem-se as seguintes alterações:

$$
\frac{\partial}{\partial P_{N_{\text {cells }}}^{t}}\left(\frac{\partial P^{t}}{\partial r}\right)_{f c, N_{\text {cells }}+1}=-1
$$

Por outro lado, quando o reservatório é isolado $Q_{\text {res }}=0$, tem-se as seguintes alterações:

$$
\frac{\partial}{\partial P_{N_{\text {cells }}}^{t}}\left(\frac{\partial P^{t}}{\partial r}\right)_{f c, N_{\text {cells }}+1}=0
$$

Pode-se adotar procedimento semelhante para as derivadas em relação ao número de mols de cada componente $N^{k}$, entretanto, por questão de simplificação, este trabalho suprime o cálculo dessas derivadas. 